\title{
Magmatismo y tectónica en la Sierra Madre Occidental y su relación con la evolución de la margen occidental de Norteamérica
}

\author{
Luca Ferrari1 ${ }^{1, *}$, Martín Valencia-Moreno², Scott Bryan ${ }^{3}$ \\ ${ }^{1}$ Centro de Geociencias, Universidad Nacional Autónoma de México, Campus Juriquilla, Apartado postal 1-742, Querétaro, Qro., \\ 76001, México \\ ${ }^{2}$ Estación Regional del Noroeste, Instituto de Geología, Universidad Nacional Autónoma de México, L.D. Colosio y Madrid S/N, \\ Campus Unison, Apartado Postal 1039, Hermosillo, Son., 83000, México \\ ${ }^{3}$ School of Earth Sciences and Geography, Kingston University, Penrhyn Road, Kingston upon Thames, Surrey KT1 2EE, Inglaterra \\ *luca@geociencias.unam.mx
}

\section{Resumen}

La Sierra Madre Occidental (SMO) es el resultado de diferentes episodios magmáticos y tectónicos durante el CretácicoCenozoico, asociados a la subducción de la placa Farallón debajo de la placa de Norteamérica y a la apertura del Golfo de California. La estratigrafía de la SMO consta de cinco conjuntos ígneos principales: (1) rocas plutónicas y volcánicas del Cretácico Superior-Paleoceno y (2) rocas volcánicas andesíticas y, en menor medida, dacítico-riolíticas del Eoceno, tradicionalmente agrupadas en el denominado "Complejo Volcánico Inferior" (CVI); 3) ignimbritas silícicas emplazadas en su mayoría en dos pulsos, en el Oligoceno temprano (32-28 Ma) y el Mioceno temprano (24-20 Ma), y agrupadas en el Supergrupo Volcánico Superior; 4) coladas basáltico-andesíticas transicionales extravasadas después de cada pulso ignimbrítico, correlacionadas con las "Andesita-Basálticas del Sur de la Cordillera" (SCORBA por sus siglas en inglés); 5) volcanismo postsubducción constituido por coladas de basaltos alcalinos e ignimbritas emplazados en diferentes episodios del Mioceno tardío, Plioceno y Cuaternario, y que se relacionan con la separación de Baja California del continente. Los productos de todos estos episodios magmáticos, parcialmente superpuestos entre sí, cubren a su vez un basamento heterogéneo pobremente expuesto con edades del Precámbrico y Paleozoico en la parte norte (Sonora y Chihuahua) y del Mesozoico en el resto de la SMO.

La deformación Laramide afectó moderadamente a las rocas más antiguas del CVI ( 101 a 89 Ma) en Sinaloa y a rocas volcánicas del Maastrichtiano en Chihuahua central. En su fase final, durante el Paleoceno y Eoceno temprano, se desarrollaron fracturas de tensión $\sim$ E-W a ENE-WSW que hospedan los principales depósitos de pórfidos cupríferos de la SMO. La tectónica extensional inició por lo menos en el Oligoceno en toda la mitad oriental de la SMO, provocando la formación de grábenes limitados por fallas de alto ángulo que se han referido como el Basin and Range mexicano. En el Mioceno temprano y medio la extensión migró hacia el occidente. En Sonora central esta deformación llegó a exhumar la corteza inferior, mientras que en el resto de la SMO no rebasó el 20\%. En el Mioceno tardío la extensión se concentró en la franja más occidental de la SMO, adyacente al Golfo de California, donde produjo sistemas de fallas NNW que limitan un conjunto de semigrábenes con vergencia tanto al ENE como al WSW con zonas de acomodo transversales. Es importante notar que buena parte de la extensión se dio mientras la subducción de la placa Farallón era todavía activa.

Los estudios geoquímicos y petrológicos indican que las rocas de la SMO forman un conjunto típicamente calcialcalino, caracterizado por concentraciones de potasio intermedias a altas y enriquecimiento relativamente bajo en $\mathrm{Fe}$. El volcanismo del Eoceno tardío al Mioceno es claramente bimodal con los miembros silícicos dominantes sobre los máficos. Las relaciones iniciales de ${ }^{87} \mathrm{Sr} /{ }^{86} \mathrm{Sr}$ están comprendidas, en su mayoría, en el rango de 0.7041 a 0.7070 , y los valores iniciales de $\varepsilon \mathrm{Nd}$ entre +2.3 y -3.2 , intermedios entre los del manto y de la corteza. Con base en los datos isotópicos de 
rocas volcánicas y xenolitos de algunos pocos sitios de la SMO se han propuesto modelos contrastantes para la génesis del volcanismo silícico. Por una parte las ignimbritas silícicas se han relacionado a un proceso de cristalización fraccionada de magmas máficos del manto con poca o nula intervención de la corteza; por otra parte, se ha considerado que estas rocas son en gran medida el resultado de fusión parcial de la corteza calentada por el arribo de basaltos del manto. Diferentes evidencias sugieren que en la mayoría de los casos ambos procesos hayan ocurrido en la SMO y que la petrogénesis de las ignimbritas es dominada por procesos de mezcla y asimilación-cristalización fraccionada a gran escala inducida por el emplazamiento de cantidades significativas de magmas máficos procedentes del manto.

Los datos geofísicos indican la presencia de una corteza que alcanza los $55 \mathrm{~km}$ de espesor en el núcleo relativamente no extendido de la parte norte de la SMO, mientras que más al este el espesor es de $\sim 40 \mathrm{~km}$. El espesor anómalo de la parte central de la SMO sugiere la presencia de una corteza inferior fuertemente intrusionada por magmas máficos. En la franja costera del Golfo de California los espesores son de $\sim 25 \mathrm{~km}$, lo que implica una extensión superior a 100\%. El manto superior por debajo de la SMO se caracteriza por una amplia anomalía de baja velocidad, típica del manto astenosférico, que se extiende desde la provincia Basin and Range de Estados Unidos.

La revisión de la historia magmática y tectónica de la SMO presentada en este trabajo indica que esta provincia geológica es el resultado de la evolución del sistema de subducción Cretácico-Cenozoico del occidente de Norteamérica. En particular la SMO, como gran provincia ígnea silícica oligo-miocénica, está ligada a los eventos ocurridos en el ocaso de la subducción de la placa Farallón y puede verse como el precursor de la apertura del Golfo de California. El mecanismo responsable de los pulsos ignimbríticos se relaciona esencialmente con la remoción de la placa Farallón desde la base de la placa de Norteamérica después del término de la orogenia Laramide. Este proceso involucra el aumento rápido del ángulo de subducción y, posiblemente, el despegue de la parte más profunda de la placa subducida como consecuencia del arribo de litósfera oceánica cada vez más joven y flotante en la paleotrinchera y, finalmente, la interacción directa entre las placas Pacífico y Norteamérica.

Palabras clave: Sierra Madre Occidental, Golfo de California, magmatismo continental, grandes provincias ígneas silícicas, tectónica extensional, dinámica de la subducción.

Abstract

The Sierra Madre Occidental (SMO) is the result of Cretaceous-Cenozoic magmatic and tectonic episodes related to the subduction of the Farallon plate beneath North America and to the opening of the Gulf of California. The stratigraphy of the SMO consists of five main igneous complexes: (1) Late Cretaceous to Paleocene plutonic and volcanic rocks and (2) Eocene andesites and lesser rhyolites, traditionally grouped into the so-called "Lower Volcanic Complex" (LVC); (3) silicic ignimbrites mainly emplaced during two pulses of Oligocene ( 32-28 Ma) and early Miocene ( 24-20 Ma) ages and grouped into the "Upper Volcanic Supergroup”; 4) transitional basaltic-andesitic lavas that erupted after each ignimbritic pulse and correlated with the Southern Cordillera BasalticAndesite (SCORBA) of the southwestern USA; and 5) postsubduction volcanism consisting of alkaline basalts and ignimbrites emplaced in the late Miocene, Pliocene and Pleistocene, directly related to the separation of Baja California from the Mexican mainland. The products of all these magmatic episodes, partially overlapped, cover a poorly exposed, heterogeneous basement with Precambrian to Paleozoic ages in the northern part (Sonora and Chihuahua) and Mesozoic ages beneath the rest of the SMO.

The oldest rocks of the LVC ( 101 to $\sim 89 \mathrm{Ma})$ in Sinaloa, and Maastrichtian volcanics of the LVC in central Chihuahua are affected by moderate contractile deformation ascribed to the Laramide orogeny. In the final stages of this deformation cycle, during the Paleocene and Early Eocene, $\sim$-W to ENE-WSW-trending tension fractures formed within the LVC, along which world-class porphyry copper deposits of the SMO were emplaced. Extensional tectonics began as early as the Oligocene in the whole eastern half of the SMO, forming grabens bounded by high-angle normal faults, traditionally referred to as the southern (or Mexican) Basin and Range province. In the early to middle Miocene, extension migrated westward. In northern Sonora the deformation was sufficiently intense to exhume lower crustal rocks, whereas in the rest of SMO crustal extension did not exceed 20\%. In the late Miocene time, extension became focussed in the westernmost part of the SMO, adjacent to the Gulf of California, where NNW normal fault systems produced both ENE and WSW tilt domains separated by transverse accomodation zones. It is worth noting that most of the extension occurred when subduction of the Farallon was still active off Baja California.

Geochemical data show that the SMO rocks form a typical calc-alkaline rhyolite suite with intermediate to high Kand relatively low Fe content. late Eocene to Miocene volcanism is clearly bimodal, but silicic compositions are dominant. Initial ${ }^{87} \mathrm{Sr} /{ }^{86} \mathrm{Sr}$ ratios mostly range between 0.7041 and 0.7070, and initial $\varepsilon N d$ values are generally intermediate between crust and mantle values (+2.3 and -3.2$)$. Based on isotopic data of volcanic rocks and crustal xenoliths from a few sites in the SMO, contrasting models for the genesis of the silicic volcanism have been proposed. A considerable body of work led by Ken Cameron and others considered the mid-Tertiary SMO silicic magmas to have formed by fractional crystallization of mantle-derived mafic magmas with little ( $<15 \%)$ or no participation of the crust. In contrast, other workers have suggested the rhyolites, taken to the extreme case, could be entirely the result of partial melting of 
the crust in response to thermal and material input from basaltic underplating. Several lines of evidence suggest that SMO ignimbrite petrogenesis involved large-scale mixing and assimilation-fractional crystallization processes of crustal and mantle-derived melts.

Geophysical data indicate that the crust in the unextended core of the northern SMO is $\sim 55 \mathrm{~km}$-thick, but thins to $40 \mathrm{~km}$ to the east. The anomalous thickness in the core of the SMO suggests that the lower crust was largely intruded by mafic magmas. In the westernmost SMO adjacent to the Gulf of California crustal thickness is $\sim 25 \mathrm{~km}$, implying over $100 \%$ of extension. However structures at the surface indicate no more than about 50\%. The upper mantle beneath the SMO is characterized by a low velocity anomaly, typical of the asthenosphere, which also occurs beneath the Basin and Range province of western U.S.

The review of the magmatic and tectonic history presented in this work suggests that the SMO is the result of the CretaceousCenozoic evolution of the western North America subduction system. In particular, the Oligo-Miocene SMO is viewed as a silicic large igneous province formed as the precursor to the opening of the Gulf of California during the final stages of the subduction of the Farallon plate. The mechanism responsible for the generation of the ignimbrite pulses seems related to the removal of the Farallon plate from the base of the North American plate after the end of the Laramide orogeny. The rapid increase in the subduction angle due to slab roll-back resulted in extension of the continental margin and, possibly, the detachment of the deeper part of the subducted slab as younger and buoyant oceanic lithosphere arrived at the paleotrench, eventually leading to direct interaction between the Pacific and North American plates.

Key words: Sierra Madre Occidental, Gulf of California, continental magmatism, silicic large igneous provinces, extensional tectonics, subduction dynamics.

\section{Introducción}

En la mayoría de los continentes existen extensas franjas volcano-plutónicas de composición dominantemente riolítica y/o granítica con un volumen de rocas ígneas de $10^{5}$ hasta $>10^{6} \mathrm{~km}^{3}$, las cuales se emplazaron en periodos de 10 a 40 millones de años. Estas franjas han sido definidas como "grandes provincias ígneas silícicas" (silicic large igneous provinces, SLIP, Bryan et al., 2002) (Tabla 1). El magmatismo silícico sostenido que dio origen a estas grandes provincias no es un fenómeno común en el registro geológico, y debe tener causas relacionadas con la tectónica global. Este tipo de magmatismo contribuye fuertemente a modificar la estructura reológica y la composición de la litósfera continental así como en generar yacimientos minerales. Adicionalmente, la concentración de grandes erupciones explosivas en un tiempo relativamente corto puede afectar de manera significativa el clima mundial.

La Sierra Madre Occidental (SMO) (Figura 1) es una de las provincias ígneas silícicas más grandes del mundo y la más grande del Cenozoico (Tabla 1). La cubierta ignimbrítica de la SMO se estima en la actualidad en $\sim 300000 \mathrm{~km}^{2}$ (McDowell y Keizer, 1977; McDowell y Clabaugh, 1979; Ward, 1995). Sin embargo, la extensión intracontinental de tipo Basin and Range y la apertura del Golfo de California han ocultado una parte significativa de la superficie original de esta provincia, que pudo haber sido bastante mayor. Los picos de volcanismo ignimbríticos de la SMO se consideran la causa de un evento paleoclimático global de enfriamiento ocurrido en el límite Eoceno-Oligoceno y de un evento de enfriamiento de menor duración en el Mioceno temprano (Cather et al., 2003). Aunque la cubierta ignimbrítica es la característica más obvia de la SMO el conjunto ígneo que la subyace, referido como "Complejo Volcánico Inferior" (McDowell y Keitzer, 1977), es igualmente importante. Este conjunto, constituido por rocas plutónicas y volcánicas del Cretácico-Paleógeno similares en edad y composición a los batolitos peninsulares y al bloque Jalisco, constituye la roca encajonante de depósitos de plata y cobre gigantes ( $e$. g., Fresnillo y Juanicipio, Zac., Cananea y Nacozari, Son.; ver también Staude y Barton, 2001; Damon et al., 1983). Por otro lado, la posición y edad de este arco magmático constituye una información fundamental para entender la orogenia Laramide que afectó las porciones más orientales del continente.

A pesar de la importancia científica y económica de la SMO, los estudios disponibles en la literatura sobre este rasgo geológico mayor del territorio mexicano son relativamente escasos. A casi 30 años de las primeras publicaciones formales sobre la SMO, el conocimiento geológico detallado es todavía limitado a áreas restringidas a lo largo de caminos accesibles en vehículo o a estudios de reconocimiento basados en buena parte en métodos de percepción remota. Los estudios geoquímicos son escasos $\mathrm{y}$, por lo general, se refieren a sitios puntuales aunque los resultados han sido extrapolados a toda la provincia. Los estudios geofísicos son esencialmente de tipo regional o continental. En consecuencia, existen todavía muchos problemas abiertos a la discusión científica en lo que respecta a la génesis y la evolución de la SMO. No hay acuerdo, por ejemplo, sobre cual haya sido el mecanismo que produjo este gigantesco pulso magmático y, particularmente, cual fue el papel de la corteza en la génesis del volcanismo silícico. Por otro lado, las causas de la extensión paleógena y su relación con la última fase de la subducción tampoco son completamente claras. En muchos sentidos se puede decir que la SMO sigue siendo una frontera en el conocimiento geológico de nuestro territorio.

Este trabajo pretende resumir el estado del conocimiento geológico sobre la SMO enfocándose particularmente a la evolución del magmatismo durante el CretácicoCenozoico y la tectónica que ha acompañado y seguido a 
Tabla 1. Principales provincias silícicas del mundo ordenadas por volumen (de Bryan et al., 2005). Todas las provincias son dominadas por ignimbritas de composición riolítica.

\begin{tabular}{|c|c|c|c|c|c|}
\hline Provincia & Edad (Ma) & Volumen $\left(\mathbf{k m}^{3}\right)$ & Dimensiones (km) & $\begin{array}{l}\text { Flujo de magma } \\
\left(\mathbf{k m}^{3} \mathbf{k y r}^{-1}\right)^{*}\end{array}$ & Referencia \\
\hline $\begin{array}{l}\text { Whitsunday } \\
\text { (Australia oriental) }\end{array}$ & $\sim 132-95$ & $>1.5 \times 10^{6}$ & $>2500 \times 200$ & $>37.5$ & Bryan et al. $(1997 ; 2000)$ \\
\hline $\begin{array}{l}\text { Kennedy-Connors- } \\
\text { Auburn } \\
\text { (Australia nororiental) }\end{array}$ & $\sim 320-280$ & $>5 \times 10^{5}$ & $>1900 \times 300$ & $>12.5$ & $\begin{array}{l}\text { Bain y Draper (1997); Bryan et al. } \\
\text { (2002b) }\end{array}$ \\
\hline Sierra Madre Occidental & $\sim 38-20$ & $>3 \times 10^{5}$ & $>2000 \times 200$ a 500 & $>22$ & $\begin{array}{l}\text { McDowell y Clabaugh (1979); Ferrari } \\
\text { et al. (2002) }\end{array}$ \\
\hline $\begin{array}{l}\text { Chon Aike } \\
\text { (Sudámerica-Antarctica) }\end{array}$ & $188-153$ & $>2.3 \times 10^{5}$ & $>3000 \times 1000$ & $>7.1$ & Pankhurst et al. $(1998 ; 2000)$ \\
\hline $\begin{array}{l}\text { Altiplano-Puna } \\
\text { (Andes centrales) }\end{array}$ & $\sim 10-3$ & $>3 \times 10^{4}$ & $\sim 300 \times 200$ & $>4.3$ & De Silva (1989a, 1989b) \\
\hline $\begin{array}{l}\text { Taupo Volcanic Zone } \\
\text { (Nueva Zelandia)** }\end{array}$ & $1.6-0$ & $\sim 2 \times 10^{4}$ & $300 \times 60$ & $\sim 9.4-13$ & $\begin{array}{l}\text { Wilson et al. (1995); Houghton et al. } \\
\text { (1995) }\end{array}$ \\
\hline
\end{tabular}

*El flujo de magma es un promedio basado en las estimaciones de los volúmenes extruidos. **No incluye eventos magmáticos anteriores de la Coromandel Volcanic Zone (Adams et al., 1994; Carter et al., 2003) que extenderían el periodo de volcanismo silícico de 12 Ma.

esta actividad magmática. En la primera parte se presenta una síntesis de la información estratigráfica apoyada por los datos geocronológicos disponibles, así como un resumen de la geometría, cinemática y edad del fallamiento que ha afectado la SMO. Posteriormente se resume la información geofísica y los estudios geoquímicos y petrológicos. Finalmente se discute la evolución espacio-temporal del magmatismo y la tectónica, los modelos sobre la génesis del volcanismo silícico y los problemas que aún quedan por resolver para el entendimiento de esta provincia volcánica. Como apoyo al presente trabajo se presenta una serie de mapas geológicos regionales de síntesis de los episodios magmáticos (Figuras 2-5) y mapas tectónicos basados en la interpretación de imágenes de satélite de alta resolución y datos obtenidos de literatura (Figuras 6-9).

Otros trabajos de síntesis y revisión sobre la SMO se han publicado con anterioridad. McDowell y Clabaugh (1979) resumieron los estudios pioneros en la década de los años setenta, y esbozaron el primer acercamiento a la estratigrafía general de la SMO. En su gran mayoría, el conocimiento geológico y geocronológico sobre la parte norte y centro de la SMO se debe al trabajo realizado por investigadores y estudiantes de la Universidad de Texas en Austin y la Estación Regional del Noroeste del Instituto de Geología de la UNAM, coordinados a lo largo de más de tres décadas por Fred McDowell y resumidos en una serie de artículos publicados principalmente en el GSA Bulletin entre 1994 y 2001. Contribuciones importantes sobre la geología y tectónica en la parte central de la SMO han sido los trabajos de Chris Henry de la Universidad de Nevada, y de Jorge Aranda-Gómez y Gerardo Aguirre-Díaz del Centro de Geociencias de la UNAM. Una síntesis actualizada de estos trabajos se puede encontrar en Aranda-Gómez et al. (2003) y Henry et al. (2003). Hasta hace pocos años la parte sur de la SMO había permanecido poco estudiada en comparación con el resto de la provincia. Nieto-Samaniego et al. (1999) proporcionaron una primera síntesis de esta región en conjunto con la evolución magmática y tectónica de la Mesa Central. Más recientemente el trabajo de Ferrari et al. (2002) ha proporcionado el marco geológico y tectónico regional para este sector, y ha propuesto un modelo general para la ocurrencia de los pulsos ignimbríticos de la SMO. Trabajos de revisión sobre las edades y el marco geológico y tectónico de los yacimientos minerales de la SMO han sido realizados por Damon et al. (1983), Staude y Barton (2001) y Camprubí et al. (2003).

\section{Estratigrafía regional}

\subsection{Introducción}

Con el nombre de Sierra Madre Occidental se define tradicionalmente a la provincia fisiográfica del occidente de México, caracterizada por un altiplano con una elevación promedio de más de $2000 \mathrm{~m}$, y aproximadamente 1200 $\mathrm{km}$ de largo por 200-400 km de ancho, la cual se extiende desde la frontera con los Estados Unidos hasta la Faja Volcánica Transmexicana y limitada al oeste por el Golfo de California y al este por el Altiplano Central (o Mesa Central) mexicano (Figura 1). La apertura del Golfo de California ha inducido la formación de grandes cañadas en el flanco oeste mientras que la tectónica extensional ha provocado la formación de amplias depresiones tectónicas en el flanco este de esta provincia. El término "Sierra Madre Occidental" también se utiliza para definir la provincia volcánica terciaria caracterizada por grandes volúmenes de ignimbritas silícicas (Figura 1). Como provincia volcánica terciaria la Sierra Madre Occidental (SMO) se extiende más allá de la provincia fisiográfica, abarcando también a la Mesa Central y parte de Chihuahua oriental. En el presente trabajo se analizará la SMO como provincia fisiográfica ya 


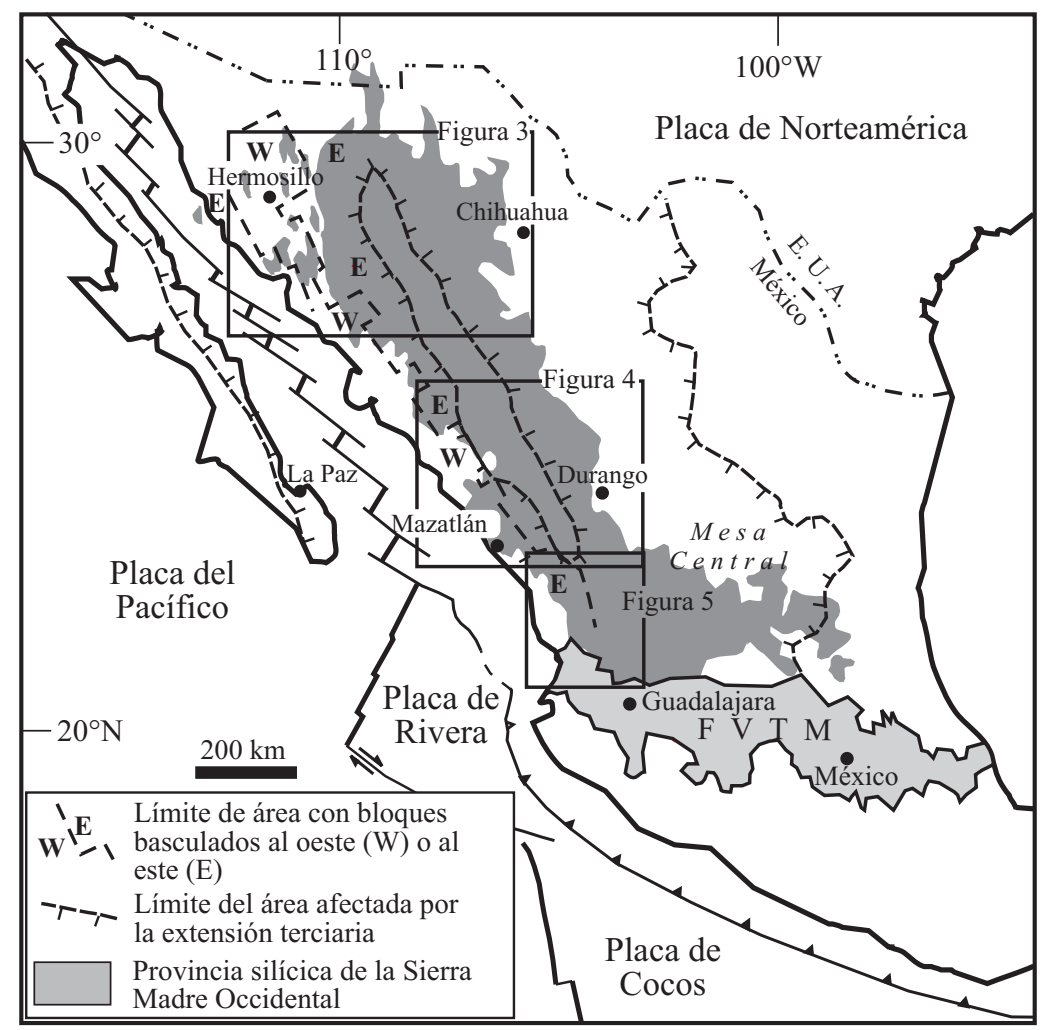

Figura 1. Esquema tectónico de México mostrando la extensión del Terciario (tomado de Henry y Aranda-Gómez, 2000 y Ferrari et al., 2002), la provincia volcánica de la SMO y la configuración actual de las placas. FVTM: Faja Volcánica Transmexicana. Los dominios regionales de basculamiento fueron tomados de Stewart et al. (1998).

que la geología de la Mesa Central es tratada en un trabajo aparte (Nieto-Samaniego et al., 2005).

La geología de la SMO está dominada por conjuntos de rocas ígneas asociados a diferentes episodios magmáticos, que resultaron de la subducción de la placa Farallón debajo de la placa de Norteamérica (Figura 2): 1) rocas plutónicas y volcánicas del Cretácico Superior-Paleoceno; 2) rocas volcánicas andesíticas $\mathrm{y}$, en menor medida, dacítico-riolíticas del Eoceno; 3) ignimbritas silícicas emplazadas en dos pulsos principales en el Oligoceno temprano y el Mioceno temprano; 4) coladas basáltico-andesíticas extravasadas después de cada pulso ignimbrítico; 5) coladas de basaltos e ignimbritas alcalinos emplazados generalmente en la periferia de la SMO en diferentes episodios del Mioceno tardío, Plioceno y Cuaternario. Los conjuntos 1 y 2 , y el conjunto 3, han sido definidos como el Complejo Volcánico Inferior (CVI) y el Supergrupo Volcánico Superior (SVS), respectivamente (McDowell y Keitzer, 1977). El conjunto 4, en la parte norte de la SMO, ha sido definido como una extensión del cinturón de "Basalto-Andesitas del Sur de la Cordillera" (SCORBA por sus siglas en inglés) (Cameron et al., 1989). Finalmente los basaltos del conjunto 5 han sido interpretados como testigos de varios episodios de extensión relacionados con la apertura del Golfo de California (Henry y Aranda-Gómez, 2000). Los productos de todos estos episodios magmáticos, parcialmente superpuestos entre sí (Figura 2), cubren a su vez un basamento hetero- géneo pobremente expuesto del Precámbrico, Paleozoico y Mesozoico.

$\mathrm{Al}$ momento de resumir la estratigrafía regional de la SMO, hay que tomar en cuenta que nuestros conocimientos están significativamente mermados por la dificultad de acceso, la escasez de afloramientos de las unidades pre-Oligoceno, y el intenso fallamiento extensional postEoceno. En particular, la extensión real del magmatismo Cretácico-Eoceno puede pasar desapercibida a un examen superficial de la geología de la región (Figuras 2-5). Para fines prácticos, el magmatismo y la tectónica durante el Cretácico-Terciario se describen dividiendo la SMO en tres sectores: norte (Sonora-Chihuahua), centro (SinaloaDurango) y sur (Nayarit-Jalisco-Zacatecas), mismos que corresponden a los tres principales transectos que cruzan la SMO de oeste a este. La geología regional de estos sectores es ilustrada en los mapas de las Figuras 3,4 y 5. Para la elaboración de los dos primeros mapas se utilizó principalmente la cartografía geológica 1:250 000 publicada en los últimos 8 años por el Consejo de Recursos Minerales, actualmente Servicio Geológico Mexicano (SGM), y en particular las hojas Hermosillo, Madera, Buenaventura, Sierra Libre, Tecoripa, Chihuahua, Guaymas, Ciudad Obregón, San Juanito, Pericos, Santiago Papasquiaro, Culiacán, Durango, Mazatlán y El Salto. Esta cartografía ha sido reinterpretada y verificada en base a todos los fechamientos disponibles en la literatura. Aunque 


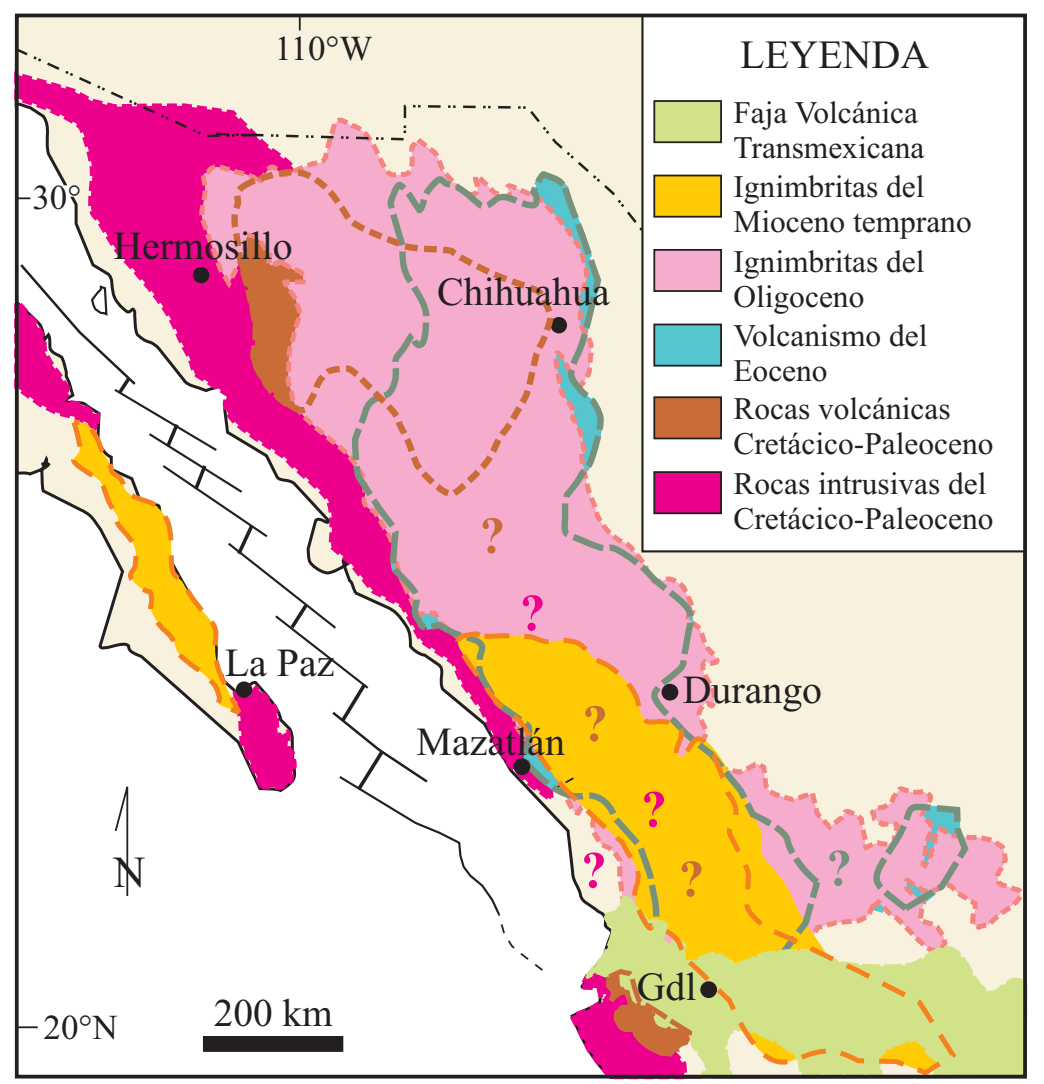

Figura 2. Extensión geográfica de los conjuntos ígneos que conforman la SMO basada en las Figuras 3, 4 y 5. La extensión de los conjuntos del CretácicoEoceno está en parte inferida debido a la extensa cubierta de las ignimbritas del Oligoceno y Mioceno temprano. Gdl: Guadalajara.

parcialmente inferida, la cartografía del SGM representa el documento más detallado y actualizado que cubre la totalidad de la SMO. El mapa de la parte sur de la SMO (Figura 5) es una modificación del que presentan Ferrari et al. (2002), trabajo que se eligió por tener un mayor detalle estratigráfico con respecto a los mapas publicados por el SGM en esta región.

\subsection{El basamento prevolcánico}

\subsubsection{Mesoproterozoico}

Abundantes afloramientos de rocas precámbricas con afinidad al cratón de Norteamérica se reconocen particularmente en el basamento del noroeste de Sonora. Parte de este basamento se presume fue desplazado $\sim 800 \mathrm{~km}$ al sureste durante el Jurásico Medio-Tardío, por un sistema de fallamineto lateral izquierdo denominado la megaciza1la Mojave-Sonora (Silver y Anderson, 1974; Anderson y Silver, 1979). Desde su propuesta inicial, este modelo ha sido muy controversial, pero continúa siendo un rasgo geológico fundamental para la reconstrucción tectónica de México (e. g., Sedlock et al., 1993, Anderson et al., 2005). Otras alternativas para el arreglo y reconstrucción tectónica de las rocas precámbricas de Sonora han sido propuestas recientemente (Dickinson y Lawton, 2001; Iriondo et al., 2004a); sin embargo, estos modelos alternativos requieren también de una zona de cizalla con desplazamientos similares a la propuesta por Anderson y Silver (1979). De acuerdo con el modelo de la megacizalla Mojave-Sonora, el basamento transportado hacia el sureste, también definido como el terreno Caborca (Campa y Coney, 1983), está formado por plutones graníticos, gneises y esquistos con edades entre 1.8 y $1.7 \mathrm{Ga}$, mientras que el basamento no transportado está caracterizado por rocas clásticas y volcánicas metamorfizadas del Esquisto Pinal, cuyas edades se estiman entre 1.7 y 1.6 Ga (Anderson y Silver, 1979; Anderson y Schmidt, 1983). A excepción de la parte más noreste de Sonora, las rocas del basamento precámbrico ígneo-metamórfico no afloran en la provincia de la SMO. Sin embargo, rocas graníticas de edad grenvilliana $(\sim 1.0 \mathrm{Ga})$ cortadas por diques anfibolíticos se reconocen en la parte centro-oriental de Chihuahua, en la Sierra de Los Filtros y la Sierra El Carrizalillo (Ruiz et al., 1988b; McDowell y Mauger, 1994) (Figura 3). También se han reconocido de manera indirecta en xenolitos de rocas volcánicas recientes en El Potrerillo y La Olivina, en el noreste y sureste de Chihuahua, respectivamente (Ruiz et al., 1988b; Cameron et al., 1992). Estos afloramientos sugieren que el basamento antiguo de Norteamérica cruza por debajo de la SMO, y podría suponerse que ha modificado de alguna manera la composición de las rocas volcánicas cenozoicas. En base 
a esta inferencia, McDowell et al. (2001) y Albrecht y Goldstein (2000) han utilizado los datos isotópicos de $\mathrm{Sr}$, $\mathrm{Nd}$ y $\mathrm{Pb}$ en ignimbritas del Eoceno-Oligoceno para definir el posible límite del basamento precámbrico por debajo de la SMO en Chihuahua. Ambos trabajos coinciden en poner el límite del basamento precámbrico a lo largo de una franja de burda dirección WNW o NW pasando entre la ciudad de Chihuahua al noreste y la caldera de Tómochic al suroeste (Figuras 3 y 6). Sin embargo, estudios isotópicos en rocas graníticas laramídicas del noroeste de México sugieren que este límite puede localizarse más al sur, en las cercanías de la frontera Sonora-Sinaloa-Chihuahua (Valencia-Moreno et al., 2001 y 2003) (Figura 6).

\subsubsection{Neoproterozoico y Paleozoico}

Extensas secuencias de rocas marinas cubren las rocas cristalinas proterozoicas del norte y noroeste de México. Estas secuencias tienen una clara continuidad temporal desde la parte superior del Proterozoico a través de todo el Paleozoico, por lo que es más conveniente tratarlas aquí como un solo conjunto. Un completo inventario y descripción de estas rocas en Sonora fue presentado por Stewart y Poole (2002). En general, se ha reconocido que los afloramientos corresponden a dos ambientes principales. Uno de plataforma marina de aguas someras bordeando la parte oeste y central de Sonora, y otro formado por sedimentos paleozoicos de cuenca marina profunda más al sur (Poole et al., 1991). Este último fue considerado como el terreno Cortés (Coney y Campa, 1987; Valencia-Moreno et al., 1999); sin embargo, otros autores consideran a estos sedimentos de cuenca marina como la parte circundante de Norteamérica, y por lo tanto parte del mismo bloque tectónico, el cual fue parcialmente transportado en el Jurásico junto con el terreno Caborca (e. g., Sedlock et al., 1993; Ortega et al., 1994). En el oriente de Sonora, las rocas sedimentarias neoproterozoicas y paleozoicas están claramente debajo de las rocas volcánicas de la SMO. Por ejemplo, al oeste de Yécora y al sureste de Sahuaripa (Stewart et al., 1999; Almazán-Vázquez et al., 1989) en el borde occidental de la SMO (Figura 3). En el norte de Sinaloa se han reconocido rocas paleozoicas deformadas de cuenca marina (Carrillo-Martínez, 1971; Mullan, 1977; Gastil et al., 1991), las cuales al parecer se extienden al norte hacia la porción sur de Sonora cerca de Álamos (Figura 3).

El contacto entre estos dos ambientes paleozoicos se conoce bien en Sonora central (e. g., Poole et al., 1991; Valencia-Moreno et al., 1999), y su extensión hacia el este está cubierta bajo las rocas volcánicas de la SMO. Al oriente de la SMO, los afloramientos de rocas paleozoicas son relativamente más escasos, pero se conocen en la región norte de Chihuahua, donde se consideran una prolongación del cinturón Ouachita (Stewart, 1988) (Figura 6). Más al sur en esta región, los sedimentos del cinturón Ouachita contienen remanentes de la acreción de Gondwana y Laurencia a principios del Pérmico, particularmente representados por el bloque Coahuila, que incluye rocas paleozoicas con metamorfismo de bajo grado y secuencias volcánicas y volcaniclásticas asociadas al Arco Las Delicias (McKee et al., 1988; Sedlock et al., 1993; Dickinson y Lawton, 2001).

Las ocurrencias más meridionales de rocas pre-mesozoicas en la SMO se encuentran en el norte de Durango y el norte de Sinaloa. Limitados afloramientos de esquistos muscovíticos afloran por debajo de las ignimbritas del Oligoceno al suroeste de San Juan del Río en Durango (Figura 4). La edad mínima del metamorfismo de estas rocas ha sido recientemente asignada al Permico-Triásico por medio de un fechamiento ${ }^{40} \mathrm{Ar} /{ }^{39} \mathrm{Ar}$ en muscovita (Iriondo et al., 2003). Otra secuencia metamórfica volcanosedimentaria está ampliamente expuesta al este de Culiacán, principalmente en el valle del río San Lorenzo (Figura 4) donde se conoce como grupo El Fuerte. La edad de estas rocas es incierta, sin embargo, Mullan (1978) refiere este conjunto al Jurásico o posiblemente a edades más antiguas.

\subsubsection{Mesozoico prevolcánico}

Las rocas mesozoicas son abundantes hacia el oeste de la SMO en Sonora, pero son menos comunes hacia el sur del estado. En la porción centro-oriental de Sonora, las rocas mesozoicas más antiguas consisten en una secuencia de sedimentos clásticos continentales y, en menor medida, marinos del Triásico Tardío-Jurásico Temprano (Stewart y Roldán-Quintana, 1991; Valencia-Moreno et al., 1999). Estas rocas son localmente conocidas como el Grupo Barranca (Alencaster y De Cserna, 1961), el cual está caracterizado por la presencia de un miembro intermedio con horizontes importantes de carbón, limitado por dos miembros conglomeráticos. Los afloramientos del Grupo Barranca se depositaron en una cuenca alargada en dirección E-W, cuyo límite norte restringe de manera abrupta a los afloramientos de rocas paleozoicas (Valencia-Moreno et al., 1999). Esta cuenca se extiende hasta el margen occidental de la SMO, pero presumiblemente continua más al oriente. Su origen se considera genéticamente asociado a una ruptura extensional tipo pull-apart ocurrida a principios del Triásico (Stewart y Roldán-Quintana, 1991). Rocas de esta misma edad, pero de ambiente marino, están también reportadas en el noroeste de Sonora como El Grupo Antimonio (González-León, 1997), pero la relación entre ambos grupos no se conoce muy bien. De manera discordante sobre estas rocas se depositó una secuencia de sedimentos clásticos con flujos volcánicos intercalados, cuya edad isotópica y fosilífera se estima entre el Jurásico Temprano y el Jurásico Tardío. Estas rocas son más comunes en el noroeste de Sonora, pero sus afloramientos se extienden más al oriente del estado (Anderson y Silver, 1979; Rodríguez-Castañeda, 1996). Las rocas ígneas asociadas a esta secuencia jurásica, la cual incluye además varios plutones, permiten definir la presencia de un arco continental en ese tiempo en Sonora. Más aún, el afloramiento de un plutón de edad Triásico Tardío reportado en el noroeste de Sonora, sugiere que la actividad de este 
arco magmático pudo haber sido relativamente continua desde $\sim 220$ hasta $140 \mathrm{Ma}$ (e. g., Anderson y Silver, 1979; Damon et al., 1981; Stewart, 1988). Edades similares en rocas ígneas se han reportado en el sur de Chihuahua y el norte de Durango, lo cual ha sido interpretado como una prolongación del arco Triásico-Jurásico, desplazado al oriente por efectos de la megacizalla Mojave-Sonora (Grajales-Nishimura et al., 1992).

Discordantemente sobre estas secuencias jurásicas se depositaron sedimentos fluvio-deltáicos y marinos del Jurásico Tardío y Cretácico Temprano del Grupo Bisbee, asociados al relleno de cuencas de subsidencia (GonzálezLeón, 1994). Estos sedimentos afloran en una gran parte de Sonora, particularmente en la porción norte y central, pero se conocen también en Arivechi (Almazán-Vázquez, 1989) y Lampazos (González-León, 1997) en el oriente del estado, y cerca de Caborca, en el noroeste de Sonora (Jacques-Ayala, 1995). A escala más regional, secuencias sedimentarias similares se han reportado al oriente de la SMO, en las cuencas de Chihuahua y Sabinas (Dickinson et al., 1989; Haenggi, 2002). El equivalente temporal más occidental es la Formación Alisitos, expuesta principalmente en la parte norte de la península de Baja California. Esta formación consiste en secuencias volcánicas, volcanoclásticas y carbonatadas principalmente marinas del AlbianoAptiano (Almazán-Vázquez, 1988; Dickinson y Lawton, 2001), las cuales caracterizan al terreno Alisitos (Campa y Coney, 1983), redefinido más tarde como el terreno Yuma (Sedlock et al., 1993). Para el Cretácico Tardío, en el noreste de Sonora se desarrollaron cuencas sintectónicas asociadas a la orogenia Laramide, las cuales fueron rellenadas por sedimentos fluviales y lacustres, coronadas por cuñas de sedimentos clásticos gruesos (González-León y Lawton, 1995). Localmente, estos depósitos sedimentarios integrados como el Grupo Cabullona, contienen horizontes con abundantes restos de plantas, invertebrados y vertebrados, incluyendo huesos de dinosaurios (Lucas et al., 1995).

En Sinaloa las rocas anteriores al batolito de edad cretácica consisten de ortogneises, rocas metasedimentarias y metavolcánicas (Henry et al., 2003). Los ortogneises están intensamente foliados y han sido referidos al Jurásico con base en inferencias estratigráficas (Mullan, 1978). Henry y Mortenson (comunicación escrita, 2005) obtuvieron una edad U-Pb en circones del límite Jurásico-Cretácico. La

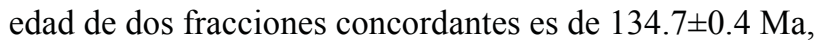
indistinguible de las edades K-Ar de hornblendas de gabro estratificado de la misma área. Las rocas metasedimentarias son filitas, cuarcitas, y esquistos de cuarzo, muscovita y biotita de probable edad jurásica así como mármol producto de metamorfismo de contacto con el batolito (Henry et al., 2003). Las calizas metamorfizadas de Sinaloa son del Albiano y están localmente subyacidas por andesitas y conglomerados (Bonneau, 1970). Escasos afloramientos de anfibolitas de edad pre-Albiano son también reportados en el sur de Sinaloa (Henry et al., 2003).

En la parte sur de la SMO la existencia de un basamento
pre-Cenozoico no volcánico es sugerida por la presencia de pequeños afloramientos de pizarra, grauvaca y caliza expuestas en el cañón del río Santiago antes de la construcción de la presa de Aguamilpa (Figura 5) (Gastil et al., 1978; Ferrari et al., 2000). Estas rocas están espacialmente asociadas con cuerpos intrusivos graníticos que han proporcionado invariablemente edades del Oligoceno al Mioceno temprano (Gastil et al., 1978; Nieto-Obregón et al., 1985; Ferrari et al., 2002). Rocas ígneas más antiguas no han sido reportadas en esta región pero sí afloran inmediatamente al sur de la FVTM en el bloque Jalisco (Figura 2) (Ferrari et al., 2000).

\subsection{Arco magmático del Cretácico Tardío-Paleoceno}

\subsubsection{Sector norte}

Durante el fin del Cretácico y el principio del Terciario, el magmatismo en el norte de México estuvo dominado por la actividad de un arco nombrado "Laramide" por ser contemporáneo con el periodo en que se desarrolló la deformación laramídica en norteamérica. La actividad de este arco produjo una gran cantidad de rocas plutónicas y volcánicas, que fueron agrupadas en el llamado Complejo Volcánico Inferior (CVI) por McDowell y Keizer (1977). El complejo está constituido por grandes batolitos graníticos compuestos, que varían en composición desde diorita y cuarzodiorita a granito alcalino (e. g., Roldán-Quintana 1991; Valencia-Moreno et al., 2001), y por una secuencia volcánica de composición dominantemente andesítica, conocida como Formación Tarahumara (Wilson y Rocha, 1949). Esta secuencia volcánica incluye a su vez un miembro superior de tobas y flujos de riolita y dacita, intercalados con horizontes de rocas sedimentarias, localmente conteniendo restos de plantas fósiles (GonzálezLeón et al., 2000; McDowell et al., 2001). De acuerdo con Damon et al. (1983), las rocas plutónicas del CVI en el noroeste de México tienen edades entre 90 y 40 Ma, y la distribución espacial de las mismas muestra un arreglo progresivamente más joven hacia el oriente. Sin embargo, un estudio más reciente de las rocas volcánicas de la Formación Tarahumara, en la porción centro-oriental de Sonora, indicó edades de cristalización entre 90 y 60 Ma (McDowell et al., 2001). Esto hace suponer que el magmatismo laramídico en esta región del país fue quizás más complejo que el modelo tradicional basado en un simple arco magmático migrando hacia el oriente (e. g., Coney y Reynolds, 1977; Damon et al., 1983). En general se acepta que las rocas del CVI fueron producidas durante la actividad magmática cordillerana asociada a la orogenia Laramide. Sin embargo, en el trabajo de McDowell y Clabaugh (1979), el CVI incluye además a las rocas del batolito de las Sierras Peninsulares en Baja California y su extensión a Sinaloa, cuyas edades son relativamente más antiguas $(\sim 120-85 \mathrm{Ma})$. 
En su porción más occidental, el CVI está muy bien expuesto; sin embargo, el levantamiento asociado a la actividad tectónica terciaria erosionó profundamente el miembro volcánico de este conjunto, exponiendo las rocas plutónicas. Las rocas volcánicas de la Formación Tarahumara están mejor preservadas en la parte centrooriental y norte-noreste de Sonora (e. g., González-León et al., 2000; McDowell et al., 2001). Una de las características más notables del CVI, aparte del gran volumen de sus afloramientos, es la clara relación con la generación $\mathrm{y}$ acumulación de yacimientos minerales de varios tipos, los cuales fueron también expuestos por el levantamiento tectónico. Entre estos se pueden mencionar los numerosos sistemas de pórfido cuprífero distribuidos particularmente en la porción oriental del cinturón laramídico en Sonora y Sinaloa (Damon et al., 1983; Staude y Barton, 2001), y especialmente en el noreste de Sonora, donde se conocen ocurrencias de clase mundial, como los distritos mineros de Cananea y La Caridad (Valencia-Moreno et al., 2005).

En Sonora, el cinturón de rocas del CVI es considerablemente más amplio que su prolongación al sur, en Sinaloa. No obstante, este rasgo quizá no refleja la distribución original de estas rocas, sino que es un reflejo de la amplitud de la franja extendida durante el Terciario tardío (Damon et al., 1983). Hacia el oriente, estas rocas desaparecen debajo de la provincia volcánica ignimbrítica de la SMO, pero existen evidencias que permiten extender el cinturón hasta Chihuahua central. A $\sim 30 \mathrm{~km}$ al NW de la ciudad de Chihuahua, Mauger $(1981 ; 1983)$ describe una secuencia de más de $3000 \mathrm{~m}$ de espesor (Peñas Azules Volcanics), interpretada como un complejo de estratovolcanes, que ha sido fechada en $68.2 \pm 1.6 \mathrm{Ma}$ (K-Ar en plagioclasa) y $67.5 \pm 1 \mathrm{Ma}$ (U-Pb en circones) (McDowell y Mauger, 1994). Adicionalmente, estos autores reportan pequeños cuerpos intrusivos y tobas silícicas con edades paleocénicas en la región colindante a la ciudad de Chihuahua.

\subsubsection{Sector centro}

En este sector, el magmatismo del Cretácico-Paleoceno ha sido estudiado de manera más detallada en la margen oeste de la SMO, en Sinaloa, donde la extensión asociada a la apertura del Golfo de California ha expuesto de manera más continua los batolitos del CVI. Sin embargo, batolitos del Cretácico-Paleoceno podrían subyacer a buena parte de la SMO dado que cuerpos dioríticos cretácicos son reportados también en el área de Nazas, en el occidente de Durango (Aguirre-Díaz y McDowell, 1991). Todas las rocas intrusivas son calcialcalinas y la composición varía de diorítica a granítica siendo la granodiorítica la dominante. Las rocas granitoides asociadas a los batolitos de Sinaloa tienen edades U-Pb y K-Ar entre 101 y 46 Ma y han sido divididas en dos grupos: rocas pre- o sintectónicas y rocas postectónicas (Henry y Fredrikson, 1987; Henry et al., 2003). Las primeras presentan foliación y lineación mineral que indican su emplazamiento antes o durante un episodio de deformación compresiva ocurrido antes de $\sim 85 \mathrm{Ma}$. Las postectónicas son más homogéneas y masivas. Las rocas pre- y sintectónicas están emplazadas en una franja cercana a la costa, mientras que las postectónicas se encuentran más al este, a partir de $\sim 30 \mathrm{~km}$ de la costa (Figura 4).

Las rocas volcánicas del CVI han sido poco estudiadas en la parte central de la SMO, en gran medida debido a la intensa alteración hidrotermal que presentan. En general se trata de lavas andesíticas y riolíticas e ignimbritas silícicas expuestas en las partes más profundas de los cañones. Los afloramientos principales ocurren en el cañón del río Piaxtla y del río Presidio, así como en la cercanías de Pánuco y Copales en el camino Mazatlán-El Salto (Henry y Fredikson, 1987).

\subsubsection{Sector sur}

Cuerpos intrusivos de edad Cretácico-Paleoceno afloran de manera aislada en el borde este de la SMO en Zacatecas. En el área de La Tesorera-Zacatón, $20 \mathrm{~km}$ al este de Zacatecas, la ciudad capital del estado, afloran rocas de composición granodiorítica para las cuales se han reportado fechas K-Ar en biotita del Campaniano (74 $\pm 6 \mathrm{Ma}$

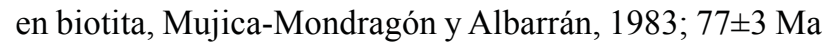
en biotita, Solé et al., en prensa). Estos cuerpos plutónicos intrusionan regularmente a rocas sedimentarias marinas del Cretácico Temprano (CRM, 1997). Hacia el oeste, en Jalisco occidental y Nayarit no existe reporte de rocas magmáticas pre-cenozoicas. La escasez de afloramientos del arco Cretácico-Paleoceno en el sector sur de la SMO puede deberse a la extensa cobertura de las ignimbritas del Oligoceno y, sobretodo, del Mioceno temprano, que tienen su máxima extensión en esta región.

\subsection{Arco magmático del Eoceno}

En las primeras síntesis de la SMO (e. g., McDowell y Clabaugh, 1979) las rocas magmáticas eocénicas habían sido agrupadas en el (CVI) junto con las rocas batolíticas y volcánicas del Cretácico-Paleoceno. Sin embargo, trabajos posteriores han documentado la extensión espacio-temporal y las peculiaridades de este volcanismo que constituye un episodio distinto en la evolución magmática del occidente de México. Por esta razón, en este trabajo consideramos el arco Eoceno como un evento magmático aparte, que en varias áreas puede interpretarse como el precursor del episodio ignimbrítico del Oligoceno.

\subsubsection{Sector norte}

En el sector norte el volcanismo Eoceno está expuesto principalmente en Chihuahua, en el borde este de la SMO y en las barrancas más profundas del interior de la sierra (Figura 3). En general, las primeras ignimbritas eocénicas de la parte norte de la SMO se distinguen por ser porfídicas y ricas en cristales, entre los cuales se encuentra comúnmente la biotita (Magonthier, 1988). 
El volcanismo del Eoceno a la longitud de la ciudad de Chihuahua está bien representado en una franja N-S que incluye la sierras de El Gallego (Keller et al., 1982), del Nido, Sacramento, Pastorías, Las Palomas, Magistral (McDowell y Mauger, 1994 y referencias incluidas), Santa Eulalia (Megaw, 1990) y Los Arados (Iriondo et al., 2003) (Figura 3). Este episodio inicia a los 46 Ma después de un periodo de magmatismo escaso e intermitente y sigue prácticamente sin interrupciones hasta los $27.5 \mathrm{Ma}$, ligando así el magmatismo Eoceno con las ignimbritas del Supergrupo Volcánico Superior. En Chihuahua central las rocas eocénicas constan de dos secuencias de ignimbritas silícicas separadas por una potente secuencia de coladas masivas de composición de intermedia a silícica (McDowell y Mauger, 1994 y referencias incluidas). Una secuencia parecida, aunque menos completa, está expuesta más al occidente en el interior de la SMO en el área de Tómochic. En esta región Wark et al. (1990) reportan una sucesión de lavas andesíticas con edades entre 238 y $35 \mathrm{Ma}$, cubierta por una secuencia ignimbrítica de $34 \mathrm{Ma}$ asociada a la formación de la caldera de Las Varas. A su vez esta secuencia está parcialmente cubierta por los productos de las dos calderas oligocénicas de Tómochic y Ocampo (Swanson y McDowell, 1985, posteriormente revisado en Wark et al., 1990). Esta secuencia podría extenderse aún más al oeste en Sonora oriental, donde Montigny et al. (1987) obtuvieron una edad K-Ar de 35.3 Ma en sanidino para una ignimbrita porfírica al este de Yécora. En Sonora, sin embargo, el volcanismo del Eoceno tiene por lo general edades más antiguas. En el área de Santa Rosa (Figura 3), Gans (1997) obtuvo dos fechas ${ }^{40} \mathrm{Ar} /{ }^{39} \mathrm{Ar}$ de $54.3 \pm 0.2 \mathrm{Ma}$ (sanidino) y $43.8 \pm 0.2 \mathrm{Ma}$ (sanidino) de una secuencia de ignimbrita y lavas dacíticas de varios cientos de metros. El mismo autor menciona la posibilidad de que esta secuencia pueda ser cogenética con un plutón granodiorítico que fechó en $60.0 \pm 0.5$ Ma y que aflora cerca de de Santa Rosa. En este caso, estas rocas podrían correlacionarse con el miembro superior félsico del CVI, cuyos afloramientos se reconocen relativamente cerca hacia el oeste (McDowell et al., 2001). Más estudios geocronológicos son necesarios para establecer con mayor precisión el alcance del volcanismo del Eoceno en el sector norte de la SMO.

\subsubsection{Sector centro}

En la parte central de la SMO el mayor espesor de rocas eocénicas se encuentra en el límite Sinaloa-Durango, en el área de Tayoltita (Figuras 4 y 8) (Henry y Fredikson, 1987). En esta área el río Piaxtla ha disectado un profundo cañón que expone por lo menos $1500 \mathrm{~m}$ de la secuencia eocénica con importante mineralización de oro y plata (Horner, 1998; Horner y Enríquez, 1999; Enríquez y Rivera, 2001). La secuencia, que se encuentra fuertemente basculada al ENE, consiste de coladas riolíticas y andesíticas, y cuerpos subvolcánicos de composición diorítica que han arrojado edades K-Ar de 39.9 a $36.6 \mathrm{Ma}$ y cubren a un batolito granodiorítico-diorítico fechado en
45.1 Ma (Enríquez y Rivera, 2001). Los fechamientos en adularia de las vetas mineralizadas dieron edades lige-

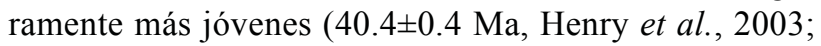
38.5 a 32.9 Ma, Enríquez y Rivera, 2001), sugiriendo una relación genética con la secuencia del Eoceno. Esta secuencia se encuentra separada de una serie ignimbrítica del Mioceno inferior por una secuencia fluvio-lacustre de conglomerados, areniscas y lutitas (Horner y Enríquez, 1999). Por analogía con la estratigrafía del valle del río Piaxtla, rocas andesíticas reportadas en muchas áreas de Sinaloa por debajo de cubierta ignimbrítica oligo-miocena se han referido al Eoceno en este trabajo (Figura 4). Sin embargo, no existen datos geocronológicos que comprueben de manera segura esta correlación.

Otra área donde se ha podido documentar una importante actividad del Eoceno se encuentra en la periferia este de la SMO. En la región de Nazas (Figura 4), la secuencia incluye lavas andesíticas de 48.8 y $40.3 \mathrm{Ma}$ separadas por lavas riolíticas e ignimbritas de 45.2 a 42.9 Ma y cubiertas por riolitas de $34 \mathrm{Ma}$ (Aguirre-Díaz y McDowell, 1991). Depósitos de capas rojas separan la secuencia del Eoceno de las ignimbritas del Oligoceno. En el área de El Cuarenta, a $\sim 210 \mathrm{~km}$ al NNW de la ciudad de Durango (Figura 4), una ignimbrita de la base de la secuencia riolítica ha sido fechada por el método ${ }^{40} \mathrm{Ar} /{ }^{39} \mathrm{Ar}$ en 39.6 Ma (Tuta et al., 1988). Más recientemente, Solé et al. (en prensa) obtuvieron una edad K-Ar de $42 \pm 1 \mathrm{Ma}$ (sanidino+cuarzo) para una ignimbrita riolítica ubicada $\sim 20 \mathrm{~km}$ al norte de General Escobedo (Figura 4). Finalmente, al sur de la ciudad de Durango, en el graben de Mezquital (Figura 8) McDowell y Keitzer (1977) también reportan una espesa secuencia de lavas andesíticas de las cuales sólo pudieron obtener una fecha K-Ar de $\sim 52 \mathrm{Ma}$ en roca total.

\subsubsection{Sector sur}

Volcanismo del Eoceno ha sido documentado también en la parte sur de la SMO (Nieto-Samaniego et al., 1999). Ignimbritas silícicas, domos riolíticos y coladas andesíticas con edades K-Ar entre 38 y $34 \mathrm{Ma}$ afloran localmente en el área de Fresnillo y Sain Alto, Zac. (Ponce y Clark 1988; Lang et al., 1988; Tuta et al., 1988), mientras que Nieto-Samaniego et al. (1996) reportan una edad K-Ar de 40.6 $\pm 1 \mathrm{Ma}$ (sanidino) para una riolita expuesta en el Cerro El Picacho, Ags. Más al oeste, una secuencia de lavas andesíticas intensamente alteradas con una edad $\mathrm{K}$-Ar de 48.1 $\pm 2.6 \mathrm{Ma}$ (feldespato) aflora en la base de la secuencia terciaria en el área de Juchipila (Webber et al., 1994). Esta secuencia está cubierta por areniscas rojizas y conglomerados con clastos de andesitas que la separan de las ignimbritas del Oligoceno-Mioceno. Ferrari et al. (2000) señalan una secuencia parecida en el área de Santa María del Oro (Figura 5) aunque no disponen de una edad absoluta para ella. Por otro lado, andesitas fechadas por ${ }^{40} \mathrm{Ar} /{ }^{39} \mathrm{Ar}$ en $\sim 51$ Ma han sido encontradas por debajo de las rocas de la Faja Volcánica Transmexicana en los 


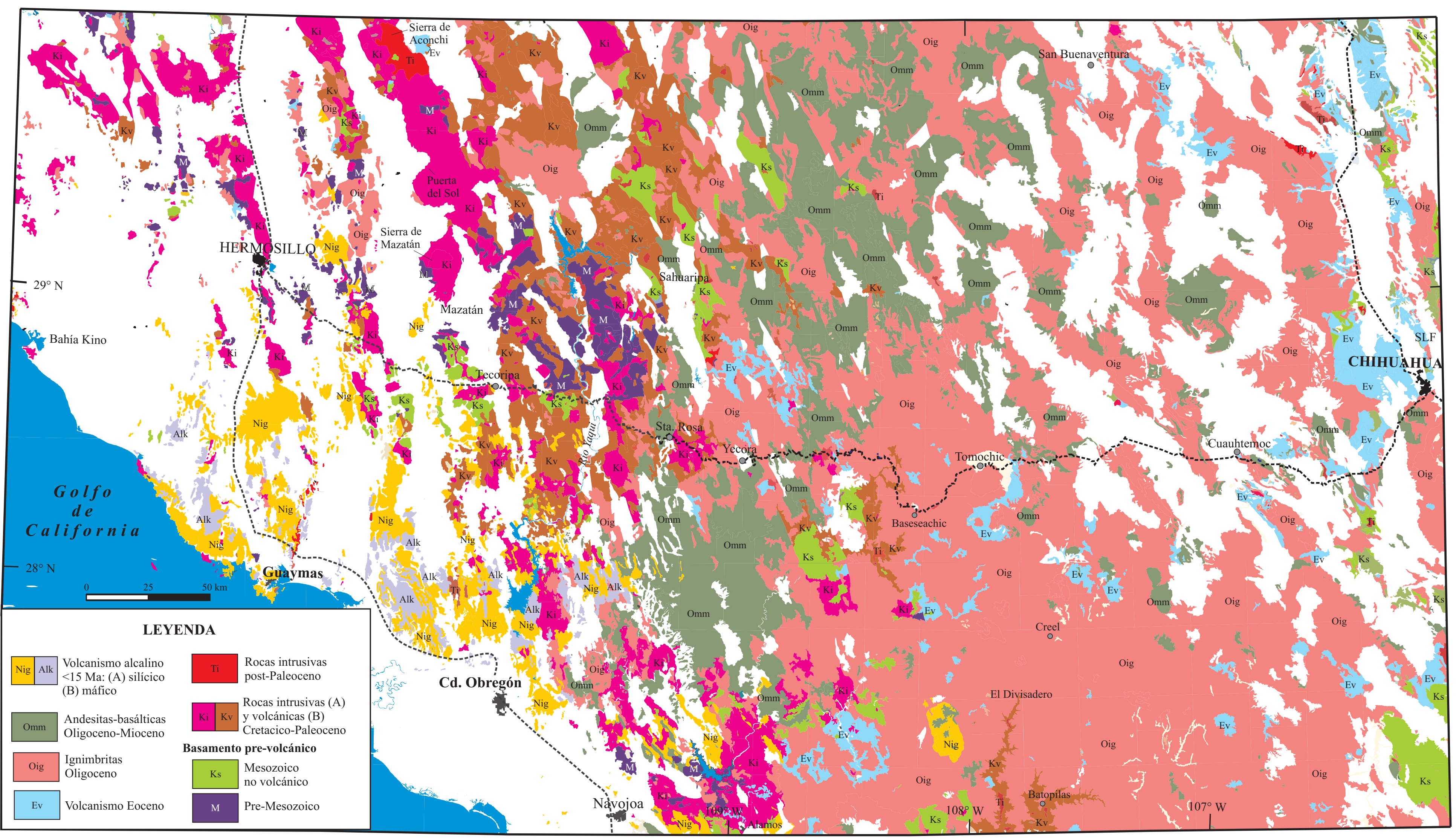




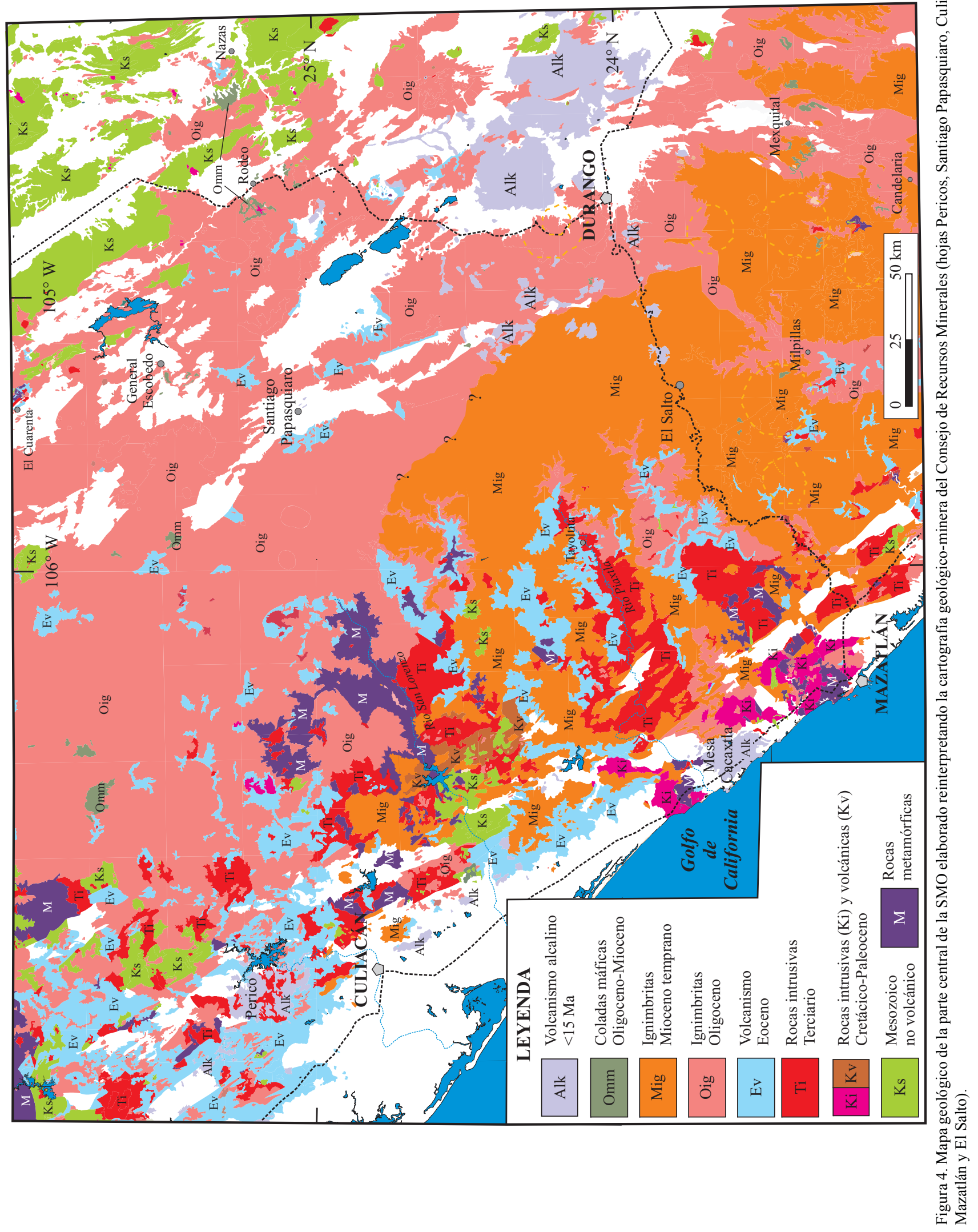




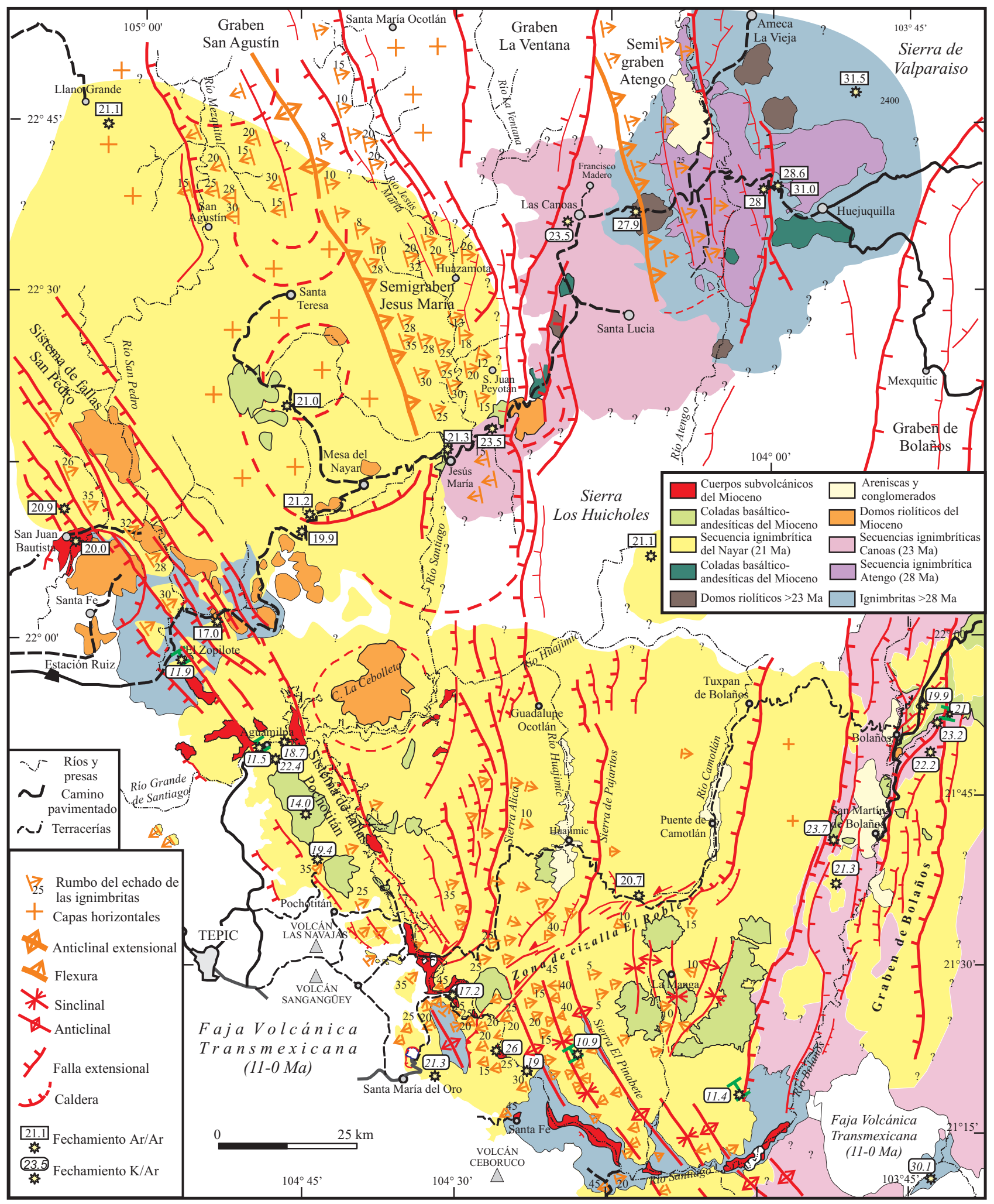

Figura 5. Mapa geológico de la parte sur de la SMO basado en Ferrari et al. (2002). 
pozos geotérmicos perforados en el graben de San PedroCeboruco (Ferrari et al., 2003) localizado inmediatamente al sur de la SMO (Figura 5).

\subsection{Pulsos ignimbríticos del Oligoceno-Mioceno temprano (Ignimbrite flare up)}

La SMO como provincia volcánica es comúnmente asociada a la inmensa sucesión ignimbrítica con espesores de hasta más de 1000 metros que cubre gran parte del occidente de México (McDowell y Clabaugh, 1979). Esta secuencia, conocida también como el Supergrupo Volcánico Superior (SVS), fue emplazada de manera discordante sobre las rocas del CVI (McDowell y Kaizer, 1977) y del arco Eoceno. El SVS está compuesto por una potente secuencia de tobas de flujos piroclásticos, tobas de caída y lavas de composición silícica a intermedia, y en menor proporción, flujos de composición máfica particularmente expuestos en los bordes de la provincia volcánica (McDowell y Clabaugh, 1979; Cochemé y Demant, 1991). Con un ancho promedio de $250 \mathrm{~km}$, un largo de aproximadamente 1200 $\mathrm{km}$ y un volumen de $\sim 300000 \mathrm{~km}^{3}$, esta cubierta silícica constituye el rasgo geológico más notable del subcontinente mexicano. Además del tamaño, otro elemento a destacar de esta sucesión es el tiempo relativamente corto en el cual se emplazaron las ignimbritas. Varios estudios geocronológicos han demostrado que el primer y más extenso pulso ignimbrítico se dio con un impresionante sincronismo a principio del Oligoceno en toda la provincia y que un segundo pulso ocurrió en el Mioceno temprano en la parte suroeste de la SMO. A continuación se analizan estos episodios volcánicos explosivos.

\subsubsection{Sector norte}

Varias secciones estudiadas en diferentes lugares a la longitud de la ciudad de Chihuahua muestran una secuencia de ignimbritas con edades K-Ar de $\sim 33$ a $\sim 30 \mathrm{Ma}$ (McDowell y Mauger, 1994), seguida por tobas peralcalinas con una distribución más restringida y edades de 30.5 a 29.0 Ma (Mauger, 1981). En San Buenaventura (Figura 3), al noroeste de Chihuahua, la secuencia incluye ignimbritas riolíticas intercaladas con derrames dacíticos y riolíticos y menores basaltos que se emplazaron en un basamento antiguo que incluye rocas proterozoicas (Albrecht y Goldstein, 2000). Estos autores obtuvieron una edad Rb-Sr de 33.2 Ma para la parte inferior de la secuencia. En el interior de la SMO, donde la secuencia ignimbrítica alcanza su máximo espesor $(\sim 1 \mathrm{~km})$, las edades se restringen a un intervalo de menos de 3 millones de años. Wark et al. (1990) reportan edades de 31.8 a 31.4 Ma para la Toba Río Verde, asociada a la formación de la caldera de Tómochic (Figuras 4 y 6) y de 29.0 Ma para la Toba Cascada, cuyas facies intracaldera forman la espectacular cascada de Baseseachic (Figura 3). Más al sur, la gruesa secuencia ignimbrítica de Batopilas (Figura 3) ha sido fechada por K-Ar entre 30.1 y 28.1 Ma (Lanphere et al., 1980). En este rango de edad caen las fechas obtenidas para la secuencia expuesta en La Barranca del Cobre: 30 Ma en El Divisadero (Albrecht y Goldstein, 2000) y 29.3 Ma en Pito Real (Montigny et al., 1987) (Figura 3).

En Sonora, la cubierta ignimbrítica de la SMO se extiende hasta la mitad oriental del estado (Figura 3). La sección mejor estudiada se localiza en la región de Yécora (Figura 3), la cual fue documentada por Bockoven (1980), Cochemé y Demant (1991), y posteriormente por Gans (1997). En esta zona, las rocas volcánicas de la SMO fueron depositadas discordantemente sobre una sección erosionada del CVI, cuyo contacto está caracterizado por un horizonte conglomerático con clastos de un plutón granodiorítico subyacente (Bockoven, 1980; Cochemé y Demant, 1991). En esta parte de Sonora la secuencia ignimbrítica no ha sido fechada sistemáticamente, como lo ha sido en Chihuahua. De todas formas una edad ${ }^{40} \mathrm{Ar} /{ }^{39} \mathrm{Ar}$ de 33.0 $\pm 0.1 \mathrm{Ma}$ (sanidino) en Santa Rosa (Figura 3) (Gans, 1997) y dos edades K-Ar de $33.5 \pm 0.8$ (plagioclasa) y $27.1 \pm 0.9 \mathrm{Ma}$ (feldespato) en el valle del río Yaqui (Figura 3) (McDowell et al., 1997) indican un rango parecido de actividad. En esta parte de la SMO la cubierta ignimbrítica se vuelve mucho más delgada que en la región occidental de Chihuahua. En el área de Tecoripa, McDowell et al. (2001) reportan espesores promedio de solo $100 \mathrm{~m}$ para ignimbritas riolíticas provenientes de erupciones localizadas hacia el oriente.

\subsubsection{Sector centro}

En el sector central de la SMO, la secuencia ignimbrítica aflora principalmente en el estado de Durango, donde ha sido estudiada con cierto detalle a lo largo de la carretera Durango-Mazatlán y en el área de Nazas. En Nazas (Figura 4), Aguirre-Díaz y McDowell (1993) reconocen dos paquetes ignimbríticos del Oligoceno que alcanzan un espesor conjunto de $\sim 500 \mathrm{~m}$, y para los cuales obtuvieron edades K-Ar de $32.2 \pm 0.7$ y $29.5 \pm 0.6 \mathrm{Ma}$, respectivamente. Fechamientos ${ }^{40} \mathrm{Ar} /{ }^{39} \mathrm{Ar}$ en el área adyacente de Rodeo han producido edades similares en sanidino de $32.3 \pm 0.09$ y $30.6 \pm 0.09 \mathrm{Ma}$ (Luhr et al., 2001). En este mismo rango se sitúa la fecha ${ }^{40} \mathrm{Ar} /{ }^{39} \mathrm{Ar}$ obtenida por Iriondo et al. (2004b) para un vitrófiro en la localidad de Ignacio Ramírez, 90 $\mathrm{km}$ más al sur. Más hacia el este, la secuencia oligocénica del la ciudad de Durango se compone de una serie de paquetes ignimbríticos con un espesor aproximado de $800 \mathrm{~m}$ asociados a la formación de la caldera Chupaderos (Swanson et al., 1978). Estas ignimbritas produjeron edades $\mathrm{K}$-Ar comprendidas entre 32.8 y $29.5 \mathrm{Ma}$, recalculadas según las nuevas constantes de decaimiento (McDowell y Keizer, 1977; Swanson et al., 1978). Sin embargo, las edades obtenidas por el método ${ }^{40} \mathrm{Ar} /{ }^{39} \mathrm{Ar}$ sobre los mismos separados minerales han arrojado un rango aún más restringido de entre 32 a 30 Ma (Aranda-Gómez et al., 2003). Al sur de la ciudad de Durango, en el área comprendida entre Mezquital y Milpillas (Figura 4), tres unidades ignimbrí- 
ticas han arrojado edades K-Ar en el rango $\sim 27$ a $\sim 28 \mathrm{Ma}$ (Solé et al., en prensa).

Hacia el suroeste, a lo largo de la carretera DurangoMazatlán, la secuencia de Durango es cubierta por un extenso domo riolítico (Las Adjuntas) con una edad de 28 Ma, y por la secuencia ignimbrítica del Mioceno temprano de El Salto-Espinazo del Diablo (McDowell y Keitzer, 1977) (Figura 4). Esta secuencia consta de 4 paquetes de ignimbritas, una unidad de lavas riolíticas, y otra más de lavas basálticas, con un espesor total de $\sim 1000 \mathrm{~m}$. Las edades K-Ar obtenidas por todas estas unidades se traslapan entre sí y se agrupan a los 23.5 Ma (McDowell y Keitzer, 1977). Iriondo et al. (2004b) obtuvieron una fecha ${ }^{40} \mathrm{Ar} /{ }^{39} \mathrm{Ar}$ idéntica para un vitrófiro andesítico perteneciente a esta secuencia muestreado a $\sim 15 \mathrm{~km}$ al oeste de El Salto. Ignimbritas del Mioceno temprano afloran por buena parte del transecto Durango-Mazatlán, sin embargo, se desconoce qué tanto más al norte se puedan extender (Figura 4). Las localidades más septentrionales donde se encuentran rocas silícicas de esta edad, se ubican en la región de Tayoltita y de Culiacán. En Tayoltita, ignimbritas y lavas que coronan a la secuencia han sido fechadas por K-Ar a 24.5 y $20.3 \mathrm{Ma}$ (Enríquez y Rivera, 2001); al norte de Culiacán, Iriondo et al. (2003) obtuvieron una edad ${ }^{40} \mathrm{Ar} /{ }^{39} \mathrm{Ar}$ de $23.2 \pm 0.15 \mathrm{Ma}$ para concentrados de horneblenda de un cuerpo subvolcánico granodiorítico. En el área de Milpillas (Figura 4), Solé et al. (en prensa) reportan una edad K-Ar de $24.0 \pm 1 \mathrm{Ma}$ para una colada de andesita basáltica que subyace a una de las últimas ignimbritas de la secuencia allí expuesta. En la proximidad de la costa de Sinaloa, rocas volcánicas del Oligoceno vuelven a aflorar (Figura 4). Henry y Fredrikson

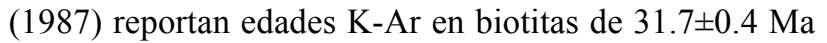
para un dique cuarzodiorítico en el área de Tayoltita y de $28.3 \pm 0.7$ Ma para una ignimbrita riolítica afectada por fallas y basculada al norte de Mazatlán. Asimismo, Solé et al. (en prensa) obtuvieron una edad K-Ar de $32 \pm 2$ Ma por una ignimbrita riolítica en el área de Milpillas (Figura 3).

\subsubsection{Sector sur}

La parte sur de la SMO se encuentra cubierta por ignimbritas silícicas que se habían tradicionalmente considerado como del Oligoceno (e. g., McDowell y Clabaugh, 1979) por correlación con las que afloran más al este en la Mesa Central (Nieto-Samaniego et al., 1999). Sin embargo, recientemente se ha probado que en esta región existen dos pulsos ignimbríticos claramente separados; uno del Oligoceno temprano y el otro del Mioceno temprano (Ferrari et al., 2002). Las ignimbritas del Oligoceno dominan en la parte oriental, entre Aguascalientes, Zacatecas y el norte de Jalisco (Nieto-Samaniego et al., 1999 y referencias incluidas). En el área de Fresnillo, al norte de Zacatecas, riolitas e ignimbritas de la sierra de Valdecañas han arrojado edades K-Ar entre 29.1 y 27.5 Ma, mientras que cuerpos subvolcánicos asociados a mineralización de plata han sido fechados entre 33.5 y 32.2 Ma y (Lang et al., 1988). Más al sureste, una buena exposición de rocas del Oligoceno se encuentra en la Sierra de Morones, entre Jalpa y Tlaltenango (Figura 9) donde Nieto-Obregón et al. (1981) reportaron una edad K-Ar de 29.1 $\pm 0.6 \mathrm{Ma}$ (sanidino) para una de las ignimbritas estratigráficamente más altas en la secuencia. En esta zona la secuencia oligocénica se compone de tobas de flujo de cenizas silícicas con extensa distribución superficial y espesor limitado, que están separadas de la secuencia andesítica eocénica por areniscas y conglomerados rojos continentales. Más al occidente, en el transecto Huejuquilla-Estación Ruiz, ignimbritas y riolitas con edades ${ }^{40} \mathrm{Ar} /{ }^{39} \mathrm{Ar}$ entre 31.5 y 28 Ma conforman la sierra de Valparaíso y están expuestas en el área de Huejuquilla y el semigraben de Atengo (Figura 5) (Ferrari et al., 2002). Un complejo de domos riolíticos exógenos en la parte oeste del semigraben ha sido fechado por ${ }^{40} \mathrm{Ar} /{ }^{39} \mathrm{Ar}$ en $27.9 \pm 0.3$ Ma (Ferrari et al., 2002). Estas edades resultan ser casi idénticas a las de la secuencia de Durango y el domo de Las Adjuntas, respectivamente, expuestos $\sim 80 \mathrm{~km}$ más al norte (McDowell y Keitzer, 1977).

Al occidente de Atengo y en todo el transecto BolañosTepic (Figura 5) dominan las ignimbritas de Mioceno temprano, aunque la secuencia del Oligoceno podría subyacer toda la parte oriental de la región (Figura 5), ya que un paquete de ignimbritas con una edad K-Ar de 30.1 Ma ha sido reconocido en la parte sur del graben de Bolaños (Ferrari et al., 2002). La secuencia ignimbrítica del Mioceno temprano cubre la SMO en Nayarit. Ferrari et al. (2002) reconocen dos paquetes de ignimbritas con edades y proveniencias distintas: la secuencia de Las Canoas y la secuencia del Nayar. La secuencia de Las Canoas tiene un espesor de $\sim 350 \mathrm{~m}$ y ha sido fechada tanto por K-Ar (Clark et al., 1981) como por ${ }^{40} \mathrm{Ar} /{ }^{39} \mathrm{Ar}$ (Ferrari et al., 2002) en 23.5 Ma, es decir, contemporánea a la secuencia de El Salto-Espinazo del Diablo expuesta $\sim 80 \mathrm{~km}$ más al norte (McDowell y Keitzer, 1977). Hacia el sur puede correlacionarse con la parte inferior de la sucesión expuesta en el graben de Bolaños (Figura 5) donde Scheubel et al. (1988) reportan edades K-Ar de 23.7 y 23.2 Ma para una andesita y una ignimbrita, respectivamente. Más al sureste, secuencias ignimbríticas de edades similares están en el área de Teúl ( 23 Ma; Moore et al., 1994), de la presa de Santa Rosa (23.6 Ma; Nieto-Obregón et al., 1985), en Juchipila ( 24-23 Ma; Webber et al., 1994) (Figura 9), y en la sierra de Pénjamo ( $24 \mathrm{Ma}$; Castillo-Hernández y Romero-Ríos, 1991; Solé et al., en prensa). La secuencia del Nayar cubre una franja de dirección NNW con un ancho de $75 \mathrm{~km}$ en la orilla occidental de la SMO (Figura 5). Esta secuencia alcanza su máximo espesor en la región de la Mesa del Nayar donde Ferrari et al. (2002) señalan la presencia de una serie de calderas que pueden ser su fuente (Figura 5). Al interior de la caldera del Nayar se cuentan hasta 11 unidades ignimbríticas con un espesor total de $\sim 1$ $000 \mathrm{~m}$ (Ferrari et al., 2002). Para la secuencia del Nayar estos autores obtuvieron 7 edades ${ }^{40} \mathrm{Ar} /{ }^{39} \mathrm{Ar}$ en diferentes posiciones estratigráficas que se traslapan entre sí en un rango de 21.2 a $19.9 \mathrm{Ma}$ con un promedio de 20.9 Ma. 
Hacia el sur, la secuencia se correlaciona con las ignimbritas expuestas en Santa María del Oro (21.3 Ma; Gastil et al., 1979), Aguamilpa (22.4 Ma; Damon et al., 1979), y en la parte superior de la secuencia del graben de Bolaños (21.3-20.1 Ma; Scheubel et al., 1988) (Figura 5). Para la secuencia del Nayar, Ferrari et al. (2002) estiman que un volumen de aproximadamente $4,500 \mathrm{~km}^{3}$ debió haber sido emplazado en un lapso de $\sim 1.4 \mathrm{Ma}$.

La secuencia del Nayar resulta truncada al occidente por el fallamiento extensional asociado con la apertura del Golfo de California. Sin embargo, en la parte sur de la península de Baja California (áreas de La Paz y Loreto) Hausback (1984) y Umhoefer et al. (2001) obtuvieron edades K-Ar en un rango entre $\sim 23$ y $\sim 17$ Ma para diferentes secuencias ignimbríticas intercaladas en la parte inferior de la Formación Comondú. Entre éstas se encuentra la toba La Paz, una secuencia expuesta cerca de la ciudad de La Paz, para la cual Hausback (1984) reporta edades K-Ar entre $21.8 \pm 0.2$ y $20.6 \pm 0.2$ Ma. Dada la gran extensión geográfica de la secuencia del Nayar y las edades muy similares, Ferrari et al. (2002) sugieren la posibilidad de que la toba La Paz tenga su origen en la región de la Mesa del Nayar. La distancia original entre La Paz y la Mesa del Nayar es difícil de estimar. Sin embargo, el borde de la caldera del Nayar queda a $\sim 42 \mathrm{~km}$ de la planicie costera de Nayarit, mientras que La Paz está a una distancia similar de la costa oriental de Baja California Sur. En principio, entonces, resulta posible que la toba La Paz pueda estar relacionada a una fuente a $\sim 100 \mathrm{~km}$ más al este.

El volcanismo ignimbrítico de la SMO no continúa al sur de la FVTM en el bloque Jalisco. A diferencia de lo que aparece en varios mapas geológicos regionales (e. g., Ortega-Gutiérrez et al., 1992; López-Ramos, 1995), no hay ignimbritas asignadas al Eoceno-Mioceno en el bloque Jalisco. Diferentes estudios geocronológicos han demostrado que las ignimbritas, expuestas ampliamente en la parte norte del bloque, tienen edades ${ }^{40} \mathrm{Ar} /{ }^{39} \mathrm{Ar}$ de 81 a $60 \mathrm{Ma}$ (Wallace y Carmichael, 1989; Lange y Carmichael, 1991; Righter et al., 1995; Rosas-Elguera et al., 1997), por lo que se correlacionan más bien con el CVI estudiado en Sonora (McDowell et al., 2001). Ignimbritas del Oligoceno y del Mioceno temprano se reportan al sur de la FVTM en Michoacán, al sur del Lago de Chapala (31.8 Ma, Rosas Elguera et al., 2003; 23.5 Ma, Ferrari et al., 2002) y al sur de Morelia (21 Ma; Pasquaré et al., 1991).

\subsection{Volcanismo postignimbrítico}

Después del pulso ignimbrítico (definido como ignimbrite flare up por McDowell y Clabaugh, 1979), el magmatismo se vuelve más heterogéneo y disperso en la SMO. El volcanismo es generalmente bimodal y discontinuo y tiende a migrar hacia el futuro Golfo de California. Entre las rocas máficas se pueden distinguir un grupo de composición basáltico-andesítica emplazado poco tiempo después del pulso ignimbrítico, y un grupo de composición más máfica y alcalina generalmente posterior al término de la subducción. En la parte norte de la SMO, el inicio de este segundo evento fue precedido por el emplazamiento de una serie de ignimbritas alcalinas de carácter distintivo. En esta sección se sintetizan brevemente la distribución y edad de estas rocas.

\subsubsection{Volcanismo máfico transicional posterior a los pulsos ignimbriticos (SCORBA)}

En toda la SMO, lavas de composición basálticoandesítica fueron emplazadas de manera discontinua inmediatamente después de cada episodio ignimbrítico. Los mayores afloramientos de estas lavas se distribuyen en una franja de burda dirección NNE entre San Buenaventura, Chihuahua, al norte y Navojoa, Sonora, al sur, pasando por Yécora (Figura 3). Esta rocas han sido incluidas en los denominados Basalto-Andesitas del Sur de la Cordillera (SCORBA por sus siglas en inglés), propuestos por Cameron et al. (1989) como una serie regional que se extiende también a Arizona y Nuevo México y marcaría la primera fase de extensión, probablemente en un marco tectónico intra-arco. Las edades reportadas para esta serie en Chihuahua y Sonora varían entre 33 y $17.6 \mathrm{Ma}$ (Cameron et al., 1989 y referencias incluidas; McDowell et al., 1997; Paz-Moreno et al., 2003). Sin embargo, la mayoría de las edades son del Oligoceno. En Sonora nororiental algunas tobas riolíticas están intercaladas con las coladas basálticoandesíticas y han arrojado una edad ${ }^{40} \mathrm{Ar} /{ }^{39} \mathrm{Ar}$ de $25.4 \mathrm{Ma}$ (González-León et al., 2000). Hacia el oeste, el volcanismo tiene edades más jóvenes y composición progresivamente más silícea. Al norte de Guaymas (Figura 3), en la Sierra Santa Úrsula, se reportan tobas ignimbríticas, andesitas y domos dacíticos con edades entre $\sim 23$ y 15 Ma (MoraÁlvarez y McDowell, 2000). Estas rocas afloran también más al noroeste en la región de Bahía Kino (Figura 3) donde se reportan rocas andesíticas de $\sim 18$ Ma (Gastil y Krummenacher, 1977).

En el sector central de la SMO, coladas basálticas fechadas entre 30 y 29 Ma cubren la secuencia ignimbrítica de Durango (Basaltos Caleras de Swanson et al., 1978). Por su composición y edad, Luhr et al. (2001) asocian estas rocas a los SCORBA. Basaltos con edades de $\sim 24$ Ma se encuentran cubriendo a ignimbritas del Oligoceno también en Nazas (Aguirre-Díaz y McDowell, 1993) y El Rodeo (Aranda-Gómez et al., 2003; Solé et al., en prensa). Cameron et al. (1989) incluyen los basaltos de Nazas entre los SCORBA. Sin embargo, estudios posteriores (e.g., Luhr et al., 2001; Aranda-Gómez et al., 2003) han demostrado que estas rocas alcalinas (hawaiitas) tienen firmas geoquímicas más afines a los basaltos intraplacas típicos de la provincia Basin and Range mexicana.

En la parte sur de la SMO no se cuenta con estudios geoquímicos y petrológicos sobre las rocas máficas postignimbríticas, aunque su presencia puede inferirse en diferentes lugares. Coladas basálticas emplazadas poco después 
de las ignimbritas del Oligoceno temprano se encuentran en el área de Huejuquilla (Figura 5) y son reportadas en los mapas geológicos escala 1:250 000 del Consejo de Recursos Minerales en el oeste del estado de Zacatecas y el norte de Jalisco. Coladas basálticas posteriores al pulso ignimbrítico del Mioceno temprano han sido cartografiadas en el área de Milpillas (Figura 4) donde se han obtenido edades K-Ar de $21 \mathrm{Ma}$. Asimismo se han encontrado en el área de la Mesa del Nayar y de Jesús María (Figura 5), donde dieron una edad ${ }^{40} \mathrm{Ar} /{ }^{39} \mathrm{Ar}$ de $21.3 \mathrm{Ma}$ (Ferrari et $a l ., 2002)$. Lavas basálticas similares se encuentran en el graben de Bolaños donde han sido fechadas por K-Ar en 21 y 19.9 Ma (Nieto-Obregón et al., 1981).

\subsubsection{Volcanismo alcalino y peralcalino}

En la parte noroccidental de la SMO, el inicio del magmatismo postsubducción es marcado por la erupción de una serie distintiva de ignimbritas y derrames riolíticos y riodacíticos peralcalinos, localmente conocidos como la Formación Lista Blanca. Esta serie tiene amplia distribución por toda la parte sur-occidental de Sonora (Figura 3) y edades relativamente restringidas a un rango entre $\sim 14$ y 11 Ma (Gastil y Krummenacher, 1977; Bartolini et al., 1994; McDowell et al., 1997; Mora-Álvarez y McDowell, 2000; Oskin et al., 2003; Mora-Klepeis y McDowell, 2004; Vidal-Solano et al., en prensa). Algunas de estas ignimbritas tienen composición comendítica y altos contenidos en Fe y álcalis $\left(\mathrm{Na}_{2} \mathrm{O}+\mathrm{K}_{2} \mathrm{O}=8-10 \%\right)$. Los caracteres geoquímicos de esta secuencia sugieren una procedencia del manto astenosférico (Vidal-Solano et al., 2005) lo que implicaría que su emplazamiento ocurrió después de un adelgazamiento cortical importante que permitió el ascenso del manto convectivo hasta la base de la corteza. Mora-Klepeis y McDowell (2004) interpretan las rocas silícicas de 12-11 Ma, expuestas en la sierra de Santa Úrsula, como el primer volcanismo postsubducción en Sonora, mientras que Vidal-Solano et al. (2005) las consideran como el testigo del último episodio de extension intracontinental. Dentro de esta serie de ignimbritas se encuentra la Toba San Felipe, de 12.6 Ma, una unidad cuya fuente es la provincia volcánica de Puertecitos en Baja California, y que ha podido ser correlacionada a través del Golfo de California hasta la costa de Sonora, pasando por la isla Tiburón (Oskin et al., 2001).

El en resto de la SMO el volcanismo alcalino consta esencialmente de basaltos alcalinos emplazados como pequeños derrames fisurales hasta campos monogenéticos de dimensiones mayores. En general estas rocas máficas se encuentran en la periferia de la SMO, tanto en su límite con la Mesa Central, como a la orilla del Golfo de California, y se asocian a tres episodios extensionales principales del Mioceno temprano ( 24-22 Ma), el Mioceno tardío ( 13-11 Ma) y el Plioceno-Cuaternario ( 4-0 Ma) (Henry y Aranda-Gómez, 2000). En el borde este de la SMO las principales localidades incluyen: los basaltos de Rodeo y Nazas (Figura 4) con edades de 24.1 a 23.3 Ma
(Aranda-Gómez et al., 2003; Solé et al., en prensa) y 24 Ma (Aguirre-Díaz y McDowell, 1993), respectivamente; las hawaiitas de la Formación Metates en la parte sur del graben Río Chico-Otinapa (Figura 4 y 8) con edades de 12.7-11.6 Ma (McDowell y Keitzer, 1977; Henry y Aranda-Gómez, 2000); el campo volcánico de Camargo con edades de 4.7 Ma al Holoceno (Aranda-Gómez et al., 2003); y el campo volcánico cuaternario de Durango (Smith et al., 1989). Extensas coladas basálticas expuestas en el extremo sur de la SMO en el área de La Manga (Figura 5), las cuales no han sido fechadas aún, podrían relacionarse con este episodio ya que diques máficos presentes en áreas cercanas han arrojado edades de $\sim 11 \mathrm{Ma}$ (Damon et al., 1979). En el borde occidental de la SMO, a lo largo del Golfo de California, rocas máficas postsubducción incluyen: basaltos toleíticos en la costa de Sonora de $~ 11-10$ Ma (Mora-Álvarez y McDowell, 2000; Mora-Klepeis y McDowell, 2004); el campo volcánico de Pericos al norte de Culiacán (no estudiado pero de probable edad cuaternaria por su morfología joven) y los basaltos de Punta Piaxtla y Mesa de Cacaxtla al norte de Mazatlán (3.2 a 2.1 Ma; Aranda-Gómez et al., 2003) (Figura 5). Adicionalmente, diques máficos alcalinos con dirección dominante $\mathrm{NNW}$ son comunes en la parte suroeste de la SMO y han sido fechados en el Mioceno tardío ( 12-10 Ma), tanto en el sur de Sinaloa (Henry y Aranda Gómez, 2000), como en Nayarit (Ferrari et al., 2002 y referencias incluidas). Sin embargo, los pocos análisis químicos disponibles indican que estos últimos tienen composición también subalcalina.

\section{Tectónica de los conjuntos ígneos de la SMO}

\subsection{Deformación pre-Oligoceno}

La deformación que precede la extensión en la SMO no ha sido objeto de estudios detallados, en parte debido a la escasez de afloramientos, la intensa alteración y a que frecuentemente el fallamiento normal puede llegar a obscurecer las estructuras más antiguas. En Sonora la orogenia Laramide afecta significativamente las secuencias marinas de Aptiano-Albiano, pero no parece producir una deformación intensa en las rocas del CVI. En Sinaloa, Henry et al. (2003) reconocen una deformación con desarrollo de foliación y recristalización dinámica en algunas tonalitas y granodioritas del conjunto batolítico costero. La foliación es vertical y tiene dirección ENE, subparalela a las rocas encajonantes (ortogneises, gabros y mármoles), lo que sugiere que todo el conjunto se deformó al mismo tiempo (Henry 1986; Henry et al., 2003). Usando de manera conjunta las edades $\mathrm{K}-\mathrm{Ar}$ en diferentes minerales y $\mathrm{U}-\mathrm{Pb}$ en circones provenientes de los plutones pre-, sin-, y postectónicos, Henry et al. (2003) concluyen que la deformación debió ocurrir entre $\sim 101 \mathrm{y} \sim 89 \mathrm{Ma}$.

La secuencia volcánica del Cretácico Tardío-Paleoceno de la Formación Tarahumara ( 90 a $60 \mathrm{Ma})$ está afectada 


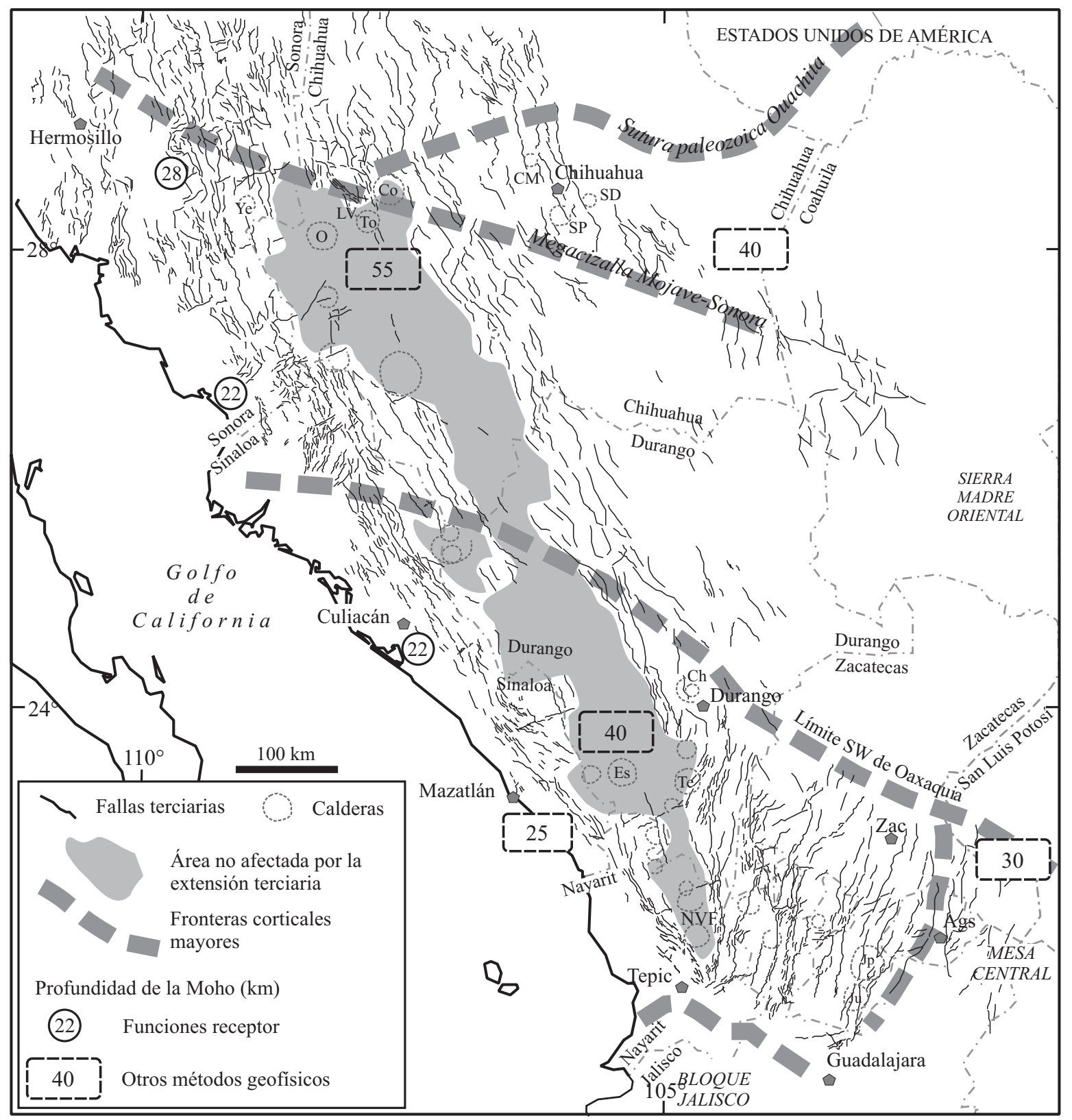

Figura 6. Mapa tectónico de la SMO. Se muestran las principales fallas terciarias reportadas en la literatura (ver texto) integradas con una interpretación de una mosaico ortorrectificado de imágenes Landsat Enhanced Thematic Mapper (bandas 7, 4 y 2) con una resolución de $14.25 \mathrm{~m}$. El límite suroccidental de Oaxaquia (tomada de Lawlor et al., 1999) corresponde también con el límite del continente al finales del Paleozoico. El límite entre SMO y Mesa Central fue tomado de Nieto-Samaniego et al. (1999). Las principales calderas son: SD: Santo Domingo (Megaw, 1986), SP: Sierra Pastoría (Megaw, 1990), CM: Caldera Majalca (Mauger, 1992; o San Marcos en Ferriz, 1981), To: Tómochic (Wark et al., 1990), LV: Las Varas (Wark et al., 1990), Co: Corralito y O: Ocampo (Swanson y McDowell, 1984), Ye: Yécora (Cochemé y Demant, 1991), Ch: Chupaderos (Swanson et al., 1985), Te: Temoaya y ES: El Salto (Swanson y McDowell, 1984), NVF: Nayar caldera field (Ferrari et al., 2002), Ju: Juchipila y Ja: Jalpa (Webber et al., 1992). Otras calderas son inferidas en base a percepción remota. Ver texto para las referencias sobre el espesor de la corteza. Ags: Aguascalientes, Zac: Zacatecas.

por fallas y basculada, pero no se observan pliegues ni cabalgaduras, por lo que el basculamiento podría también ser el efecto del fallamiento normal neogénico (McDowell et al., 2001). Más al este, en Chihuahua central, McDowell y Mauger (1994) observan un basculamiento de la secuencia volcánica de Peñas Azules, fechada en $\sim 68 \mathrm{Ma}$, que ellos atribuyen a la orogenia Laramide. Sin embargo, no se reportan fallas inversas o pliegues por lo que dicho basculamiento podría ser también producto de fallamiento normal. Al este de Zacatecas, las rocas intrusivas de edad campaniana ubicadas en el área de La Tesorera-Zacatón no presentan deformación, a diferencia de las rocas marinas del Cretácico Temprano que las intrusionan.

En suma, los pocos datos disponibles parecen indicar 
que entre el Coniaciano y el Eoceno no hubo deformación contractiva en buena parte de la SMO. Sin embargo, en la parte occidental de la SMO, en Sonora y Sinaloa, es común encontrar fracturas de tensión y fallas con dirección ENE-WSW a E-W que afectan a las rocas pre-oligocénicas (Horner y Enríquez, 1999; Staude y Barton, 2001). La mayoría de los depósitos de pórfidos de $\mathrm{Cu}-\mathrm{Mo}$ de la SMO se emplazaron en zonas fuertemente fracturadas, desarrolladas de manera contemporánea o tardía a esta fase de deformación (Barton et al., 1995; Horner y Enríquez, 1999). Los estudios geocronológicos de estos depósitos han producido sistemáticamente edades $\mathrm{K}-\mathrm{Ar}$ en el Paleoceno-Eoceno (Damon et al., 1983; Staude y Barton, 2001), algunas de las cuales han sido recientemente confirmadas por el método Re-Os (Barra et al., en prensa). Las estructuras E-W y ENE-WSW han sido interpretadas por Horner y Enríquez (1999) como el resultado de la fase final del acortamiento que acompañó a la orogenia Laramide. Sin embargo, los datos disponibles sugieren que éstas podrían deberse más bien a un episodio de deformación distinto, intermedio entre la orogenia Laramide y la extensión oligocénica-cuaternaria.

\subsection{Tectónica extensional}

Una buena parte de la SMO ha sido afectada por una deformación dominantemente extensional durante diferentes episodios que se remontan al Oligoceno o, quizás, hasta el final del Eoceno. La deformación no parece afectar al núcleo de la SMO, que constituye una especie de división geográfica entre lo que se ha definido como el Basin and Range mexicano, al este, y la Provincia Extensional del Golfo, al oeste (Henry y Aranda-Gómez, 2000). En este trabajo usamos el término Basin and Range esencialmente en sentido geográfico, sin ningún sentido genético (ver Dickinson, 2002). En los extremos norte y sur (norte de Sonora y Chihuahua y Nayarit-Jalisco, respectivamente) estas dos provincias se funden ya que la extensión afectó toda la SMO (Figura 6).

\subsubsection{Sector norte}

La reconstrucción de la tectónica que afectó a la provincia volcánica de la SMO en el sector norte es compleja, particularmente debido a la presencia de varios eventos cuya actividad se traslapa parcialmente en tiempo y espacio con el episodio ígneo asociado a la SMO. No se puede excluir que una tectónica extensional haya empezado en el Eoceno, ya que existe una discordancia angular moderada entre la serie volcánica de 42-37 Ma y las ignimbritas oligocénicas al sur de Chihuahua (Megaw, 1990). Por otro lado, McDowell y Mauger (1994) consideran que la transición entre un régimen contraccional y uno extensional ocurre desde $\sim 33 \mathrm{Ma}$ al tiempo en que empiezan a aparecer ignimbritas peralcalinas y basaltos transicionales (SCORBA) en la región.
Considerando más bien las evidencias tectónicas, el primer episodio extensional documentado regionalmente sigue inmediatamente el emplazamiento del volcanismo silícico, cuyo periodo de máxima actividad ocurrió entre 34 y 29 Ma (McDowell y Clabaugh, 1979). La extensión en Chihuahua se restringe a la formación de estructuras tipo Basin and Range que afectan a la cubierta ignimbrítica, por lo que se deduce tenga una edad menor de $29 \mathrm{Ma}$. No existen estudios estructurales detallados en esta región pero la presencia de fallas de alto ángulo y el basculamiento modesto de las secuencias sugiere que la extensión debió haber sido moderada.

En Sonora la extensión fue mucho más intensa y ligeramente más joven. Durante un evento mayor de extensión intracontinental, rocas formadas en niveles intermedios de la corteza fueron exhumados a lo largo de un cinturón alargado de forma subparalela a la SMO localizado entre Hermosillo y Tecoripa (Figura 7) (Nourse et al., 1994; Vega-Granillo y Calmus, 2003; Wong y Gans, 2003; 2004). A lo largo de este cinturón se observan fallas normales de alto y bajo ángulo, y fallas de despegue que ponen en contacto una placa superior sin deformación, con otra inferior que exhibe una serie de complejos de rocas miloníticas, gneisses, y plutones peraluminosos, denominados metamorphic core complexes (Davis y Coney, 1979; Nourse et al., 1994). La extensión cortical ocurrida durante este evento se estima que rebasó localmente el 100\% (Gans, 1997) y formó depresiones tectónicas que fueron rellenadas por sedimentos clásticos, ocasionalmente con acumulación de boratos y horizontes volcánicos, como en la zona de Magdalena (Figuras 3 y 7). Estos núcleos metamórficos se conocen muy bien en Magdalena (Nourse, 1994), Acónchi (Rodríguez-Castañeda, 1996; Calmus et al., 1996), Puerto del Sol (Nourse et al., 1994) y Mazatán (Vega-Granillo y Calmus, 2003; Gans et al., 2003; Wong y Gans, 2003) (Figuras 3 y 7). Presumiblemente los plutones peraluminosos que se encuentran en estos complejos se generaron por fusión parcial de la corteza atenuada (e.g., Davis, 1981). Modelado de edades ${ }^{40} \mathrm{Ar} /{ }^{39} \mathrm{Ar}$ en feldespato potásico indican una edad entre 20 y 16 Ma para la exhumación del core complex de Mazatán (Figura 3) (Gans et al., 2003; Wong y Gans, 2003), lo cual coincide con una edad de $18 \pm 3 \mathrm{Ma}$ obtenida por trazas de fisión en apatitas de la misma área (Vega-Granillo y Calmus, 2003). En general, las edades publicadas compiladas por Nourse et al. (1994) para las distintas localidades de núcleos metamórficos en Sonora indican un rango de $\sim 25-15 \mathrm{Ma}$ para el evento extensivo responsable de la formación de los complejos de núcleo metamórfico.

Las cuencas asociadas a la extensión en la porción centro-oriental de Sonora proporcionan otra indicación sobre la edad de la extensión. En esta región, las cuencas están limitadas por fallas normales de alto ángulo, generalmente orientadas NNW-SSE y $\sim \mathrm{N}-\mathrm{S}$ (Figura 7), y contienen gruesos espesores de conglomerados y areniscas bien consolidados, los cuales han sido asignados a la 


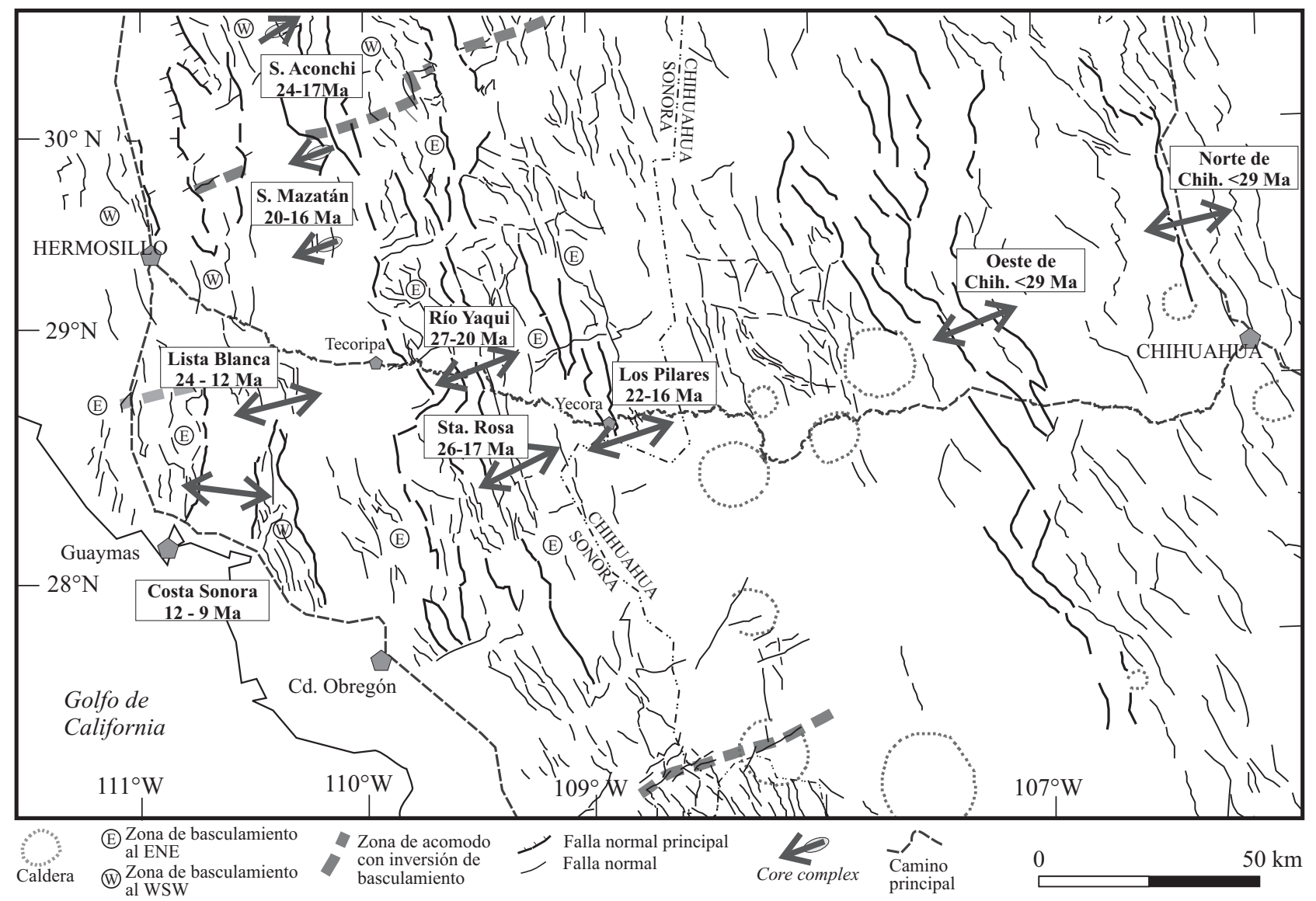

Figura 7. Mapa tectónico de la parte norte de la SMO con indicación de la orientación y edad de la deformación extensional (ver texto para detalles y referencias). Fallas y calderas como en Figura 6.

Formación Báucarit (King, 1939). Comúnmente, hacia la base de estas secuencias clásticas se depositaron flujos de lavas basálticas y andesíticas cuyas edades indican un rango entre 27 y 20 Ma (McDowell et al., 1997; Paz-Moreno et al., 2003). Hacia la parte superior, las secuencias clásticas son menos consolidadas y están intercaladas con aglomerados, tobas y derrames de riolita y riodacita del Mioceno medio. La extensión en estas cuencas es notablemente menor que en los core complexes, lo que sugiere que ésta se haya concentrado en zonas con un basamento previamente debilitado y que la extensión en Sonora llegó a ser $\sim 100 \%$ solo en ciertas áreas.

En la franja costera de Sonora las secuencias volcánicas del Mioceno medio están moderadamente basculadas, con inclinaciones entre $10-35^{\circ}$ hacia el $\mathrm{E}$ o al W (McDowell et al., 1997; Mora-Álvarez y McDowell, 2000; MacMillan et al., 2003; Gans et al., 2003). Los bloques basculados están cubiertos en discordancia por basaltos alcalinos horizontales. En la zona de Guaymas las edades de las rocas basculadas y de los basaltos horizontales limitan la deformación entre $\sim 12$ y $10 \mathrm{Ma}$ en la Sierra Libre y la Sierra del Bacatete (Mora-Álvarez y McDowell, 2000; Macmillan et al., 2003) y entre 10.7 y 9.3 Ma en el área de San CarlosEl Agujaje (Gans et al., 2003) (Figura 7). Sin embargo, al noreste de Guaymas (Figura 2), basaltos alcalinos fechados en 8.3 Ma están cortados por fallas normales asociadas a un episodio extensional más reciente del llamado graben de Empalme (Figura 7) (Roldán-Quintana et al., 2004). De acuerdo con estos autores, el graben de Empalme es una estructura que marca una etapa de transición entre el régimen de fallamiento en bloque asociado al sistema Basin and Range, y un régimen de fallamiento lateral asociado con el inicio de la apertura del Golfo.

Aunque con baja intensidad la actividad tectónica sigue activa en la parte nororiental de Sonora y noroeste de Chihuahua como lo atestigua la ocurrencia de por lo menos 64 temblores históricos en el periodo 1887-1999 (Suter, 2001). El mayor de estos eventos es el temblor de Bavispe, Sonora, ocurrido el 3 de mayo de 1887 con $\mathrm{M}_{\mathrm{w}}=7.4$, que rompió por más de $100 \mathrm{~km}$ de largo tres segmentos de una falla N-S activa desde el Mioceno (Suter y Contreras, 2002).

\subsubsection{Sector centro}

En el sector central, la tectónica extensional ha afectado la SMO principalmente en sus bordes dejando una zona relativamente no extendida en su centro (Figura 6). En el borde oriental, en Durango, se han desarrollado fallas normales de 


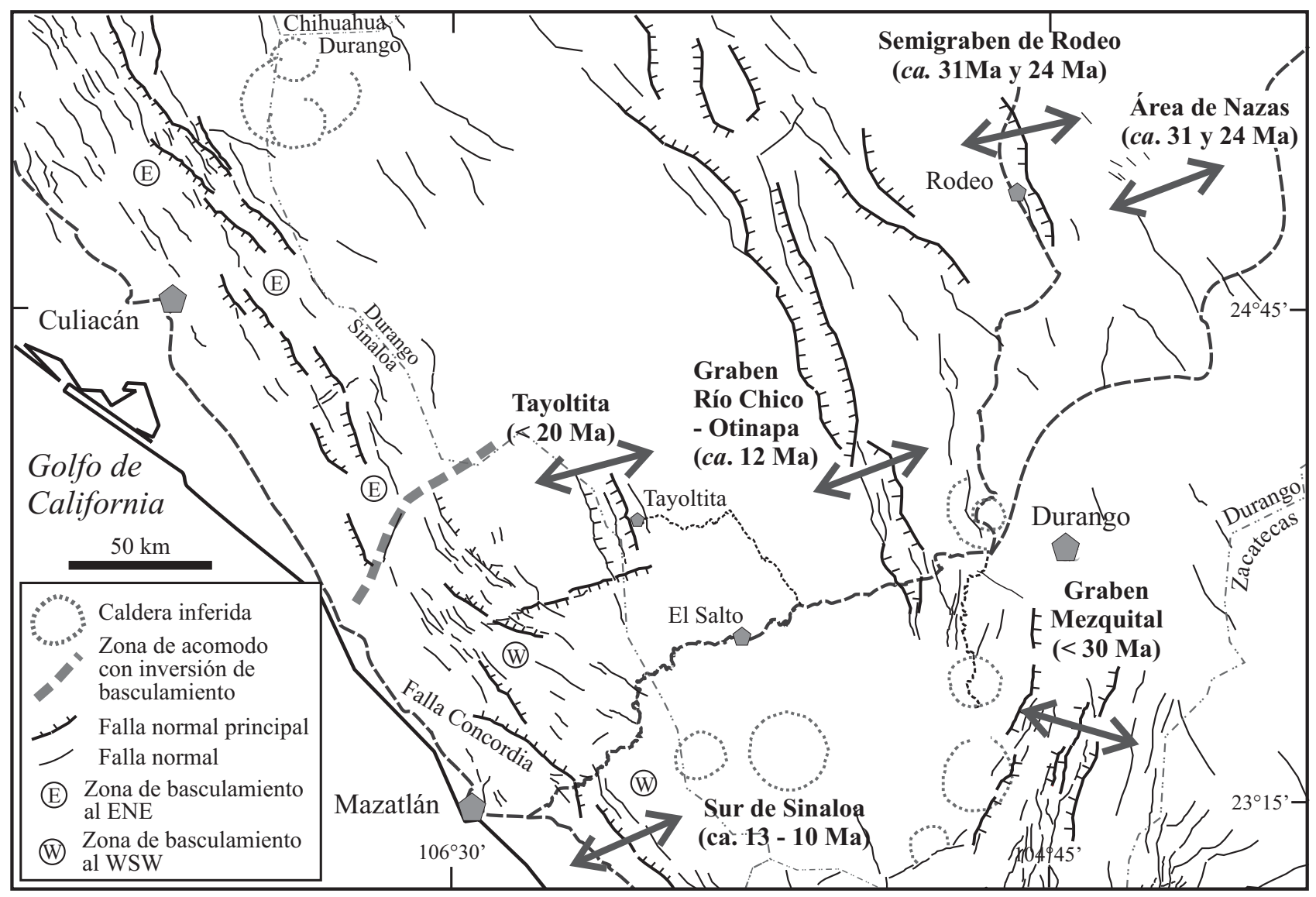

Figura 8. Mapa tectónico de la parte central de la SMO con indicación de la orientación y edad de la deformación extensional (ver texto para detalles y referencias). Fallas y calderas como en Figura 6.

alto ángulo que definen estructuras tipo Basin and Range del todo similares a las que se encuentran en Chihuahua. La edad de la deformación extensional en esta región se remonta por lo menos al principio del Oligoceno y se caracteriza por un alargamiento general ENE-WSW. En el área de Nazas, ignimbritas fechadas en 29.9 1.6 Ma se encuentran basculadas hasta $35^{\circ}$ al NE y son cubiertas por otras tobas de 29.5 \pm 0.6 Ma horizontales (Aguirre-Díaz y McDowell, 1993). En el área de Rodeo, Dgo., Luhr et al. (2001) reconocen una extensión temprana entre 32.3 y 30.6 Ma que produjo la formación de un semigraben de dirección NNW con un desplazamiento estimado en $\sim 3 \mathrm{~km}$. Adicionalmente Aranda-Gómez et al. (2003) asocian la erupción de lavas alcalinas de $\sim 24 \mathrm{Ma}$, tanto en Nazas como en Rodeo con un segundo episodio extensional en el área (Figura 8). Al sursuroeste de Durango se encuentra el graben de Mezquital, que es una estructura de aproximadamente $40 \mathrm{~km}$ de ancho y dirección general NNE. El graben no ha sido estudiado en detalle pero las rocas cortadas tienen edades oligocénicas, siendo la más reciente una ignimbrita fechada por K-Ar en 27.0 1.0 Ma (Aranda-Gómez et al., 1997). En esta área dichos autores observaron dos generaciones de estrías en planos de fallas normales: la más antigua indicaría una extensión NW, mientras que la más reciente tiene dirección NE.
Hacia el poniente de Durango, el graben Río ChicoOtinapa es una estructura extensional de más de $160 \mathrm{~km}$ de largo y $20 \mathrm{~km}$ de ancho, con dirección N-S a NNW-SSE y un desplazamiento máximo de $900 \mathrm{~m}$ (Aranda-Gómez et al., 2003) (Figura 8). Las fallas de alto ángulo que bordean el graben afectan a la secuencia ignimbrítica del Oligoceno y están cubiertas por coladas de hawaiitas, conocidas como Formación Metates (Córdoba, 1963), de las cuales fueron la vía de alimentación. Concentrados de anfíbol de estas coladas arrojaron edades de $12.7 \pm 0.4$ Ma por el método K-

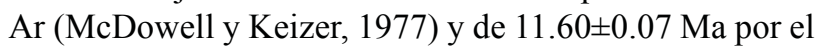
método ${ }^{40} \mathrm{Ar} /{ }^{39} \mathrm{Ar}$ (Henry y Aranda-Gómez, 2000). En base a estas relaciones tectónicas y estratigráficas se concluye que la formación del graben debe haber iniciado antes de la erupción de las lavas, probablemente a los $\sim 12$ Ma por efecto de una extensión WSW-ENE (Aranda-Gómez et al., 2003).

La parte occidental de la SMO en Sinaloa está profundamente afectada por fallamiento extensional de dirección general NNW con formación de semigrábenes. La vergencia del basculamiento cambia en correspondencia de una zona de acomodo al norte de Tayoltita, siendo la inclinación hacia el ENE al norte y al WSW al sur de ella (Figura 8). En la parte sur la estructura mejor estudiada 
es el semigraben limitado al oeste por la falla Concordia (Figura 8). La falla tiene dirección NW, una inclinación de $40^{\circ}-70^{\circ}$ al NE, y desplazamiento vertical estimado en $\sim 5 \mathrm{~km}$ (Aranda-Gómez et al., 2003). En el bloque de piso de esta falla afloran rocas intrusivas del Cretácico TardíoPaleoceno del batolito de Sinaloa, mientras que el bloque de techo lo constituyen ignimbritas del Oligoceno y Mioceno temprano cubiertas por depósitos poco consolidados y mal clasificados de gravas, a su vez intrusionados por diques máficos. Los diques han arrojado edades ${ }^{40} \mathrm{Ar} /{ }^{39} \mathrm{Ar}$ de $10.7 \pm 0.2$ y $11.03 \pm 0.16$ Ma (Henry y Aranda Gómez, 2000). Sin embargo, el hecho de que algunos diques se encuentren también basculados indica que la extensión continuó un poco más después de su emplazamiento. La extensión en esta región puede haber sido de entre $20 \%$ y $50 \%$ dependiendo si la geometría de las fallas es lístrica o plana, respectivamente (Henry, 1989).

Cerca de la frontera Sinaloa-Durango, a lo largo de la carretera federal Durango-Mazatlán, la secuencia ignimbrítica del Mioceno tardío tiene una actitud horizontal y un fallamiento mínimo. Sin embargo, al norte de esta carretera, la misma secuencia se reporta basculada hasta $30^{\circ}$ por fallamiento normal tanto en el valle del río Presidio (Aranda Gómez et. al, 2003) como en el valle del río Piaxtla cerca de Tayoltita (Horner y Enríquez, 1999; Enríquez y Rivera, 2001), sugiriendo que la extensión del Mioceno medio-tardío debe haber penetrado de manera discontinua hacia el continente.

\subsubsection{Sector sur}

En el sector sur, la tectónica extensional afecta sistemáticamente a toda la SMO (Figuras 6 y 9). En el límite

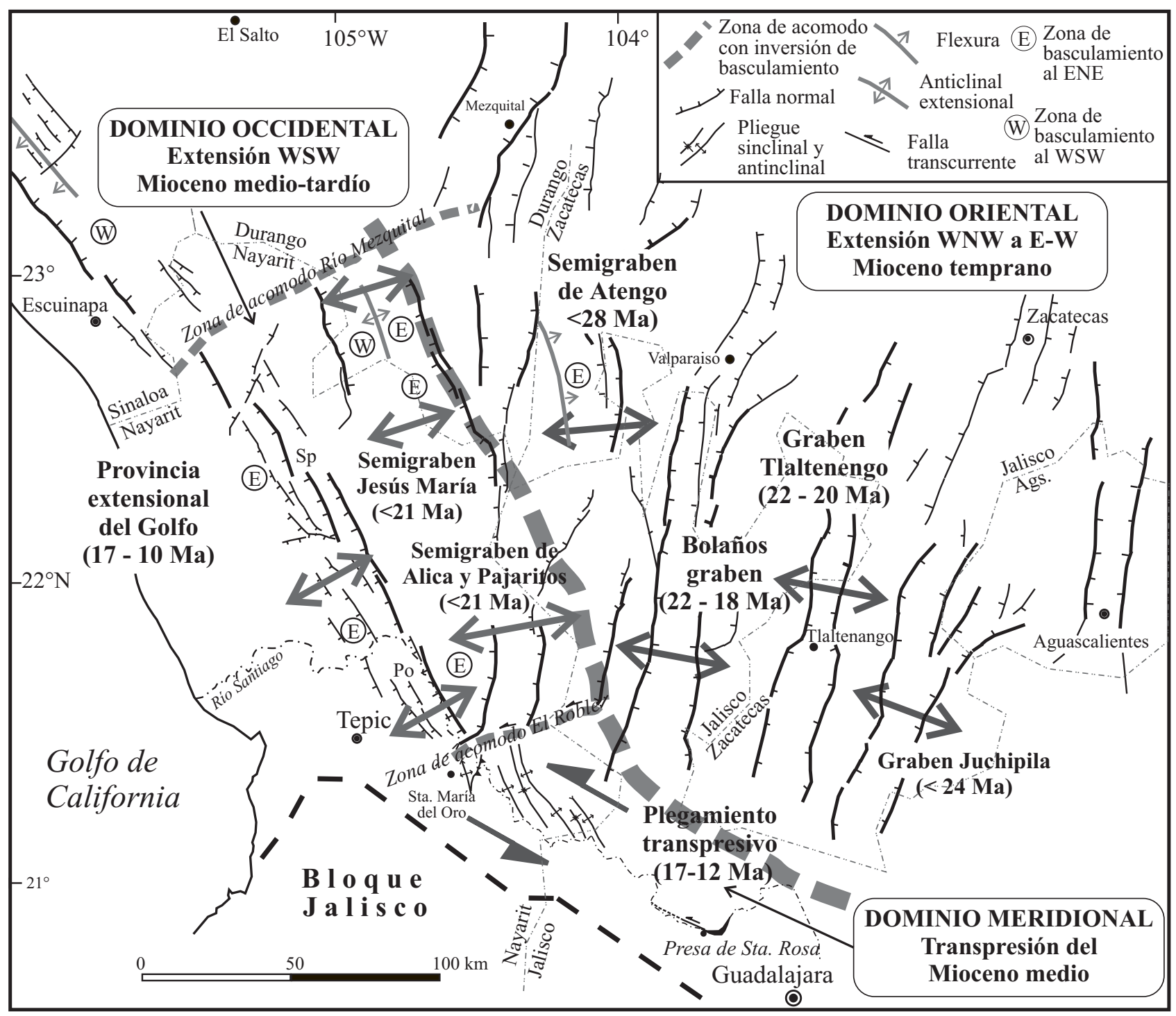

Figura 9. Mapa tectónico de la parte norte de la SMO (basado en Ferrari et al., 2002) con indicación de la edad de la deformación extensional (ver texto para los detalles). 
nororiental de esta región, en Fresnillo, Zac., hay evidencias de una extensión temprana ocurrida en el Eoceno tardío o el Oligoceno temprano, ya que ignimbritas de 39 Ma se encuentran basculadas $\sim 30^{\circ}$ hacia el SW y están cubiertas por tobas horizontales con una alteración secundaria fechada por K-Ar en 29.1 Ma (Lang et al., 1988). Sin embargo, en el resto de la región no hay evidencias de una extensión previa al Oligoceno. El sur de Zacatecas y norte de Jalisco está afectado por una serie de grábenes que constituyen la continuación occidental de las estructuras extensionales que afectan a la Mesa Central (NietoSamaniego et al., 1999) mientras que más al occidente, en Nayarit, dominan los semigrábenes (Figura 9). Ferrari et al. (2002) agrupan las estructuras de la parte sur de la SMO en tres dominios principales: oriental, occidental y meridional (Figura 9). El dominio oriental está constituido por grábenes de dirección NNE a N-S y longitud variable entre 40 a $120 \mathrm{~km}$, que afectan a ignimbritas del Oligoceno tardío o Mioceno temprano. En el graben de Tlaltenango una ignimbrita fechada 22 Ma (Moore et al., 1994) está cortada por fallas con un desplazamiento mínimo de $400 \mathrm{~m}$, mientras que un volcán escudo basáltico de 21 Ma (Moore et al., 1994) posiblemente alimentado por las fallas tiene escarpes menores a $50 \mathrm{~m}$, por lo que se considera que la extensión pudo ocurrir entre $\sim 22$ y $\sim 20 \mathrm{Ma}$ (Ferrari et al., 2002). En el graben de Bolaños, que tiene un desplazamiento vertical de más de $1400 \mathrm{~m}$, la relación de corte entre las diferentes unidades volcánicas indicaría una deformación comprendida en el Mioceno temprano, posiblemente con más de una fase de deformación (Lyons, 1988; Ferrari et al., 2002). En los demás grábenes no es posible tener una edad precisa de la deformación, pero en todos los casos las fallas normales cortan a ignimbritas del Mioceno temprano y son el producto de una extensión similar de dirección WNW a E-W, por lo que se considera que la deformación ocurrió al mismo tiempo durante el Mioceno temprano (Figura 9).

El dominio occidental se caracteriza por los semigrábenes Alica, Pajaritos y Jesús María, y los sistemas de fallas normales de Pochotitán y San Pedro (Figura 9). Estas estructuras tienen dirección de N-S a NNW-SSE y basculan sistemáticamente al ENE bloques de ignimbritas del Mioceno temprano. A lo largo del río Mezquital existe una zona de acomodo con inversión del basculamiento, ya que al norte, en Sinaloa, la vergencia es al WSW (ver sección anterior). Las fallas de los semigrábenes cortan a ignimbritas de la serie del Nayar fechadas en $\sim 21 \mathrm{Ma}$ (Ferrari et al., 2002); sin embargo, no se cuenta con una edad mínima. Los sistemas de fallas de San Pedro y Pochotitán son el resultado de una extensión de dirección ENE a NE-SW y pueden considerarse parte de la Provincia Extensional del Golfo. Las fallas del sistema Pochotitán cortan a rocas de hasta 17 Ma y están cubiertas por basaltos de $\sim 10$ Ma (Ferrari y Rosas-Elguera, 2000). Adicionalmente en esta región se encuentran numerosos diques máficos que intrusionan a las fallas normales NNW o son subparalelos a ellas. Al igual que en el sur de Sinaloa, estos diques han arrojado edades entre 11.9 y 10.9 Ma y se consideran contemporáneos a la extensión (Ferrari et al., 2002).

Finalmente, en el dominio meridional la secuencia del Oligoceno y el Mioceno inferior de la SMO está deformada en pliegues abiertos con arreglo escalonado (en échelon), pequeñas cabalgaduras y fallas izquierdas desarrolladas en el Mioceno medio (Ferrari, 1995). Estas estructuras están distribuidas en una franja de orientación WNW-ESE en el límite de la SMO con el bloque Jalisco. Los pliegues están cortados por diques máficos verticales de $\sim 11 \mathrm{Ma}$ (Damon et al., 1979) que proporcionan una edad mínima de la deformación. Ferrari (1995) interpreta esta deformación como una zona de transpresión izquierda producto del movimiento opuesto entre la SMO, durante las fases finales de la subducción de la microplaca Magdalena, y el bloque Jalisco, donde continuaba la subducción de la placa de Cocos.

\section{Petrología y características geoquímicas del magmatismo de la SMO}

Las rocas volcánicas de la SMO forman un conjunto típicamente calcialcalino, caracterizado por concentraciones de potasio intermedias a altas (Cochemé y Demant, 1991), combinadas con un enriquecimiento relativamente bajo en hierro (Cameron et al., 1980). La Figura 10, basada en datos geoquímicos mayormente provenientes de estudios realizados en el sector norte de la SMO, resume las principales características petrológicas de estas rocas. Los datos indican un amplio rango en el contenido de sílice entre $\sim 49$ y $78 \%$ de $\mathrm{SiO}_{2}$; sin embargo, existe un carácter bimodal en la distribución de los mismos. Se observa una población félsica con composiciones entre $\sim 66$ y $78 \%$ de $\mathrm{SiO}_{2}$, y otra población más máfica, con valores de $\mathrm{SiO}_{2}$ entre 49 y $62 \%$. Los datos de muestras con valores intermedios de sílice $\left(\sim 62-66 \% \mathrm{SiO}_{2}\right)$ son claramente más escasos. El primer grupo consiste en riodacitas y riolitas, que caracterizan la secuencia ignimbrítica mientras que el segundo grupo, formado por andesitas, andesitas basálticas y basaltos, corresponde a las rocas del CVI o a las que sobreyacen a la secuencia félsica. La relación sílice-álcalis total, que se muestra en la Figura 10, indica que se trata de rocas principalmente subalcalinas, aunque una cantidad relativamente importante de los datos se ubica en regiones más alcalinas. Estas últimas se refieren particularmente al volcanismo máfico postignimbrítico. Por otro lado, es interesante observar que las andesitas basálticas reportadas en estas muestras, coinciden grandemente con el campo de las andesitas definidas como SCORBA, lo cual confirma la posible extensión de esta provincia hacia la parte norte de la SMO sugerida por Cameron et al. (1989). La composición de las rocas del CVI, indicada también en la Figura 10, es en general similar al resto de las rocas de la SMO; sin embargo, a diferencia de estas últimas, las rocas del CVI 


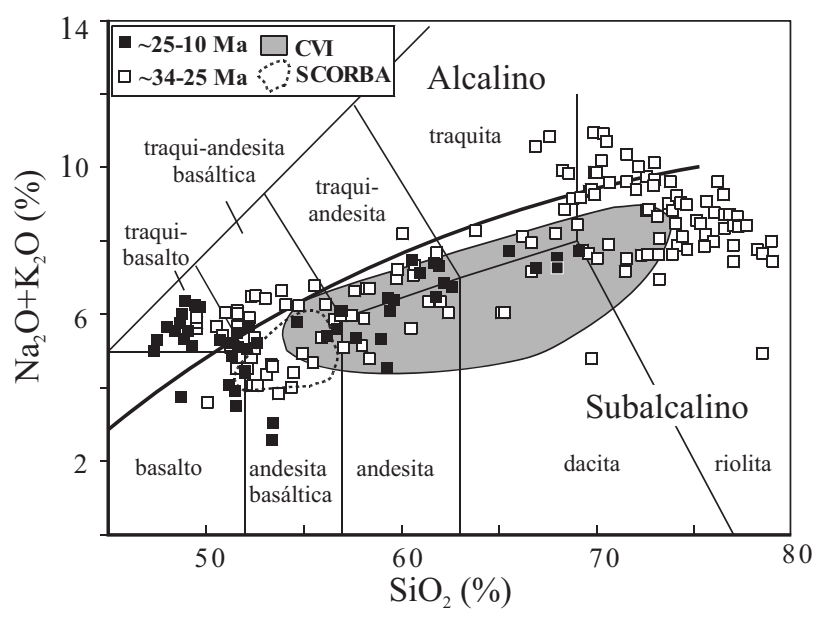

Figura 10. Diagrama de variación de sílice contra álcalis total (TAS) de acuerdo con LeMaitre et al. (1989), para rocas volcánicas del sector norte de la SMO (cuadros blancos). El límite entre las composiciones alcalina y subalcalina es el propuesto por Irvine y Baragar (1971). Los cuadros negros representan rocas volcánicas ubicadas al oriente de la SMO, en la provincia Basin and Range. Para fines de comparación, se muestran el campo composicional de los andesitas basálticas tipo SCORBA (línea punteada), basado en la figura 5 de McDowell et al. (1997), y, aunque el diagrama es esencialmente utilizado para rocas volcánicas, se muestra también la región del Complejo Volcánico Inferior (CVI) (en gris), en su mayor parte basado en datos de intrusivos graníticos. Fuentes: SMO-Cameron et al. (1980); Lanphere et al. (1980); Piguet (1987); Wark (1991); Gans (1997); McDowell et al. (1997); McDowell et al. (1999); Albrecht y Goldstein (2000); González-León et al. (2000); Mora-Álvarez y McDowell. (2000); Post-SMO-Gastil y Krummenacher (1977); Gastil et al. (1979); Bartolini et al. (1995); Gans (1997); McDowell et al. (1997); González-León et al. (2000); Mora-Álvarez y McDowell (2000); Henry et al. (2003). CVI-Bagby et al. (1981); Mora-Álvarez y McDowell (2000); Roldán-Quintana (1991); Valencia-Moreno et al. (2001); Valencia-Moreno et al. (2003); Henry et al. (2003).

están más restringidas a la región subalcalina, y no tienen un carácter bimodal (e.g., Valencia-Moreno et al., 2001 y 2003); además, el rango en los valores de sílice es más restringido hacia ambos lados. Es interesante también hacer una comparación entre las rocas de la SMO con las rocas volcánicas neógenas relativamente más jóvenes ( 25-10 $\mathrm{Ma})$, las cuales generalmente se encuentran intercaladas con horizontes clásticos de la Formación Báucarit (e.g., McDowell et al., 1997). Aunque existen relativamente pocos datos publicados de estas rocas volcánicas, en la figura se puede apreciar un rango similar en el contenido de sílice, aunque éstas no alcanzan composiciones estrictamente riolíticas. También, a excepción de los basaltos, su composición está claramente restringida a las rocas subalcalinas. En relación a la concentración de elementos traza en las rocas de la SMO, se estima que la distribución de algunos de los elementos traza, incluyendo $\mathrm{Rb}, \mathrm{Sr}, \mathrm{Nb}$, $\mathrm{Y}, \mathrm{Th}, \mathrm{Zr}$ y el grupo de las Tierras Raras, estuvo controlada mayormente por procesos de cristalización fraccionada y asimilación, a partir de magmas máficos derivados del manto (Cameron et al., 1980; Bagby et al., 1981). Este parece ser un mecanismo razonable para explicar las tendencias lineares observadas en suites de basalto-andesita- riolita observadas, por ejemplo, en la región de Batopilas (Cameron et al., 1980).

Por otro lado, el estudio del mecanismo involucrado en la generación del enorme volumen de rocas ignimbríticas de la SMO $\left(\sim 300000 \mathrm{~km}^{3}\right)$, se convirtió a partir de la década de1980 en un tema muy polémico (e. g., Cameron et al., 1980a, 1980b; Cameron y Hanson., 1982; Verma, 1984; Ruiz et al., 1988a; Cameron et al., 1992; McDowell et al., 1999; Albrecht y Goldstein, 2000). Por lo general, los estudios realizados en busca de una solución a este conflicto han recurrido al uso de firmas isotópicas grabadas en las rocas volcánicas. De acuerdo con estos estudios, las relaciones iniciales de ${ }^{87} \mathrm{Sr} /{ }^{86} \mathrm{Sr}$ en las rocas volcánicas expuestas en varios sitios de la provincia de la SMO indican un rango de 0.7041 a 0.7070 , y valores iniciales de $\varepsilon N d$ entre +2.3 y -3.2; sin embargo, valores de $\varepsilon N d$ de -5.2 y -5.8 , acoplados con relaciones ${ }^{87} \mathrm{Sr} /{ }^{86} \mathrm{Sr}$ de 0.7089 y 0.7086 , fueron reportadas en la caldera de Tómochic y San Buenaventura, respectivamente (McDowell et al., 1999; Albrecht y Goldstein, 2000). La Figura 11 muestra la distribución de estos datos isotópicos en un diagrama de variación de $\varepsilon \mathrm{Nd}$ contra ${ }^{87} \mathrm{Sr}{ }^{86} \mathrm{Sr}$. Cabe mencionar que existe un mayor número de datos isotópicos, particularmente de las relaciones de $\mathrm{Sr}$, pero sin su correspondiente composición de $\mathrm{Nd}$, por lo que no se muestran en la figura; sin embargo, estos datos indican un rango similar. En general, se puede apreciar cómo un volumen importante de los datos se ubica en una posición cercana a la composición isotópica promedio de la Tierra. La distribución de los mismos indica una progresión en la composición de las muestras de la SMO, de firmas de

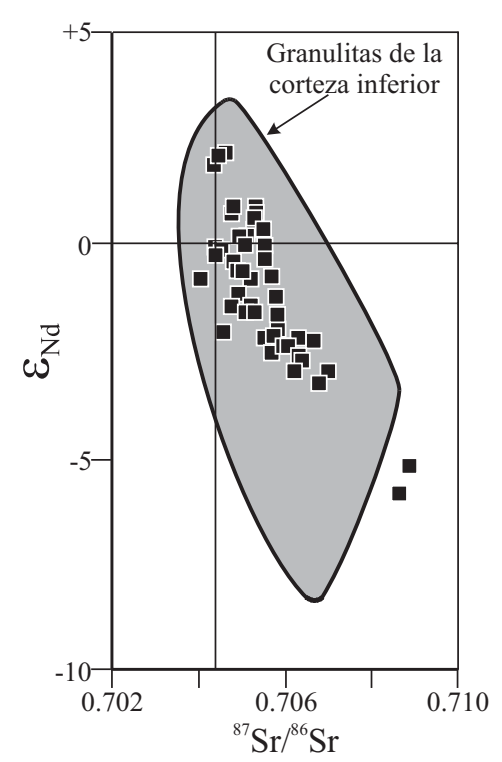

Figura 11. Diagrama de variación isotópica $\varepsilon N d-{ }^{87} \mathrm{Sr} /{ }^{86} \mathrm{Sr}$ de rocas volcánicas del Terciario medio de la SMO. El crucero entre las líneas indica la composición isotópica promedio de la Tierra. El campo de las granulitas de la corteza inferior, corresponde a un grupo de xenolitos de ortogneises de composición intermedia y máfica, tomado de Ruiz et al. (1988). Fuente de datos: Wark (1991); McDowell et al. (1999); Albrecht y Goldstein (2000). 
carácter más mantélico, caracterizadas por $\varepsilon N d$ positivos y valores relativamente primitivos de $\mathrm{Sr}$, a firmas negativas de $\varepsilon \mathrm{Nd}$, acoplados con relaciones de $\mathrm{Sr}$ más altas, que sugieren una influencia cortical importante.

Con respecto al origen de estas rocas, Cameron et al. (1980a) propusieron un modelo basado en cristalización fraccionada/asimilación (AFC, por sus siglas en inglés) de un magma máfico de origen mantélico, donde las rocas ignimbríticas representarían un volumen no mayor al 20\% de la masa magmática inicial. Esto sugiere que el $80 \%$ del volumen inicial quedó como material residual, agregando algunos kilómetros de nueva corteza gabroica debajo de la SMO (Ruiz et al., 1988b; Cameron et al., 1992). De acuerdo con Cameron et al. (1986), los modelos de AFC para la SMO sugieren un volumen menor al 25\% de corteza asimilada. Verma (1984) propuso un modelo genético similar para las ignimbritas de la SMO en Zacatecas y San Luis Potosí, pero consideró una segunda etapa más somera de cristalización fraccionada antes del emplazamiento de las ignimbritas. Por otro lado, a partir del hallazgo de una gran cantidad de xenolitos provenientes de la corteza inferior, que fueron extraídos a la superficie por flujos de basalto alcalino recientes, Ruiz et al. (1988b) propusieron que el volumen total de las rocas ignimbríticas de la SMO, pudo haber sido originado por fusión parcial de la corteza inferior. Esto a raíz de que la colección de xenolitos estudiados, los cuales incluyen principalmente granulitas de composición máfica a intermedia de edad paleozoica y precámbrica, exhiben firmas isotópicas idénticas a las de las ignimbritas de la SMO (Figura 11). De acuerdo con dichos autores, el evento magmático SMO no constituyó un periodo importante de formación de corteza. Por el contrario, Cameron et al. (1992) consideran que muchas de las rocas granulíticas son del Terciario medio, y representan kilómetros de corteza nueva formada en ese tiempo debajo de México.

\section{La corteza y el manto en la SMO: datos geofísicos}

A pesar de su importancia científica y económica la información geofísica sobre la SMO es escasa. Los estudios principales son de tipo regional y definen los rasgos mayores de la corteza y el manto en esta región pero difícilmente se pueden correlacionar con los detalles de la geología de superficie.

La estructura del manto superior por debajo de la SMO es conocida a grandes rasgos por medio de estudios de tomografía sísmica regionales o globales que utilizan diferentes tipos de ondas y de procesado (Grand, 1994; Alsina et al., 1996; Van der Lee y Nolet, 1997; Bijward y Spakman, 2000; Ritzwoller et al., 2002; Ritsema et al., 2004). Un rasgo general de todos estos estudios es que la raíz litosférica por debajo de la SMO es modesta o hasta ausente. Aunque en forma variable, todos los modelos tomográficos muestran una zona de baja velocidad que se extiende desde $\sim 80 \mathrm{~km}$ hasta $\sim 250 \mathrm{~km}$. Esta anomalía negativa de velocidades se extiende desde el Golfo de California hasta la Mesa Central y desde la provincia Basin and Range de Estados Unidos hasta la frontera sur de la SMO a la latitud $\sim 20^{\circ} \mathrm{N}$. Estimaciones de la estructura térmica basada en modelos tomográficos indican que en esta región el manto tiene temperaturas de $\sim 500{ }^{\circ} \mathrm{C}$ más elevadas que bajo el cratón de Norteamérica al este (Goes y van der Lee, 2002). Estas observaciones indican que el manto litosférico ha sido parcialmente o totalmente removido y que en su lugar se encuentra manto astenosférico.

Los datos sismológicos permiten vislumbrar una fuerte diferencia de espesor cortical entre el núcleo de la SMO y sus márgenes. En un estudio sismológico regional usando ondas superficiales y ondas S, Gomberg et al. (1988) estimaron un espesor promedio de la corteza de $40 \mathrm{~km}$ para el norte de México. Sin embargo, debido a la trayectoria de los rayos sísmicos utilizados, los autores consideran este valor como característicos de la región al este de la SMO, en la parte norte de la Mesa Central.

Más recientemente Bonner y Herrin (1999) definieron el espesor cortical de la parte norte de la SMO por medio de un estudio de dispersión de ondas superficiales. Este estudio utilizó temblores ocurridos en el Golfo de California y registrados en Texas, por lo que los resultados se pueden considerar representativos de la parte central, menos extendida, de la SMO. Los autores encuentran que el mejor modelo sísmico para esta región lo constituye una corteza de $55 \mathrm{~km}$ con tres capas: una capa delgada $(\sim 5 \mathrm{~km})$ con baja velocidad (Vs $\sim 2.8 \mathrm{~km} / \mathrm{s}$ ), una capa intermedia de $\sim 20 \mathrm{~km}$ (Vs $\sim 3.6 \mathrm{~km} / \mathrm{s}$ ), y una capa inferior de $\sim 30 \mathrm{~km}$ caracterizada por altas velocidades sísmicas (Vs $\sim 4.0 \mathrm{~km} / \mathrm{s}$ ).

En otro estudio reciente Persaud (2003) establece la profundidad de la Moho basándose en funciones de receptor en tres puntos de la margen occidental de la SMO, donde esta última ha sido adelgazada por la extensión que llevó a la formación del Golfo de California. En este estudio se estiman espesores de $28 \mathrm{~km}$ en el área al este de Hermosillo y de $22 \mathrm{~km}$ tanto para el área de la costa del sur de Sonora (Navojoa) como al norte de Sinaloa en Culiacán (Figura 6).

Couch et al. (1991) integrando datos gravimétricos y de refracción sísmica estiman un contraste un poco menor en la parte centro-sur de la SMO. Para estos autores el espesor de la corteza al centro de la SMO es de $40 \mathrm{~km}$ pero se reduce a $25 \mathrm{~km}$ en la costa este del Golfo de California. La región al este, centro y sur de la SMO tiene también un espesor menor: Fix (1975) proporciona valores de $~ 30$ $\mathrm{km}$ en base a ondas superficiales y Campos-Enríquez et al. (1994) consideran una Moho a $33 \mathrm{~km}$ para la Mesa Central (Figura 6).

Considerando los $55 \mathrm{~km}$ en el núcleo no extendido de la SMO (Figura 6) como un máximo para la profundidad de la Moho al término del pulso ignimbrítico y tomando en cuenta un espesor promedio de $\sim 25 \mathrm{~km}$ en la costa 
de Sonora y Sinaloa, el adelgazamiento continental del Oligoceno-Mioceno en el flanco occidental de la SMO debe haber sido superior al $100 \%$ si la extensión fuera uniforme. Este valor es comparable con la extensión calculada en superficie para la región de los core complexes en Sonora $(e$. g., Gans, 1987), pero contrasta con las estimaciones de la geología de superficie en otras áreas de Sonora (McDowell et al., 1997) y en Sinaloa (Henry, 1989), que indican una extensión inferior al $50 \%$ y más probablemente del orden de $\sim 20-30 \%$. Este contraste sugiere que la extensión extrema estimada en ciertas áreas de Sonora puede ser un valor local que se dio en áreas con basamento predispuesto a focalizar la deformación. Otra posibilidad que sugiere Persaud (2003) es que en esta región pudo haber ocurrido un desacoplamiento entre corteza frágil y corteza inferior dúctil, donde esta última habría fluido hacia la zona del Golfo de California durante las fases iniciales de la extensión continental.

\section{Discusión}

6.1. Evolución espacio-temporal del magmatismo de arco y de la tectónica extensional

La historia magmática de la SMO está estrechamente relacionada con la evolución de la margen occidental de la placa Norteamericana y la historia de subducción de la placa Farallón. En un contexto general, la evolución del magmatismo de la SMO se inserta en el patrón de migración del arco volcánico hacia el interior del continente y su posterior regreso hacia la trinchera que ha sido reconocida desde hace tiempo para el suroeste de la Cordillera Norteamericana entre el Cretácico Tardío y el presente $(e$. g., Coney y Reynolds, 1977; Damon et al., 1981; Damon et al., 1983) (Figura 12a). De acuerdo con este modelo la migración del arco estuvo esencialmente controlada por la variación del ángulo de subducción de la placa Farallón debajo de Norteamérica. A principio del Cretácico Tardío, el arco se encuentra próximo a la trinchera (Sierra Nevada, batolitos peninsulares de Baja California y del CVI), luego empieza paulatinamente a migrar hacia el este conforme el slab se vuelve subhorizontal. Durante este periodo tiene lugar la orogenia Laramide. Una vez cesada la contracción, a finales del Eoceno, iniciaría el regreso del arco a medida que la placa subducida aumenta su ángulo.

Este patrón general de migración puede aplicarse, con ciertas limitaciones, a la SMO (Figura 12). La migración inicial hacia el este del arco es más evidente en Estados Unidos y norte de la SMO, donde alcanza los $1000 \mathrm{~km}$ desde la trinchera (Damon et al. 1981), que en su parte centro y sur. Henry et al. (2003) muestran que en el sector central de la SMO el arco sólo llegó a unos $400 \mathrm{~km}$ de la paleotrinchera y que la migración hacia el este del magmatismo ocurrió a una tasa de un orden de magnitud menor $(1-1.5 \mathrm{~km} / \mathrm{Ma})$ que su regreso hacia la trinchera. Para la
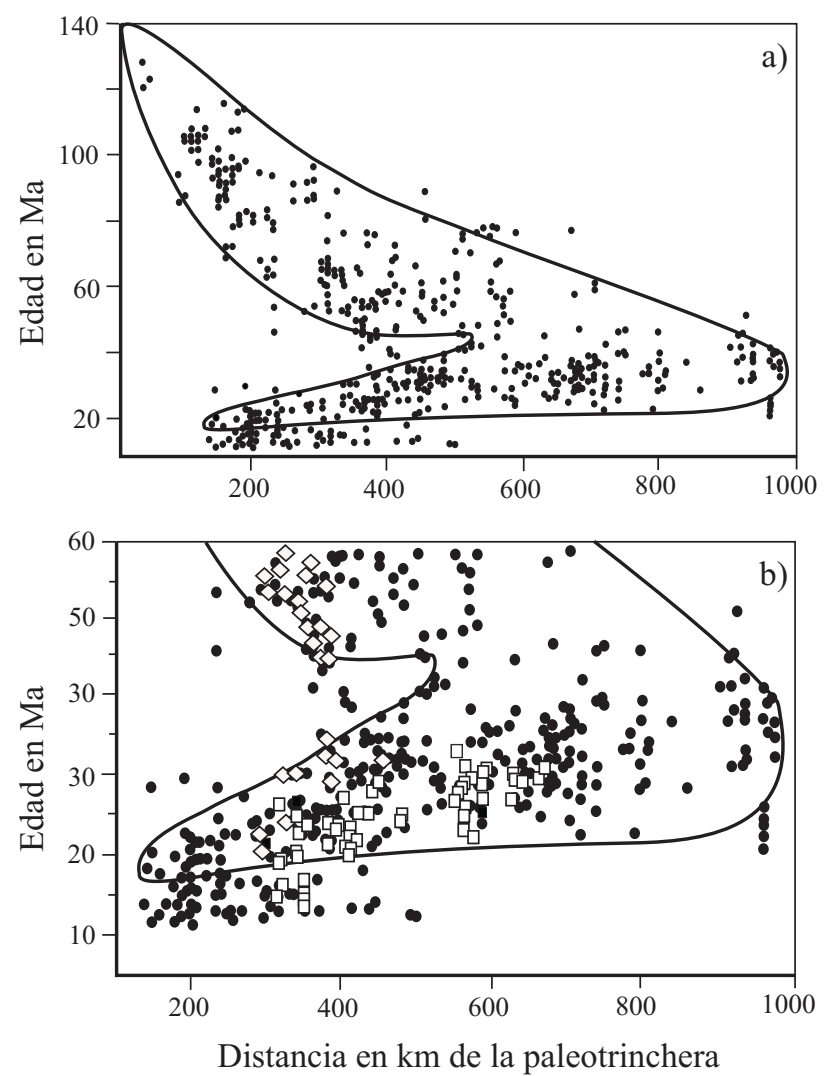

Figura 12. Distribución de los datos geocronológicos de las rocas ígneas del Cretácico Temprano al Mioceno en México en función a la distancia a la paleotrinchera: a) distribución de las edades entre $\sim 140$ y $10 \mathrm{Ma}$ (modificado de Damon et al., 1981) que muestra la migración del magmatismo cordillerano hasta aproximadamente $1000 \mathrm{~km}$ de la paleotrinchera entre el inicio del Cretácico y el fin del evento Laramide ( $40 \mathrm{Ma})$, seguido por un aparente rápido regreso de la actividad magmática hacia la costa. Las edades menores que $20 \mathrm{Ma}$ debajo del espectro marcado por la línea sólida corresponden principalmente a basaltos asociados a extensión; b) acercamiento a la gráfica anterior que muestra un mayor detalle de la sección entre 60 y $10 \mathrm{Ma}$. Los círculos negros son los datos de Damon et al. (1981). Se muestran además las edades reportadas por Nieto-Samaniego et al. (1999) para la parte sur de la provincia de la SMO (cuadros) y las edades reportadas por Henry et al. (2003) para el sur de Sinaloa (rombos).

parte sur de la SMO la mayor distancia de la paleotrinchera es alcanzada en el Oligoceno, cuando el arco llega a distancias máximas de $600 \mathrm{~km}$ de la paleotrinchera (NietoSamaniego et al., 1999). Durante esta migración al este, el volcanismo de la parte norte de la SMO parece posdatar a la deformación compresiva. Las rocas volcánicas del CVI ( 90-60 Ma) tanto en Sonora (Formación Tarahumara) como en Chihuahua (Peñas Azules volcanics) sólo están basculadas y no presentan evidencias claras de que esto se haya debido a un acortamiento. Por otro lado en la parte central de la SMO la deformación en las rocas del CVI (plutones sintectónicos de Sinaloa, 101-89 Ma) antecede la deformación laramídica de la Sierra Madre Oriental, que tiene edades del Paleógeno (Eguiluz de Antuñano et $a l ., 2000)$. Finalmente, el arco Eoceno en toda la SMO no tiene evidencias de una deformación contractiva. La pre- 
sencia durante el Cretácico Tardío-Paleógeno de un arco magmático ubicado entre la paleotrinchera y el frente de la deformación impide extender el modelo de subducción subhorizontal invocado para explicar la orogenia Laramide en los Estados Unidos (e. g., Coney y Reynolds, 1977, Bird, 1984, 1988; Saleeby, 2003) a México, ya que el acoplamiento entre placa subducida y placa superior cierra la cuña del manto donde se genera el magmatismo de arco. Este argumento es válido tanto para el sector mexicano como para el sector canadiense de la cadena Laramide (English et al., 2003) y plantea la necesidad de un modelo alternativo para explicar esta deformación en México. Una alternativa es que la deformación Laramide pueda haber sido producida por la subducción de un sector engrosado y discreto de la placa Farallón (¿plateau oceánico?) y que la cuña del manto se haya restablecido mientras la subducción de dicho sector seguía hacia el este. Este escenario, que nunca ha sido considerado, tiene numerosas implicaciones para la tectónica y el volcanismo de la SMO que necesitan de un análisis cuidadoso que va más allá del propósito de este artículo.

A escala continental, a partir del Oligoceno el volcanismo inicia su regreso hacia la trinchera, aunque en detalle la evolución puede ser más compleja. El pulso ignimbrítico (flare up) del Oligoceno tardío tiene esencialmente la misma edad en toda la SMO (32-28 Ma) y se distribuye en una amplia franja de dirección general NNW (Figura 2) sin aparente migración interna. El volcanismo del Mioceno temprano está claramente más desplazado hacia la mitad occidental de la SMO y tiene diferencias notables de norte a sur. Mientras que en la parte norte de la SMO este volcanismo es escaso y de composición dominantemente basáltica, en la parte centro y sur consta de un segundo pulso masivo de ignimbritas silícicas con cantidades pequeñas de basaltos. Andesitas del Mioceno temprano y medio están presentes también más al occidente, en Baja California (Figura 2), en el Arco Comondú (Sawlan, 1981; Umhoefer et al., 2001), lo que completaría el patrón de regreso hacia la trinchera del volcanismo de arco. Sin embargo, en la parte sur de la SMO el patrón de migración es más complejo. Ferrari et al. (1999) han mostrado que la orientación del arco tiende a rotar de forma antihoraria desde el Oligoceno, cuando el arco tiene una dirección NNW, al Mioceno temprano y medio cuando el arco se extiende a Baja California sur con una dirección WNW y cesa su actividad al sur de la Latitud $20^{\circ} \mathrm{N}$. Más en detalle, Ferrari et al. (2002, figura 6) muestran que durante el pulso ignimbrítico del Mioceno temprano el volcanismo tiende a migrar hacia el ESE alcanzando la longitud $101^{\circ} \mathrm{W}$.

A escala de toda la provincia, el inicio de la extensión está asociado al regreso del arco hacia la trinchera. Los datos reportados en la sección 3 (Tectónica de los conjuntos ígneos de la SMO) indican que la extensión o quizás el frente extensional, migró episódicamente de este a oeste a lo largo de toda la SMO (ver también Stewart, 1998). Asimismo, el inicio de la extensión parece seguir el inicio del primer pulso ignimbrítico. La extensión inicia en la Mesa Central probablemente ya en el Eoceno (ArandaGómez y McDowell, 1998; Nieto-Samaniego et al., 1999; Nieto-Samaniego et al., 2005); sin embargo, una extensión con alta tasa de deformación ocurre a los $\sim 30 \mathrm{Ma}$, después del emplazamiento de la primera parte de la serie riolítica (Orozco-Esquivel et al., 2002). En la parte oriental de la SMO central la extensión más temprana ocurre también a mediados del Oligoceno después del emplazamiento de las primeras ignimbritas (a los $230 \mathrm{Ma}$ en Nazas y Rodeo, Dgo., Aranda-Gómez et al., 2003; entre 39 y 29 Ma en Fresnillo, Zac.; Lang et al., 1988).

En un segundo episodio, el frente extensional se mueve hacia el oeste y afecta la parte central de la SMO entre el final del Oligoceno y el Mioceno temprano. En Chihuahua occidental y en Durango, el fallamiento normal con alto ángulo posdata ignimbritas de $\sim 28$ a 27 Ma (ver sección 3 y Figuras 4 y 5). Este episodio extensional se propaga hasta Sonora oriental donde las principales cuencas de la Formación Báucarit y los core complexes se desarrollan entre $\sim 26$ y 16 Ma (Figura 7). En la parte centro de la SMO, la única evidencia reportada de este episodio es la erupción de basaltos alcalinos en Rodeo y Nazas, Dgo., a los 24 Ma (Aranda-Gómez et al., 2003). En la parte sur de la SMO este episodio extensional se manifiesta en la formación de varios grábenes de dirección $\sim \mathrm{NNE}-\mathrm{SSO}$ a $\mathrm{N}-\mathrm{S}$ en el sur de Zacatecas y noreste de Jalisco (Figura 9) entre 22 y $18 \mathrm{Ma}$, después del inicio del pulso ignimbrítico de 24-20 Ma.

A finales de Mioceno medio ( $12 \mathrm{Ma})$, un tercer episodio extensional afecta la franja más occidental de la SMO. La edad de esta deformación, tradicionalmente definida como Provincia Extensional del Golfo o Proto-gulf extensión, es notablemente coherente en toda la SMO entre $\sim 12$ y 9 Ma, tanto en Sonora (Gans et al., 2003) como en Sinaloa (Henry y Aranda-Gómez, 2000) y Nayarit (Ferrari y Rosas-Elguera, 2000; Ferrari et al., 2002). Aunque en menor medida, este episodio extensional se percibe al este de la SMO, en la Mesa Central, a través de la formación del graben de Río Chico-Otinapa (Henry y Aranda-Gómez, 2000) y otras estructuras que siguen sísmicamente activas en el campo volcánico de Durango y Tepehuanes (NietoSamaniego et al., 2005), así como la extrusión de lavas alcalinas en el campo volcánico de Los Encinos en San Luis Potosí (Luhr et al. 1995).

La evolución geográfica de la tectónica extensional resumida en la sección anterior, indica claramente una progresión de la extensión a través de episodios discretos que afectan a toda la región comprendida entre la Sierra Madre Oriental hasta el Golfo de California (Figura 1). En este sentido, es difícil establecer un límite entre la Provincia Extensional del Golfo y el Basin and Range mexicano. En sintonía con esta idea, Henry y ArandaGómez (2000) proponen que la Provincia Extensional del Golfo sea parte de la provincia Basin and Range, y que sólo en la parte central el núcleo relativamente no- 
extendido de la SMO (Figura 6) separa geográficamente las dos provincias. Esta visión indica que el proceso de extensión continental fue un fenómeno general que afectó toda la margen sur-occidental de la placa Norteamericana, pero que tuvo desenlaces distintos en Estados Unidos y en México. Mientras que en la parte occidental de los Estados Unidos la deformación terciaria llegó a formar una provincia extensional de más de $1000 \mathrm{~km}$ de ancho sin llegar a la ruptura de la litósfera, en México, después de más de $20 \mathrm{Ma}$, la extensión se localizó en la región del Golfo de California provocando la formación de un rift con formación de corteza oceánica desde el Plioceno. En este marco la región de Sonora, con una extensión superior a la del resto de la SMO, representaría una zona de transición entre los dos dominios.

A escala continental hay dos causas complementarias que pueden explicar esta diferencia de comportamiento: 1) el contraste en la reología de la corteza, y 2) un debilitamiento térmico de la zona del futuro Golfo de California. La primera causa ha sido propuesta por Langenheim y Jachens (2003) quienes han sugerido que la presencia de un bloque cortical de mayor resistencia constituido por los batolitos peninsulares (junto con su parte más profunda de composición máfica) provocaría la localización de la deformación a lo largo del límite oriental del bloque batolítico peninsular, provocando la separación de Baja California de México continental. La otra explicación sugiere que la extensión se localizaría en la zona del futuro Golfo de California debido a que el arco estuvo activo en esta región durante el periodo inmediatamente anterior a la apertura del rift. Esta hipótesis está sustentada por la edad del volcanismo del denominado Arco Comondú en Baja California Sur. Aunque la presencias de rocas volcánicas del Mioceno temprano-medio ha sido reportado en Baja California ( $e$. g., Sawlan, 1991; Stock y Lee, 1994) la parte más antigua de este volcanismo es frecuentemente constituida por depósitos masivos (conglomerados fluviales producto de la erosión del arco) y por ignimbritas en facies distales (e.g., Hausback, 1984; Dorsey y Burns, 1994; Umhoefer et al., 2001). En realidad, es durante el Mioceno medio-tardío ( $15-12 \mathrm{Ma})$ cuando un arco andesítico se encuentra activo en las inmediaciones de la costa este de Baja California (ver sección 2, Estratigrafía Regional, para Sonora y Umhoefer et al., 2001, para Baja California Sur). El debilitamiento térmico de la corteza provocado por la presencia del Arco Comondú pudo finalmente ser la causa de la focalización de la extensión en región del futuro Golfo de California.

\subsection{Génesis del magmatismo silícico}

El aspecto más peculiar del magmatismo de la SMO es ciertamente la erupción de grandes volúmenes de magma silícico en un tiempo relativamente corto. Estos pulsos ignimbríticos no son cosas comunes en los arcos volcánicos y la discusión sobre su génesis ha sido recurrente en la literatura. La discusión sobre la petrogénesis de los magmas silícicos de la SMO ha sido generalmente polarizada entre dos modelos extremos. El primer modelo prevé que las riolitas se formen esencialmente por fusión parcial de la corteza (e. g., Huppert y Sparks, 1988) en consecuencia del arribo de grandes cantidades de magmas basálticos desde el manto, que proveerían el calor necesario para fundir la corteza (Ruiz et al., 1988a, 1990; Albrecht y Goldstein, 2000; Ferrari et al., 2002). Este modelo ha sido invocado para la generación de otras grandes provincias ígneas silícicas (Graham et al., 1995; Pankhurst y Rapela, 1995; Ewart et al., 1998; Riley et al., 2001; Bryan et al., 2002). En el segundo modelo, las riolitas serían el producto final de la diferenciación de magmas basálticos con poca o nula intervención de la corteza (Cameron y Hanson, 1982; Cameron y Cameron, 1985; Cameron et al., 1980a, 1980b; Cameron y Robinson, 1990; Wark, 1991; Smith et al., 1996). Una limitante de algunos de estos modelos ha sido que las observaciones en que se basan se refieren a sitios muy restringidos y a escalas de tiempo muy limitadas (e. $g$., unas cuantas muestras de una sección que no rebasa más de 1-2 Ma) y se han generalizados para explicar el origen de grandes volúmenes $\left(>10^{4} \mathrm{~km}^{3}\right)$ de riolitas sobre rangos de tiempos relativamente largos (5-10 Ma). En particular hay que considerar que los estudios existentes sobre la petrogénensis de las riolitas de la SMO se limitan a cuatro sitios en la parte nororiental (Batopilas, Divisadero, San Buenaventura y Tómochic, todos en Chihuahua), un sitio ubicado en Zacatecas, en el extremo oriental de la parte sur de la SMO, y a dos sitios ubicados en la Mesa Central (La Olivina, Chih. y San Luis Potosí, S.L.P.).

La distinción entre los dos términos extremos sobre la generación de ignimbritas riolíticas (anatexis versus cristalización fraccionada) puede parecer relativamente fácil desde un punto de vista isotópico y, de hecho, esto ha sido en enfoque principal bajo el cual se ha tratado el problema para la SMO (Cameron et al., 1980a, 1980b; Cameron y Hanson, 1982; Cameron y Cameron, 1985; Ruiz et al., 1988a, 1990; Cameron y Robinson, 1990; Wark, 1991; Smith et al., 1996; Albrecht y Goldstein, 2000). Este enfoque se basa en la hipótesis de que la corteza continental tiene composiciones isotópicas de ${ }^{87} \mathrm{Sr} /{ }^{86} \mathrm{Sr}$ y $\varepsilon \mathrm{Nd}$ (y otros sistemas isotópicos) distintas con respecto al manto. En la práctica este enfoque ha dado frecuentemente resultados ambiguos (ver sección 4, Petrología y características geoquímicas del magmatismo de la SMO), porque las riolitas y las raras lavas máficas asociadas han arrojado composiciones isotópicas de $\mathrm{Sr}$ y $\mathrm{Nd}$ intermedias (e. g., $\varepsilon N d$ de $\sim+4$ a -4 , Figura 11), entre las que se infieren para el manto modificado por la subducción y la corteza paleozoica o mesozoica (especialmente corteza inferior) por la que han pasado (Wark, 1991; Johnson, 1991).

La problemática del origen mantélico versus cortical de las ignimbritas riolíticas de la SMO tiene varias implicaciones que han sido analizadas en la literatura para otras grande provincias ígneas silícicas. Si su generación 
se debe a la cristalización fraccionada de magmas juveniles del manto, esto implica una significativa transferencia de material y formación de nueva corteza. Por otro lado, si las riolitas son producto exclusivamente de la diferenciación de basaltos, esto requiere de un volumen por lo menos cuatro veces mayor de cúmulos máficos en la corteza ( $e$. g., Cameron et al., 1980a; Cameron y Hanson, 1982; Ruiz et al., 1988a). A su vez si estos residuos máficos se forman cerca de la Moho, esto podría llevar a una inestabilidad convectiva y subsiguiente delaminación de la base de la corteza (e. g., Kay y Mahlburg-Kay, 1991; Kay et al., 1992; Meissner y Mooney, 1998; Jull y Keleman, 2001). Por otro lado, si estos cúmulos se forman en otros niveles de la corteza esto tendría consecuencias sobre la variación de la composición y la estructura térmica de la corteza, y sus propiedades isostáticas, sísmicas y reológicas (Gans, 1997; Gans et al., 1989; Klemperer, 1989; Glazner y Ussler, 1989; Johnson, 1991; Miller y Paterson, 2001). Si las riolitas se han formado esencialmente por fusión parcial de la corteza, se necesita la generación de una cantidad mucho menor de magmas basálticos en el cúmulo residual (Ruiz et al., 1988a), y esto llevaría a un diferente perfil petrológico y reológico de la corteza. Independientemente de si un magma basáltico contribuye con transferencia de calor o de masa a la generación de riolitas, la pregunta relevante es la localización y el destino del material cúmulo residual (Smith et al., 1996; Jull y Keleman, 2001; Ducea, 2002).

En el caso de México, los datos geofísicos sintetizados en este trabajo indican que la corteza en el núcleo no extendido de la SMO tiene mayor espesor respecto a la que se encuentra en sus lados (Figura 6). En la parte norte se tienen $\sim 55 \mathrm{~km}$ en la parte no extendida contra $\sim 40 \mathrm{~km}$ al este y $\sim 28$ a $22 \mathrm{~km}$ en la costa del Golfo de California. El espesor del núcleo de la SMO resulta excesivo para una corteza precámbrica o paleozoica normal (e. g., Money et al., 1998). Asimismo, la parte centro y sur de la SMO, presumiblemente subyacida por un basamento post-Paleozoico, tiene un espesor de cerca de $10 \mathrm{~km}$ mayor que su contraparte en la Mesa Central (ver también Nieto-Samaniego et al., 1999). Estos espesores anómalos y el fuerte contraste en las velocidades sísmicas de la capa inferior detectadas por Bonner y Herrin (1999) en la parte norte de la SMO, sugieren que la corteza inferior puede haber sido fuertemente intrusionada por magmas máficos. Esta interpretación está reforzada por la existencia en superficie de varias calderas (Figura 6) y de los mayores espesores de ignimbritas. La adición de magmas máficos en la base de la corteza (underplating) puede producir la formación de nueva corteza y, por consecuencia, el hundimiento de la Moho, una situación común a muchos márgenes continentales activos (Klemperer, 1989). El carácter regional de los estudios sísmicos disponibles para la SMO junto a la falta de estimaciones detalladas de los volúmenes de ignimbritas y su equivalente de intrusivos no permiten discriminar entre el modelo de fusión de la corteza o de cristalización fraccionada; sin embargo, la presencia de cantidades significativas de instrusiones máficas en la corteza inferior sugiere que la causa de los pulsos ignimbríticos fue el arribo de grandes cantidades de magmas basálticos desde el manto.

A nivel más general, otra pregunta importante se refiere a ¿qué aspecto controla la generación de riolitas o de basaltos en las grandes provincias ígneas (LIPs por sus siglas en Ingles)?. La fertilidad de la corteza ha sido invocada como factor determinante para la generación de riolitas (Bryan et al., 2002), ya que muchas de las grandes provincias silícicas se encuentran sobre cortezas del Fanerozoico, mientras que las del Arqueano están más comúnmente asociadas a grandes provincias máficas. Adicionalmente, modelados numéricos de la intrusión de magmas máficos en la corteza inferior han demostrado que la presencia de minerales hidratados y de basaltos con alta temperatura y bajo contenido en agua favorecen la fusión de corteza (Annen y Sparks, 2002). En el caso de la SMO, no parece que la presencia de una corteza precámbrica en la parte norte de la provincia haya tenido alguna influencia sobre el tipo de volcanismo, ya que las ignimbritas del Oligoceno se han emplazado con volumen parecido en toda la provincia. Sin embargo, la fertilidad de la litósfera puede haber sido incrementada por fenómenos ocurridos anteriormente a los pulsos ignimbríticos. Humphreys et al. (2003) han propuesto que la subducción subhorizontal de la placa Farallón, ocurrida durante la orogenia Laramide, habría producido una hidratación y fertilización significativa de la placa Norteamericana (precámbrica); posteriormente, una vez removida la placa en el Terciario, el calentamiento inducido por la exposición al manto astenosférico habría redundado en una "explosión" de volcanismo silícico. Este modelo, propuesto para explicar el volcanismo silícico terciario del suroeste de Estados Unidos puede igualmente aplicarse a la SMO, que comparte una historia tectónica similar con el sur de Estados Unidos.

En conclusión, parece evidente que en la SMO existe todo un rango de posibilidades para la generación de magmas silícicos, donde la cristalización fraccionada y la anatexis representan los términos extremos. La información geofísica y los estudios petrogenéticos son todavía escasos para poder definir con mayor precisión donde el proceso de generación de magmas silícicos se acerca más a uno o al otro término extremo. Sin embargo la presencia de (1) firmas isotópicas corticales y diferencias isotópicas entre ignimbritas emitidas a través de diferentes tipo de corteza (McDowell et al., 1997; Albrecht y Goldstein, 2000; Valencia-Moreno et al., 2001), (2) herencias precámbricas, mesozoicas y terciarias en circones magmáticos (McDowell et al., 1997; Bryan et al., 2005), y 3 ) un volcanismo esencialmente bimodal sin miembros intermedios (andesitas) en el pulso del Oligoceno y Mioceno temprano, sugieren que la asimilación y/o fusión de la corteza debe haber ocurrido en mayor o menor medida en la SMO. En general consideramos que en la SMO la petrogénesis fue dominada por procesos de mezcla y asimilación-cristalización frac- 
cionada a gran escala para producir grandes volúmenes de magmas silícicos y volúmenes menores de magmas basálticos o basáltico-andesíticos con contaminación variable. En detalle, el lugar de la corteza involucrado en la asimilación/fusión es probable que varíe en el tiempo, y que zonas progresivamente más someras sean afectadas a medida que la intrusión de magmas máficos induzca una densificación de la corteza inferior.

\subsection{Causas geodinámicas del magmatismo} y la extensión

Con base en las consideraciones de la sección anterior parece claro que, independientemente del mecanismo responsable de la generación de las riolitas, cada pulso ignimbrítico debe de estar relacionado con el arribo de cantidades significativas de magmas máficos del manto a la base de la corteza. El notable sincronismo y el gran volumen del primer pulso ignimbrítico, que abarca toda la SMO, sugiere que este fenómeno no puede ser la consecuencia de un régimen de subducción "normal", sino que debe ser el efecto de un mecanismo a escala continental relacionado con la historia tectónica global. Los resultados de distintos estudios de tomografía sísmica indican que el manto subcortical por debajo de la SMO está caracterizado por una anomalía térmica significativa (ver sección 5 , La corteza y el manto en la SMO: datos geofísicos), indicativa de la presencia de astenósfera. La evolución tectono-magmática cenozoica de la SMO muestra que esta anomalía térmica es el resultado de la remoción de la placa Farallón desde la base de la placa Norteamericana a mediados del Terciario (e.g., Humphreys, 1995). En México, la remoción de la placa Farallón subducida ocurrió en varias etapas caracterizadas por diferentes mecanismos. La presencia de un arco volcánico en el Eoceno en la parte oriental de la SMO indica que para este tiempo la placa Farallón ya había empezado a despegarse de la placa de Norteamérica. Este episodio volcánico coincide con un primer episodio de disminución de la velocidad de convergencia entre placa Farallón y Norteamérica entre 43 y 39 Ma (Norton, 1995). Por otro lado, el primer pulso ignimbrítico ( 32-28 Ma) coincide con un segundo periodo de disminución de la convergencia entre $\sim 33$ y $25 \mathrm{Ma}$ (Norton, 1995). La disminución de la velocidad de convergencia está relacionada con el arribo de corteza cada vez más joven y flotante en la paleotrinchera en la víspera del primer contacto entre la Dorsal de Pacífico Oriental con Norteamérica, ocurrido en el sur de California a los $\sim 28 \mathrm{Ma}$ (Atwater y Stock, 1989). La disminución de la velocidad de la subducción provoca, típicamente, el aumento de la inclinación del slab. Este, a su vez, induce una fuerte convección al "succionar" material astenosférico en la cuña del manto que va abriéndose. Lo anterior redunda en un aumento repentino de la fusión parcial del manto, que en tiempos cortos llegaría a generar un pulso ignimbrítico.
El segundo pulso ignimbrítico en la parte sur de la SMO ( 24-20 Ma) coincide, en buena medida, con la formación de los complejos de núcleo metamórfico (metamorphic core complexes), en la parte norte de la SMO. Durante este periodo la placa Farallón todavía subduce bajo México; sin embargo, la placa del Pacífico y Norteamérica ya han entrado en contacto más al norte, en California. La interacción entre las dos placas provoca la formación de una ventana astenosferica (slab window) frente a la zona de contacto (Atwater y Stock, 1998; Dickinson, 1997, 2002) donde la parte más profunda de la placa en subducción se despega de la parte más somera. Ferrari et al. (2002) proponen que la ruptura en la placa puede haberse propagado hacia el sur-sureste por efecto del aumento del slab pull en la parte todavía unida de la placa en subducción, de manera similar a lo observado en otras áreas del mundo (e. g., Wortel y Spakman, 2000). De esta forma material astenosférico habría fluido en la cuña del manto. En la parte norte de la SMO el flujo de material astenosférico, junto con las fuerzas aplicadas al límite de placa (e. g., Sonder y Jones, 1999), podrían haber provocado la notable extensión que formó a los metamorphic core complexes. En la parte sur de la SMO la ruptura del slab habría provocado un segundo evento de underplating con fusión parcial en la corteza y el subsecuente pulso ignimbrítico.

La revisión de la historia magmática y tectónica de la SMO presentada en este trabajo indica que esta provincia geológica es el resultado de la evolución del sistema de subducción Cretácico-Cenozoico de la placa Farallón por debajo de la placa Norteamericana. En particular, la SMO como una gran provincia ígnea silícica del OligocenoMioceno es el resultado de los eventos ocurridos en el ocaso de la subducción de la placa Farallón. La SMO comparte muchas características con otras grandes provincias silícicas (Tabla 1) que anteceden la formación de márgenes pasivos de tipo volcánico (volcanic rifted margins). En este sentido, los pulsos ignimbríticos de la SMO no constituyen el producto normal de un volcanismo de arco, sino pueden verse como los precursores de la ruptura litosférica que llevó a la formación del Golfo de California.

\section{Agradecimientos}

Parte de los resultados reportados en este trabajo para el norte y el sur de la SMO son producto de los proyectos CONACyT I29887 T (M. Valencia) y P-0152 T (L. Ferrari). El Centro de Geociencias, UNAM, apoyó trabajo de campo relacionado con este proyecto en Chihuahua, Zacatecas y Jalisco durante 2004. Agradecemos a la Sociedad Geológica Mexicana y los editores de este volumen por haber estimulado la realización de este trabajo, así como las revisiones exahustivas de Chris Henry y Ángel Nieto Samaniego y la revisión informal de Enrique González Torres y Gabriel Chávez Cabello que contribuyeron a mejorar la claridad del trabajo final. 


\section{Referencias bibliográficas}

Aguirre-Díaz, G. J., McDowell, F. W., 1991, The volcanic section at Nazas, Durango, Mexico, and the possibility of widespread Eocene volcanism within the Sierra Madre Occidental: Journal of Geophysical Research, 96, 13373-13388.

Aguirre-Díaz, G. J., McDowell, F. W., 1993, Nature and Timing of faulting and syn-extensional magmatism in the southern Basin and Range, central-eastern Durango, Mexico: Geological Society of America Bulletin, 105, 1435-1444.

Albrecht, A., Goldstein, S. L., 2000, Effects of basement composition and age on silicic magmas across an accreted terrane-Precambrian crust boundary, Sierra Madre Occidental, Mexico: Journal of South American Earth Sciences, 13, 255-273.

Alencaster, G., De Cserna, Z., 1961, Paleontología del Triásico Superior de Sonora Parte 1, Estratigrafía del Triásico Superior de la parte central del Estado de Sonora: Universidad Nacional Autónoma de México, Instituto de Geología, Paleontología Mexicana, 11, 18 p.

Almazán-Vázquez, E., 1989, El Cámbrico-Ordovícico de Arivechi, en la región centrooriental del Estado de Sonora: Universidad Nacional Autónoma de México, Revista del Instituto de Geología, 8, 58-66.

Alsina, D., Woodward, R. L., Snieder, R. K., 1996, Shear wave velocity structure in North America from large-scale waveform inversions of surface waves: Journal of Geophysical Research, 101, 1596915986.

Anderson, T. H., Silver, L. T., 1979, The role of the Mojave-Sonora megashear in the tectonic evolution of northern Sonora, en Anderson, T. H., y Roldán-Quintana, J. (eds.), Geology of northern Sonora: Guidebook-field trip No. 27, Annual meeting of the Geological Society of America, Universidad Nacional Autónoma de México, Instituto de Geología and the University of Pittsburgh, Pittsburgh, 59-68.

Anderson, T. H., Schmidt, V. A., 1983, The evolution of Middle America and the Gulf of Mexico-Caribbean Sea region during Mesozoic time: Geological Society of America Bulletin, 94, 941-966.

Anderson, T. H., Nourse, J. A., McKee, J. W., Steiner, M. B. (eds.), 2005, The Mojave-Sonora megashear hypothesis: development, assessment, and alternatives: Geological Society of America Special Paper 393, $693 \mathrm{p}$.

Annen, C., Sparks, R. S. J., 2002, Effects of repetitive emplacement of basaltic intrusions on thermal evolution and melt generation in the crust: Earth and Planetary Science Letters, 203, 937-955.

Aranda-Gómez, J. J., McDowell, F. W., 1998, Paleogene extension in the southern basin and range province of Mexico: Syndepositional tilting of Eocene red beds and Oligocene volcanic rocks in the Guanajuato mining district: International Geology Review, 40, 116-134.

Aranda-Gómez, J. J., Henry C. D., Luhr, J. F., McDowell, F. W., 1997, Cenozoic volcanism and tectonics in NW Mexico a transect across the Sierra Madre Occidental volcanic field and observations on extension related magmatism in the southern Basin and Range and Gulf of California tectonic provinces: en Aguirre-Díaz, G. J., Aranda-Gómez, J. J., Carrasco-Núñez, G., Ferrari, L. (eds.), Magmatism and tectonics in the central and northwestern Mexico -a selection of the 1997 IAVCEI General Assembly excursions, México, D. F.: Universidad Nacional Autónoma de México, Instituto de Geología, p. 41.

Aranda-Gómez, J. J., Luhr, J. F., Housh, T. B., Connor, C. B., Becker, T., Henry, C. D., 2003, Synextensional Pliocene-Pleistocene eruptive activity in the Camargo volcanic field, Chihuahua, México: Geological Society of America Bulletin, 115, 298-313.

Atwater, T., Stock, J. M., 1998, Pacific-North America plate tectonics of the Neogene southwestern United States: an update: International Geology Review, 40, 375-402.

Axen, G. J., Taylor W. J., Bartley J. M., 1993, Space-time patterns and tectonic controls of Tertiary extension and magmatism in the Great Basin of the Western United States: Geological Society of America Bulletin, 105, 56-76.

Bagby, W.C., Cameron, K.L., Cameron, M., 1981, Contrasting evolution of calc-alkalic volcanic and plutonic rocks of western Chihuahua, Mexico: Journal of Geophysical Research, 86, 10402-10410.
Barboza, S. A., Bergantz, G. W., 1998, Rheological transitions and the progress of melting crustal rocks: Earth and Planetary Science Letters, 158, 19-29.

Barra, F., Ruiz, J., Valencia, V. A., Ochoa-Landín, L, Chesley, J. T., Zürcher, L., Laramide porphyry $\mathrm{Cu}-\mathrm{Mo}$ mineralization in northern Mexico: Age constraints from Re-Os geochronology in molybdenites: Economic Geology, in press.

Bartolini, C., Morales, M., Damon, P., Shafiqullah, M., 1991, Geology and geochronology of the Sierra Lista Blanca, central Sonora, México: A progress report: Universidad de Sonora, Boletín del Departamento de Geología, 8, 1-5.

Bartolini, C., Damon, P., Shafiqullah, M., Morales, M., 1994, Geochronologic contributions to the Tertiary sedimentary volcanic sequences ("Baucarit Formation") in Sonora, Mexico, Geofísica Internacional, 33, 67-77.

Bartolini, C., Damon, P. E., Shafiqullah, M., Morales-Montaño, M., 1995, Geochronologic contributions to the Tertiary sedimentaryvolcanic sequences ("Baucarit Formation") in Sonora, Geofísica Internacional, 33, 67-77.

Barton, M. D., Staude, J-M.G., Zürcher, L., Megaw, P. K., 1995, Porphyry copper and other intrusion-related mineralization in Mexico, en Pierce, F.W. y Bolm, J.G. (eds.), Bootprints of the Cordillera: Arizona Geological Society Digest, 20, 487-524.

Bergantz, G. W., 1989, Underplating and partial melting implications for melt generation and extraction: Science 254, 1093-1095.

Bergantz, G. W., Dawes R., 1994, Aspects of magma generation and ascent in continental lithosphere, en Ryan, M. (ed.), Magmatic Systems: Academic, San Diego, 291E317.

Best, M. G., Christiansen, E. H., 1991, Limited extension during peak Tertiary volcanism, Great Basin of Nevada and Utah: Journal of Geophysical Research, 96, 13509-13528.

Bijwaard, H., W. Spakman, 2000, Non-linear global P-wave tomography by iterated linearized inversion: Geophysical Journal International, $141,71-82$.

Bird, P., 1984, Laramide crustal thickening event in the Rocky Mountain foreland and Great Plains: Tectonics, 3, 741-758.

Bird, P., 1998, Kinematic history of the Laramide orogeny in latitudes $35^{\circ}$ $-49^{\circ} \mathrm{N}$, western United States: Tectonics, 17, 780-801.

Bohannon, R. G., Parson, T., 1995, Tectonic implications of post-30 Ma Pacific and North American relative plate motions: Geological Society of America Bulletin, 107, 937-959.

Bonneau, M., 1970, Una nueva área cretácica fosilífera en el estado de Sinaloa: Boletín de la Sociedad Geológica Mexicana, 32, 159167.

Bonner, J. L., Herrin, E. T., 1999, Surface wave study of the Sierra Madre Occidental of northern Mexico: Bulletin of the Seismological Society of America, 89, 1323-1337.

Bryan, S.E., Constantine, A.E., Stephens, C.J., Ewart, A., Schön, R.W., Parianos, J., 1997, Early Cretaceous volcano-sedimentary successions along the eastern Australian continental margin: implications for the break-up of eastern Gondwana: Earth and Planetary Science Letters, 153, 85-102.

Bryan, S. E., Ewart, A., Stephens, C. J., Parianos, J., Downes, P. J., 2000, The Whitsunday Volcanic Province, central Queensland, Australia: Lithological and Stratigraphic investigations of a silicic-dominated large igneous province: Journal of Volcanology and Geothermal Research, 99, 55-78.

Bryan, S. E., Riley, T. R., Jerram, D. A., Leat, P. T., Stephens, C. J., 2002, Silicic volcanism: an undervalued component of large igneous provinces and volcanic rifted margins, en Menzies, M. A., Klemperer, S. L., Ebinger, C. J., Baker J. (eds.), Magmatic Rifted Margins: Geological Society of America Special Paper, 362, 99-120.

Calmus, T., Pérez-Segura, E., Roldán-Quintana, J., 1996, The $\mathrm{Pb}-\mathrm{Zn}$ ore deposits of San Felipe (Sonora, Mexico): an example of detached mineralization in the basin and range Province: Geofísica Internacional, 35, 115-124.

Cameron, K. L., Cameron, M., 1985, Rare earth element, ${ }^{87} \mathrm{Sr} /{ }^{86} \mathrm{Sr}$, and ${ }^{143} \mathrm{Nd} /{ }^{144} \mathrm{Nd}$ compositions of Cenozoic orogenic dacites from Baja California, northwestern Mexico, and adjacent West Texas; evidence 
for the predominance of a subcrustal component: Contributions to Mineralogy and Petrology, 91, 1-11.

Cameron, K. L., Hanson, G. N., 1982, Rare earth element evidence concerning the origin of voluminous mid-Tertiary rhyolitic ignimbrites and related volcanic rocks, SMO, Chihuahua, Mexico: Geochimica et Cosmochimica Acta, 46, 1489-1503.

Cameron, K. L., Robinson, J. V., 1990, Nd-Sr isotopic compositions of lower crustal xenoliths-evidence for the origin of mid-Tertiary felsic volcanics in Mexico: Comment: Contributions to Mineralogy and Petrology, 104, 609-618.

Cameron, M., Bagby, W. C., Cameron, K. L., 1980a, Petrogenesis of voluminous mid-Tertiary ignimbrites of the Sierra Madre Occidental: Contributions to Mineralogy and Petrology, 74, 271-84.

Cameron, K. L., Cameron, M., Bagby, W. C., Moll, E. J., Drake, R. E., 1980b, Petrologic characteristics of mid-Tertiary volcanic suites, Chihuahua: Geology, 8, 87-91.

Cameron, K. L., Cameron, M., y Barreiro, B., 1986, Origin of voluminous mid-Tertiary ignimbrites of the Batopilas region, Chihuahua: Implications for the formation of continental crust beneath the Sierra Madre Occidental: Geofisica Internacional, 25-1, 39-59.

Cameron, K. L., Nimz, G. J., Kuentz, D., Niemeyer, S., Gunn, S., 1989, Southern Cordilleran basaltic andesite suite, southern Chihuahua, Mexico; a link between Tertiary continental arc and flood basalt magmatism in North America: Journal of Geophysical Research, 94, 7817-7840.

Cameron, K. L., Robinson, J. V., Niemeyer, S., Nimz, G. J., Kuentz, D. C., Harmon, R. S., Bohlen, S. R., Collerson, K. D., 1992, Contrasting styles of Pre-Cenozoic and mid-Tertiary crustal evolution in northern Mexico: evidence from deep crustal xenoliths from La Olivina: Journal of Geophysical Research, 97, 17353-17376.

Campa, M. F., Coney, P. J., 1983, Tectono-stratigraphic terranes and mineral resource distribution in Mexico: Canadian Journal of Earth Sciences 20, 1040-1051.

Campos-Enríquez, J. O., Kerdan, T., Morán-Zenteno, D. J., UrrutiaFucugauchi, J., Sánchez-Castellanos, E., Alday-Cruz, R., 1994, Estructura de la litósfera superior a lo largo del Trópico de Cáncer: Geos, 12, 75-76.

Camprubí, A., Ferrari, L., Cosca, M., Cardellach, E., Canals, A., 2003, Age of epithermal deposits in Mexico: regional significance and links with the evolution of Tertiary volcanism: Economic Geology, 98, 1029-1037.

Carrillo-Martínez, M., 1971, Geología de la hoja San José de Gracia, Sinaloa (tesis profesional): México, D.F., Universidad Nacional Autónoma de México, 154 p.

Castillo-Hernández, D., Romero-Ríos, F., 1991, Estudio geológico-regional de Los Altos de Jalisco y El Bajío, Informe 02-91, Comisión Federal de Electricidad, Gerencia de Proyectos Geotermoeléctricos, Departamento de Exploración, Morelia, Michoacán, México, 35 p.

Cather, S. M., Dunbar, N. W., McDowell, F. W., McIntosh, W. C., Sholle, P. A., 2003, Early Oligocene global cooling, volcanic iron fertilization, and the ignimbrite flare-up of southwestern North America: Geological Society of America Abstracts with Programs, 35, 255.

Charlier, B. L. A., Peate, D. W., Wilson, C. J. N., Lowenstern, J. B., Storey, M., Brown, S. J. A., 2003, Crystallisation ages in coeval silicic magma bodies: ${ }^{238} \mathrm{U}-{ }^{230} \mathrm{Th}$ disequilibrium evidence from the Rotoiti and Earthquake Flat eruption deposits, Taupo Volcanic Zone, New Zealand: Earth and Planetary Science Letters, 206, 441-457.

Clark, K. F., Damon, P. E., Shafiquillah, M., Ponce, B. F., Cárdenas, D., 1981, Sección geológica-estructural a través de la parte sur de la Sierra Madre Occidental, entre Fresnillo y la costa de Nayarit: Asociación Ingenieros de Minas, Metalurgistas y Geólogos de México, Memoria Técnica XIV, 69-99.

Clemens, J. D., 2003, S-type granitic magmas-petrogenetic issues, models and evidence. Earth-Science Reviews, 61, 1-18.

Cochemé, J. J., Demant, A., 1991, Geology of the Yécora area, northern Sierra Madre Occidental, Mexico, en Pérez-Segura, E., JacquesAyala, C. (eds.), Studies of Sonoran geology: Geological Society of America Special Paper, 254, 81-94.

Coney, P. J., Campa, M. F., 1987, Lithotectonic Terrane Map of Mexico (west of the 91 $91^{\text {st }}$ meridian): Miscelaneous Field Studies, Map MF 1874-D.

Coney, P. J., Reynolds, S. J., 1977, Cordilleran Benioff zones: Nature, 270, 403-406.

Consejo de Recursos Minerales (CRM), 1997, Carta geológico-minera Zacatecas F13-6. Secretaria de Comercio y Fomento Industrial. 1 hoja.

Córdoba, D. A., 1963, Geología de la región entre Río Chico y Llano Grande, Municipio de Durango, Estado de Durango. Universidad Nacional Autónoma de México, Boletín del Instituto de Geología, 71, Parte 1, p. 21

Couch, R. W., Ness, G. E., Sánchez-Zamora, O., Calderón-Riveroll, G., Doguin, P., Plawman, T., Coperude, S., Huehn, B., Gumma, W., 1991, Gravity anomalies and crustal structure of the Gulf and Peninsular Province of the Californias, en: Dauphin, J. P., Simoneit, B. R. T., (eds.), The Gulf and the Peninsular Province of the Californias: American Association of Petroleum Geologists, Memoir, 47, 47-70.

Damon, P. E., Nieto-Obregón, J., Delgado-Argote, L., 1979, Un plegamiento neogénico en Nayarit y Jalisco y evolución geomórfica del río Grande de Santiago: Asociación Ingenieros de Minas, Metalurgistas y Geólogos de México, Memoria Técnica, XIII, 156-191.

Damon, P. E., Shafiqullah, M., Clark, K. F., 1981, Age trends of igneous activity in relation to metallogenesis in the southern Cordillera: Arizona Geological Society Digest, 14, 137-154.

Damon, P. E., Shafiqullah, M., Clark K., 1983, Geochronology of the porphyry copper deposits and related mineralization in Mexico: Canadian Journal of Earth Sciences, 20, 1052-1071

Damon, P. E., Shafiqullah, M., Roldán-Quintana, J., 1984, The Cordilleran Jurassic arc from Chiapas (southern Mexico) to Arizona: Geological Society of America Abstracts with Programs, 16, 482.

Davis, G. H., Coney, P. J. 1979, Geological development of metamorphic core complexes: Geology, 7, 120-124.

De Silva, S. L., 1989a, Altiplano-Puna volcanic complex of the central Andes: Geology, 17, 1102-1106.

De Silva, S. L., 1989b, Geochronology and stratigraphy of the ignimbrites from the $21^{\circ} 30^{\prime} \mathrm{S}$ to $23^{\circ} 30^{\prime} \mathrm{S}$ portion of the central Andes of northern Chile: Journal of Volcanology and Geothermal Research, 37, 93-131.

Dickinson, W. R., 1997, Tectonic implications of Cenozoic volcanism in coastal California: Geological Society of America Bulletin, 109, 936-954.

Dickinson, W. R., 2002, The Basin and Range Province as a composite extensional domain: Internacional Geology Review, 44, 1-38.

Dickinson, W. R., Lawton, T. F., 2001, Carboniferous to Cretaceous assembly and fragmentation of Mexico: Geological Society of America Bulletin, 113, 1142-1160.

Dickinson, W. R., Fiorillo, A. R., Hall, D. L., Monreal-Saavedra, R., Potochnik, A. R., Swift, P. N., 1989, Cretaceous strata of southern Arizona, en Jenney, J. P., Reynolds, S. J. (eds.), Geologic evolution of Arizona: Arizona Geological Society Digest, 17, 447-461.

Dorsey, R. J. Burns, B. A., 1994, Regional stratigraphy, sedimentology and tectonic significance of Oligocene-Miocene sedimentary and volcanic rocks, northern Baja California, Mexico: Sedimentary Geology, 88, 231-251.

Ducea, M. N., 2002, Constraints on the bulk composition and root foundering rates of continental arcs-a California arc perspective: Journal of Geophysical Research, 107, 2304, DOI: 10.1029/2001JB000643.

Eguiluz de Antuñano, S., Aranda-García, M., Marrett R., 2000, Tectónica de la Sierra Madre Oriental, México: Boletín de la Sociedad Geológica Mexicana, 53, 1-26.

English, J., Johnston, S. T., Wang, K., 2003, Thermal modelling of the Laramide orogeny: testing the flat slab subduction hypothesis: Earth and Planetary Science Letters, 214, 619-632.

Enríquez, E., Rivera, R., 2001, Timing of magmatic and hydrothermal activity in the San Dimas District, Durango, Mexico, en New Mines and Mineral Discoveries in Mexico and Central America, Society of Economic Geologists Special Publication, 8, 33-38.

Ewart, A., Milner, S. C., Armstrong, R. A., Duncan, A. R., 1998, Etendeka volcanism of the Goboboseb Mountains and Messum Igneous 
Complex, Namibia. Part II: Voluminous quartz latite volcanism of the Awahab magma system: Journal of Petrology, 39, 227-253.

Ferrari, L., 1995, Miocene shearing along the northern boundary of the Jalisco block and the opening of the southern Gulf of California, Geology, 23, 751-754.

Ferrari, L., Rosas-Elguera, J., 2000, Late Miocene to Quaternary extension at the northern boundary of the Jalisco block, western Mexico: the Tepic-Zacoalco rift revised: Geological Society America Special Paper 334, 41-64.

Ferrari, L., López-Martínez, M., Aguirre-Díaz, G., Carrasco-Núñez, G., 1999, Space-time patterns of Cenozoic arc volcanism in central Mexico: from the Sierra Madre Occidental to the Mexican Volcanic Belt: Geology, 27, 303-306.

Ferrari, L., Pasquaré, G., Venegas, S., Romero, F., 2000, Geology of the western Mexican Volcanic Belt and adjacent Sierra Madre Occidental and Jalisco block: Geological Society of America Special Paper, 334, 65-84.

Ferrari, L., López-Martínez, M., Rosas-Elguera, J., 2002, Ignimbrite flareup and deformation in the southern Sierra Madre Occidental, western Mexico-implications for the late subduction history of the Farallon Plate: Tectonics, 21, 10.1029/2001TC001302.

Ferrari, L., Petrone, C. M., Francalanci, L., Tagami, T., Eguchi, M., Conticelli, S., Manetti, P. Venegas-Salgado, S., 2003, Geology of the San Pedro-Ceboruco graben, western Trans-Mexican Volcanic Belt: Revista Mexicana de Ciencias Geológicas, 20, 165-181.

Ferriz, H., 1981, Geología de la caldera de San Marcos, Chihuahua: Universidad Nacional Autónoma de México, Revista del Instituto de Geología, 5, 65-79.

Fix, J. E., 1975, The crust and upper mantle of central Mexico: Geophysical Journal of the Royal Astronomical Society, 43, 453-499.

Gans, P. B., 1997, Large-magnitude Oligo-Miocene extension in southern Sonora: Implications for the tectonic evolution of northwest Mexico: Tectonics, 16, 388-408.

Gans, P. B., Bohrson, W. A., 1997, Suppression of volcanism during rapid extension in the Basin and Range Province, United States: Science, 279, 66-68

Gans, P. B., Mahood, G. A., Schermer, E. R., 1989, Synextensional magmatism in the Basin and Range Province-a case study from the eastern Great Basin: Geological Society of America Special Paper, 233, 1-53.

Gans, P. B., MacMillan, I., Roldán-Quintana, J., 2003, Late Miocene (Proto Gulf) extension and magmatism on the Sonoran margin: EOS, Transactions AGU, 84(46), Fall Meet. Suppl., F1405.

Gastil, R. G., Krummenacher, D., 1977, Reconnaissance geology of coastal Sonora between Puerto Lobos and Bahía de Kino: Geological Society of America Bulletin, 88, 189-198.

Gastil, R. G., Krummenacher D., Jensky W. E., 1978, Reconnaissance geology of west-central Nayarit, Mexico: Geological Society of America, text to accompany Map and Chart Series, Map MC-24.

Gastil, R. G., Krummenacher, D., Minch, J., 1979, The record of Cenozoic volcanism around the Gulf of California: Geological Society of America Bulletin, 90, 839-857.

Gastil, R. G., Miller, R., Anderson, P., Crocker, J., Campbell, M., Buch, P., Lothringer, C., Leier Englehardt, P., DeLattre, M., Hoobs, J., Roldán-Quintana, J., 1991b, The relation between the Paleozoic strata on opposite sides of the Gulf of California, en Pérez-Segura, E., Jacques-Ayala, C. (eds.), Studies of Sonoran geology: Geological Society of America Special Paper 254, 7-18.

Glazner, A. F., Ussler III, W., 1989, Crustal extension, crustal density, and the evolution of Cenozoic magmatism and the Basin and Range of the western United States: Journal of Geophysical Research, 94, 7952-7960.

Goes, S., van der Lee, S., 2002, Thermal structure of the North American uppermost mantle inferred from seismic tomography, Journal of Geophysical Research, 107, DOI: 10.1029/2000JB000049.

Gomberg, J. S., Priestley, K. F., Masters, G., Brune, J., 1988, The structure of the crust and upper mantle in northern Mexico: Geophysical Journal, 94, 1-20.

González-León, C. M., 1994, Early Cretaceous tectono-sedimentary evolution on the southwestern margin of the Bisbee basin: Revista
Mexicana de Ciencias Geológicas, 11, 139-146.

González-León, C. M., 1997, Sequence stratigraphy and paleogeographic setting of the Antimonio Formation (Late Permian-Early Jurassic), Sonora, Mexico: Revista Mexicana de Ciencias Geológicas 14, 136-148

González-León, C., Lawton, T. F., 1995, Stratigraphy, depositional environments, and origin of the Cabullona Basin, northeastern, en Jacques-Ayala, C., González-León, C. M., Roldán-Quintana, J. (eds.), Studies on the Mesozoic of Sonora and adjacent areas: Boulder, Colorado, Geological Society of America, Special Paper, 301, 121-142.

González-León, C. M., McIntosh, W. C., Lozano-Santacruz, R., ValenciaMoreno, M., Amaya-Martínez, R., Rodríguez-Castaneda, J. L., 2000, Cretaceous and Tertiary sedimentary, magmatic, and tectonic evolution of north-central Sonora (Arizpe and Bacanuchi Quadrangles), northwest Mexico: Geological Society of America Bulletin, 112, 600-610.

Graham, I. J., Cole, J. W., Briggs, R. M., Gamble, J. A., Smith, I. E. M., 1995, Petrology and petrogenesis of volcanic rocks from Taupo Volcanic Zone: a review: Journal of Volcanology and Geothermal Research, 68, 59-87.

Grajales-Nishimura, J. M., Terrel, D. J., Damon, P. E., 1992, Evidencias de la prolongación del arco magmático cordillerano del Triásico Tardío-Jurásico en Chihuahua, Durango y Coahuila: Boletín de la Asociación Mexican de Geólogos Petroleros, 42(2), 1-18.

Grand, S. P., 1994, Mantle shear structure beneath the Americas and surrounding oceans: Journal of Geophysical Research, 99, 1159111621.

Hausback, B. P., 1984, Cenozoic volcanic and tectonic evolution of Baja California Sur, Mexico, en Frizzell, A. (ed.), Geology of the Baja Peninsula: Society of Economic Paleontologists and Mineralogists Special Paper, 39, 219-236.

Haenggi, W. T., 2002, Tectonic history of the Chihuahua trough, Mexico and adjacent USA, Part II: Mesozoic and Cenozoic: Boletín de la Sociedad Geológica Mexicana, 54, 38-94.

Henry, C. D., 1986, East-norteast trending structures in western México: evidence for oblique convergence in the late Mesozoic: Geology, 14, 314-317.

Henry, C. D., 1989, Late Cenozoic Basin and Range structure in western Mexico adjacent to the Gulf of California: Geological Society of America Bulletin, 101, 1147-1156.

Henry, C. D., Aranda-Gómez, J. J., 2000, Plate interactions control middlelate Miocene proto-Gulf and Basin and Range extension in the southern Basin and Range: Tectonophysics, 318, 1-26.

Henry, C. D., Fredrikson, G., 1987, Geology of part of southern Sinaloa, Mexico, adjacent to the Gulf of California: Geological Society of America, Maps and Chart serie, MCH 063, 1 sheet, $14 \mathrm{p}$.

Henry, C. D., McDowell, F. W., Silver, L. T., 2003, Geology and geochronology of the granitic batholithic complex, Sinaloa, México: Implications for Cordilleran magmatism and tectonics: Geological Society of America Special Paper, 374, 237-274.

Horner, H., 1998, Structural Geology and Exploration in the San Dimas District, Durango, Mexico -An Alternative Geologic Model: Faculty of Natural Sciences, Universidad de Salzburg, $120 \mathrm{p}$.

Horner, J. T., Enríquez, E., 1999, Epithermal precious metal mineralization in a strike-slip corridor: the San Dimas district, Durango, Mexico: Economic Geology, 94, 1375-1380.

Huppert, H. E., Sparks, R. S. J., 1988, The generation of granitic magmas by intrusion of basalt into continental crust: Journal of Petrology, 29, 599-642

Humphreys, E. D., 1995, Post-Laramide removal of the Farallon slab, western United States: Geology, 23, 987-990.

Humphreys, E. D, Hessler, E., Dueker, K., Erslev, E., Farmer, G.L., Atwater, T., 2003, How Laramide-age hydration of North America by the Farallon slab controlled subsequent activity in the western U.S.: International Geology Review, 45, 575-595.

Iriondo, A., Kunk, M. J., Winick, J. A., Consejo de Recursos Minerales, $2003,{ }^{40} \mathrm{Ar} /{ }^{39} \mathrm{Ar}$ dating studies of minerals and rocks in various areas in Mexico: USGS/CRM Scientific Collaboration (Part I). U.S.G.S. Open File Report 2003-020, online edition, 79 p. 
Iriondo, A., Premo, W. R., Martínez-Torres, L. M., Budahn, J. R., Atkinson, W .W., Siems, D. F., Guarás-González, B., 2004a, Isotopic, geochemical, and temporal characterization of Proterozoic basement rocks in the Quitovac region, northwestern Sonora, Mexico: Implications for the reconstruction of the southwestern margin of Laurentia: Geological Society of America Bulletin, 116, 154-170.

Iriondo, A., Kunk, M. J., Winick, J. A., Consejo de Recursos Minerales, $2004 \mathrm{~b},{ }^{40} \mathrm{Ar} /{ }^{39} \mathrm{Ar}$ dating studies of minerals and rocks in various areas in Mexico: USGS/CRM Scientific Collaboration (Part II). U.S.G.S. Open File Report, 2004-1444, online edition.

Jacques-Ayala, C., 1995, Paleogeography and provenance of the Lower Cretaceous Bisbee Group in the Caborca-Santa Ana area, northwestern Sonora: Geological Society of America Special Paper, 301, 79-98.

Johnson, C. M., 1991, Large-scale crust formation and lithosphere modification beneath Middle to Late Cenozoic calderas and volcanic fields, western North America: Journal of Geophysical Research, 96, 13845-13507.

Jull, M., Kelemen, P. B., 2001, On the conditions for lower crustal convective instability: Journal of Geophysical Research, 106, 6423-6446.

Kay, R. W., Mahlburg-Kay, S., 1991, Creation and destruction of lower continental crust: International Journal of Earth Sciences, 80, 259-278.

Kay, R. W., Mahlburg-Kay, S., Arculus, R. J., 1992, Magma genesis and crustal processing, en Fountain, D. M., Arculus, R., Kay, R. W. (eds.), Continental Lower Crust: Developments in Geotectonics, $23,423-445$.

Keller, P., Bockoven, N., McDowell, F. W., 1982, Tertiary volcanic history of the Sierra del Gallego area, Chihuahua, Mexico: Geological Society of America Bulletin, 93, 303-314.

King, R. E., 1939, Geologic reconnaissance in the northern Sierra Madre Occidental of Mexico: Geological Society of America Bulletin, $50,1625-1722$

Klemperer, S. L., 1989, Deep seismic reflection profiling and the growth of the continental crust: Tectonophysics, 161, 233-244.

Lang, B., Steinitz, G., Sawkins, F. J., Simmons, S. F., 1988, K-Ar Age studies in the Fresnillo Silver District, Zacatecas, Mexico: Economic Geology, 83, 1642-1646.

Lange, R., Carmichael, I. S. E., 1991, A potassic volcanic front in western Mexico: lamprophyric and related lavas of San Sebastian: Geological Society of America Bulletin, 103, 928-940.

Langenheim, V. E., Jachen, R. C., 2003, Crustal structure of the Peninsular Ranges batholith from magnetic data: Implications for Gulf of California rifting: Geophysical Research Letters, 30, 1597, DOI:10.1029/2003GL017159.

Lanphere, M. A., Cameron, K. L., Cameron, M., 1980, Sr isotopic geochemistry of voluminous rhyolitic ignimbrites and related rocks, Batopilas area, western Mexico: Nature, 286, 594-596.

López-Ramos, E., 1995, Carta geológica de los estados de Jalisco y Aguascalientes, escala 1:750000, con resumen: Universidad Nacional Autónoma de México, Instituto de Geología, Cartas Geológicas Estatales.

Lucas, S. G., Kues, B. S., y González-León, C. M., 2005, Paleontology of the Upper Cretaceous Cabullona Group, northeastern Sonora: Geological Society of America Special Paper, 301, 143-165.

Luhr, J. F., Pier, J. G., Aranda-Gómez, J. J., Podosek, F. A., 1995, Crustal contamination in early Basin-and-Range hawaiites of the Los Encinos Volcanic Field, central Mexico: Contribution to Mineralogy and Petrology, 118, 321-339.

Luhr, J. F., Henry, C. D, Housh, T. B., Aranda-Gómez, J. J., McIntosh, W. C., 2001, Early extension and associated mafic alkalic volcanism from the southern Basin and Range Province: Geology and petrology of the Rodeo and Nazas volcanic fields, Durango (Mexico): Geological Society of America Bulletin, 113, 760-773.

Lyons, J. I., 1988, Geology and ore deposits of the Bolaños silver district, Jalisco, Mexico: Economic Geology, 83, 1560-1582.

MacMillan, I., Gans, P. B., Roldán-Quintana, J., 2003, Voluminous midMiocene silicic volcanism and rapid extension in the Sierra Libre, Sonora, Mexico: Geological Society of America, Abstracts with
Programs, 35, 26.

Magonthier, M. C., 1988, Distinctive rhyolite suites in the mid-Tertiary ignimbritic complex of the Sierra Madre Occidental, western Mexico: Bulletin de la Société Géologique de France, Huitieme Serie, 4, 57-68.

Mauger, R. L., 1981, Geology and petrology of the Calera-del Nido block, Chihuahua Mexico, en Goodell, P. C. (ed.), Uranium in volcanic and vocaniclastics rocks: American Association of Petroleum Geologists, Studies in Geology, 13, 202-242.

Mauger, R. L., 1983, Geologic map of the Majalca-Punta de Agua area, central Chihuahua, Mexico, en Clark, K.F., y Goodell, P.C. (eds.), Geology and mineral resources of north-central Chihuahua: Guidebook of the El Paso Geological Society field conference, 169-174.

Megaw, P. K. M., 1986, Geology and geological history of the Santa Eulalia Mining District, Chihuahua, Mexico, en Clark, K.F., y otros (eds.), Field excursion guidebook: Society of Economic Geology, 213-232.

Megaw, P. K. M., 1990, Geology and geochemistry of the Santa Eulalia mining district, Chihuahua, Mexico: Ph. D. Thesis, University of Arizona, Tucson, Arizona, 463 p.

McDowell, F. W., Clabaugh, S. E., 1979, Ignimbrites of the Sierra Madre Occidental and their relation to the tectonic history of western Mexico: Geological Society of America Special Paper, 180, 113124.

McDowell, F. W., Keizer, R. P., 1977, Timing of mid-Tertiary volcanism in the Sierra Madre Occidental between Durango City and Mazatlán, Mexico: Geological Society of America Bulletin, 88, 1479-1487.

McDowell, F. W., Maugher, R. L., 1994, K-Ar and U-Pb zircon chronology of Late Cretaceous and Tertiary magmatism in central Chihuahua State, Mexico: Geological Society of America Bulletin, 106, 118132.

McDowell, F. W., Roldán-Quintana, J., Amaya-Martínez, R., 1997, Interrelationship of sedimentary and volcanic deposits associated with Tertiary extension in Sonora, Mexico, Geological Society of America Bulletin, 109, 1349-1360.

McDowell, F. W., Housh, T. B., Wark, D. A., 1999, Nature of crust beneath west-central Chihuahua, Mexico, based upon $\mathrm{Sr}, \mathrm{Nd}$, and $\mathrm{Pb}$ isotopic compositions at the Tómochic volcanic center: Geological Society of America Bulletin, 111, 823-830.

McDowell, F. W., Roldán-Quintana, J., Connelly, J. N., 2001, Duration of Late Cretaceous-early Tertiary magmatism in east-central Sonora, Mexico: Geological Society of America Bulletin, 113, 521-531.

McKee, J. W., Jones, N. W., Anderson, T. H., 1988, Las Delicias basin: a record of late Paleozoic arc volcanism in northeastern Mexico: Geology, 16, 37-40.

Meissner, R. O., Mooney, W. D., 1998, Weakness of the lower continental crust; a condition for delamination, uplift, and escape: Tectonophysics, 296, 47-60.

Miller, R. B., Paterson S. R., 2001, Influence of lithological heterogeneity, mechanical anisotropy, and magmatism on the rheology of an arc, North Cascades, Washington: Tectonophysics, 342, 351-370.

Miranda-Gasca, M. A., De Jong, K. A., 1992, The Magdalena mid-Tertiary extensional basin, en Clark, K. F., Roldán-Quintana, J., y Schmidt, R. H. (eds.), Geology and mineral resources of the northern Sierra Madre Occidental, México: Guidebook of the El Paso Geological Society field conference, 377-384.

Miranda-Gasca, M. A., Gómez-Caballero, J. A., Eastoe, C. J., 1998, Borate deposits of Northern Sonora, Mexico - Stratigraphy, tectonics, stable isotopes, and fluid inclusions: Economic Geology, 93, 510-523.

Montigny, R., Demant, A., Delpretti, P., Piguet, P., Cocheme, J. J., 1987, Chronologie K/Ar de secuences volcanique tertiaires du nord de la Sierra Madre Occidental, Mexique: Académie des Sciences Comptes Rendus, Paris, D, 304, 987-992.

Mooney, W. D., Laske G., Masters, G. T., 1998, Crust 5.1: a global crustal model at $5 \times 5$ degrees: Journal of Geophysical Research, $103,727-747$.

Moore, G., Marone, C., Carmichael, I. S. E., Renne, P., 1994, Basaltic volcanism and extension near the intersection of the Sierra Madre volcanic province and the Mexican Volcanic Belt: Geologial Society 
America Bulletin, 106, 383-394.

Mora-Álvarez, G., McDowell, F. W., 2000, Miocene volcanism during late subduction and early rifting in the Sierra Santa Ursula of Western Sonora, Mexico, en Stock, J. M., Delgado-Granados, H., AguirreDíaz, G. (eds.), Cenozoic tectonics and volcanism of Mexico: Geological Society of America Special Paper, 334, 123-141.

Mora-Klepeis, G., McDowell, F. W., 2004, Late Miocene calc-alkalic volcanism in northwestern Mexico: an expression of rift or subduction-related magmatism?: Journal of South American Earth Science, 17, 297-310.

Morales-Montaño., M., Bartolini, C., Damon, P. E., Shafiqullah, M., 1990, K-Ar dating, stratigraphy, and extensional deformation of Sierra Lista Blanca, Central Sonora, Mexico: Geological Society of America Abstracts with Programs, 22, A364.

Mujica-Mondragón, M. R., Albarrán, J. J., 1983, Estudio petrogenético de las rocas ígneas y metamórficas del Altiplano Mexicano: Instituto Mexicano del Petróleo, Subdirección Técnica de Exploración, Proyecto C-1156 (reporte interno), $83 \mathrm{p}$.

Mullan, H. S., 1978, Evolution of part of the Nevada orogen in northwest Mexico: Geological Society of America Bulletin, 111, 347-363.

Nourse, J. A., Anderson, T. H., Silver, L. T., 1994, Tertiary metamorphic core complexes in Sonora, northwestern Mexico: Tectonics, 13, 359-366.

Nieto-Obregón, J., Delgado-Argote, L., Damon, P. E., 1981, Relaciones petrológicas y geocronológicas del magmatismo de la Sierra Madre Occidental el Eje Neovolcánico en Nayarit, Jalisco y Zacatecas: Asocociación de Ingenieros de Minas, Metalurgistas y Geólogos de México, Memoria Técnica, XIV, 327-361.

Nieto-Obregón, J., Delgado-Argote, L., Damon, P. E., 1985, Geochronologic, petrologic, and structural data related to large morphologic features between the Sierra Madre Occidental and the Mexican volcanic belt: Geofísica Internacional, 24, 623-663.

Nieto-Samaniego, A. F., Macías-Romo, C., Alaniz-Álvarez, S. A., 1996, Nuevas edades isotópicas de la cubierta volcánica cenozoica de la parte meridional de la Mesa Central, México: Revista Mexicana de Ciencias Geológicas, 13, 117-122.

Nieto-Samaniego, A. F., Ferrari, L., Alaniz-Álvarez, S. A., LabartheHernández, G., Rosas-Elguera, J., 1999, Variation of Cenozoic extension and volcanism across the southern Sierra Madre Occidental volcanic province, Mexico: Geological Society of America Bulletin, 111, 347-363.

Nieto-Samaniego, A. F., Alaniz-Álvarez, S. A., Camprubí i Cano, A., 2005, La Mesa Central de México: estratigrafía, estructura y evolución tectónica cenozoica: Boletín de la Sociedad Geológica Mexicana, 57(3), 285-318.

Norton, I., 1995, Plate motions in the North Pacific: The 43 Ma nonevent: Tectonics, 14, 1080-1094, DOI: 10.1029/95TC01256.

Orozco-Esquivel, M. T., Nieto-Samaniego, A. F., Alaniz-Álvarez, S. A., 2002, Origin of rhyolitic lavas in the Mesa Central, Mexico, by crustal melting related to extension: Journal of Volcanology and Geothermal Research, 118, 37-56.

Ortega-Gutiérrez, F., Mitre-Salazar, L. M., Roldán-Quintana, J., ArandaGómez, J. J., Morán-Zenteno, D. J., Alaniz-Álvarez S. A., NietoSamaniego, A. F., 1992, Carta geológica de la Republica Mexicana: Universidad Nacional Autónoma de México, escala 1:2 000 000, 1 carta, $74 \mathrm{p}$.

Ortega-Gutiérrez, F., Sed1ock, R. L., Speed, R. C., 1994, Phanerozoic tectonic evolution of Mexico, en Speed, R. C. (ed.), Phanerozoic evolution of North American continent-ocean transitions: Geological Society of America, Decade of North American Geology Summary Volume to accompany the DNAG Continent-Ocean Transects Series, 265-306.

Oskin, M., Stock, J. M, Martín-Barajas, A., 2001, Rapid localization of Pacific-North America plate motion in the Gulf of California: Geology, 29, 459-462.

Oskin, M., Iriondo, A., Nourse, J., 2003, Geologic reconnaissance and geochronology of proto-Gulf of California extension, western Sonora: Geological Society of America Abstracts with Programs, $99^{\text {th }}$ Cordilleran Meeting.

Pankhurst, R. J., Rapela, C. R., 1995, Production of Jurassic rhyolite by anatexis of the lower crust of Patagonia: Earth and Planetary Science Letters, 134, 25-36.

Pankhurst, R. J., Leat, P. T., Sruoga, P., Rapela, C. W., Márquez, M., Storey, B.C., Riley, T. R., 1998, The Chon Aike silicic igneous province of Patagonia and related rocks in Antarctica: a silicic large igneous province: Journal of Volcanology and Geothermal Research, 81, 113-136.

Pankhurst, R. J., Riley, T. R., Fanning, C. M., Kelley, S. R., 2000, Episodic silicic volcanism along the proto-Pacific margin of Patagonia and the Antarctic Peninsula: plume and subduction influences associated with the break-up of Gondwana. Journal of Petrology, 41, 605-625.

Paterson, B. A., Stephens, W. E., Rogers, G., Williams, I. S., Hinton, R. W., Herd D. A., 1992, The nature of zircon inheritance in two granitic plutons: Transactions of the Royal Society of Edinburgh: Earth Sciences, 83, 459-471.

Patiño-Douce, A. E., 2000, What do experiments tell us about the relative contributions of crust and mantle to the origin of granitic magmas? en Castro, A., Fernández, C., Vigneresse, J. L. (eds.), Understanding granites: Integrating New and Classical Techniques: Geological Society of London Special Publication, 168, 55EE75.

Pasquarè, G., Ferrari, L., Garduño, V. H., Tibaldi, A., Vezzoli, L., 1991, Geological map of the central sector of Mexican Volcanic Belt, States of Guanajuato and Michoacan: Geological Society of America Map and Chart series, $\mathrm{MCH} 072,1$ sheet, $20 \mathrm{p}$.

Paz-Moreno, F., Demant, A., Cochemé, J. J., Dostal, J., Montigny, R., 2003, The Quaternary Moctezuma volcanic field: A tholeiitic to alkali basaltic episode in the central Sonoran Basin and Range Province, Mexico: Geological Society of America Special Paper, 374, 439-455.

Perry, F. V., DePaolo, D. J., Baldridge, W. S., 1993, Neodymium isotopic evidence for decreasing crustal contributions to Cenozoic ignimbrites of the western United States: implications for the thermal evolution of the Cordilleran crust: Geological Society of America Bulletin, $105,872-882$.

Persaud, P., 2003, Images of early continental breakup in and around the Gulf of California and the role of basal shear in producing wide plate boundaries. Ph.D. thesis, California Institute of Technology, $144 \mathrm{p}$.

Petford, N., Gallagher, K., 2001, Partial melting of mafic (amphibolitic) lower crust by periodic influx of basaltic magma: Earth and Planetary Science Letters, 193, 483-499.

Piguet, P., 1987, Contribution a l'etude de la Sierra Madre Occidental (Mexique): la séquence volcanoque tertiaire de la transversale Moctezuma-La Norteña. Ph.D. thesis, Universite de Droit. d'Économie et des Sciences D'Aix-Marseille, 300p.

Ponce, B., Clark, K., 1988, The Zacatecas mining district-a Tertiary caldera complex associated with precious and base metal mineralization: Economic Geology, 83, 1668-1682.

Poole, F. G., Madrid, R. J., Oliva-Becerril, J. F., 1991, Geological setting and origin of stratiform barite in central Sonora, Mexico, en Raines, G. L., Lisle, R. E., Schafer, R. W., Wilkinson, W. H. (eds.), Geology and ore deposits of the Great Basin: Geological Society of Nevada, 1, 517-522.

Poole, F. G., Stewart, J. H., Berry, W. B. N., Harris, A. G., Repetski, J. E., Madrid, R. J., Ketner, K. B., Carter, C., Morales-Ramírez, J. M., 1995, Ordovician ocean-basin rocks of Sonora, Mexico, en Cooper, J. D., Droser, M. L., Finney, S. C. (eds.), Ordovician Odyssey: Short Papers for the Seventh International Symposium on the Ordovician System, Las Vegas: Fullerton, California: Pacific Section Society for Sedimentary Geology (SEPM), book no. 77, 277-284.

Righter, K., Carmichael, I. S. E., Becker, T., 1995, Pliocene-Quaternary faulting and volcanism at the intersection of the Gulf of California and the Mexican Volcanic Belt: Geological Society of America Bulletin, 107, 612-627.

Riley, T. R., Leat, P. T., Pankhurst, R. J., Harris, C., 2001, Origins of large volume rhyolitic volcanism in the Antarctic Peninsula and Patagonia by crustal melting: Journal of Petrology, 42, 1043-1065.

Ritsema, J., Van Heijst, H., Woodhouse, J., 2004, Global transition zone tomography: Journal of Geophysical Research, 109, DOI: 
10.1029/2003JB002610

Ritzwoller, M. H., Shapiro, N. M., Barmin, M. P., Levshin, A., 2002, Global surface wave diffraction tomography: Journal of Geophysical Research, 107, B02302, 2335, DOI:0.1029/2002JB001777.

Rodríguez-Castañeda, J. L., 1996, Late Jurassic and mid-Tertiary brittleductil deformation in the Opodepe region, Sonora, México: Revista Mexicana de Ciencias Geológicas, 13, 1-9.

Roldán-Quintana, J., 1991, Geology and chemical composition of El Jaralito and Aconchi batholiths in east-central Sonora, en PérezSegura, E., y Jacques-Ayala, C. (eds.), Studies of Sonoran geology: Geological Society of America, Special Paper, 254, 19-36.

Roldán-Quintana, J., Mora-Klepeis, G., Calmus, T., Valencia-Moreno, M., Lozano-Santacruz, R., 2004, El graben de Empalme, Sonora, México: magmatismo y tectónica extensional asociados a la ruptura inicial del Golfo de California: Revista Mexicana de Ciencias Geológicas, 21, 320-334.

Rosas-Elguera, J., Ferrari, L., López-Martínez, M., Urrutia-Fucugauchi, J., 1997, Stratigraphy and tectonics of the Guadalajara region and the triple junction area, western Mexico: International Geology Review, 39, 125-140.

Rosas-Elguera, J., Alva-Valdivia, L. M., Goguitchaichvili, A., UrrutiaFucugauchi, J., 2003, Counterclockwise rotation of the Michoacan block: Implications for the tectonics of western Mexico: International Geology Review, 45, 814-826.

Rossotti, A., Ferrari, L., López-Martínez, M., Rosas-Elguera, J., 2002, Geology of the boundary between the Sierra Madre Occidental and the Trans-Mexican Volcanic Belt in the Guadalajara region, western Mexico: Revista Mexicana de Ciencias Geológicas, 19, 1-15.

Rudnick, R. L., Cameron, K. L., 1991, Age diversity of the deep crust in northern Mexico: Geology, 19, 1197-1200.

Ruiz, J., Patchett, P. J., Arculus, R. J., 1988a, Nd-Sr isotope composition of lower crustal xenoliths: evidence for the origin of mid-Tertiary felsic volcanics in Mexico: Contributions to Mineralogy and Petrology, 99, 36-43.

Ruiz J., Patchett, P. J., Ortega-Gutiérrez, F., 1988b, Proterozoic and Phanerozoic basement terranes of Mexico from Nd isotopic studies: Geological Society of America Bulletin, 100, 274-281.

Ruiz, J., Patchett, P. J., Arculus, R. J., 1990, Reply to "Comments on Nd$\mathrm{Sr}$ isotopic compositions of lower crustal xenoliths -Evidence for the origin of mid-Tertiary volcanics in Mexico", by K.L. Cameron and J.V. Robinson: Contributions to Mineralogy and Petrology, 104, 615-618.

Saleeby, J., 2003, Segmentation of the Laramide Slab - evidence from the southern Sierra Nevada region: Geological Society of America Bulletin, 115, 655-668.

Sawlan, M. G., 1991, Magmatic evolution of the Gulf of California rift, en Dauphin, J. P. Simoneit, B. A. (eds.), The Gulf and Peninsular Province of the Californias: American Association of Petroleum Geologists Memoir, 47, 301-369.

Scheubel, F. R., Clark, K. F., Porter, E. W., 1988, Geology, tectonic environment, structural controls in the San Martin de Bolaños District, Jalisco: Economic Geology, 83, 1703-1720.

Sedlock, R., Ortega-Gutiérrez F., Speed, R. C., 1993, Tectonostratigraphic terranes and tectonic evolution of Mexico: Geological Society of America Special Paper, 278, 153 p.

Silver, L. T., Anderson, T. H., 1974, Possible left-lateral early to middle Mesozoic disruption of the southwestern North America craton margin: Geological Society of America Abstracts with Programs, 6, 955-956.

Smith, J. A., Luhr, J. F., Pier, J. G., Aranda-Gómez, J. J., 1989, Extensionrelated magmatism of the Durango volcanic field, Durango, Mexico: Geological Society of America Abstracts with Programs, 21, A201.

Smith, R. D., Cameron, K. L., McDowell, F. W., Niemeyer, S., Sampson, D. E., 1996, Generation of voluminous silicic magmas and formation of mid-Cenozoic crust beneath north-central Mexico-evidence from ignimbrites, associated lavas, deep crustal granulites, and mantle pyroxenites: Contributions to Mineralogy and Petrology, 123, 375-389.

Solé, J., Salinas-Prieto, J. C., González-Torres, E., Cendejas-Cruz, J. E.,
2006, Edades K-Ar de 54 rocas ígneas y metamórficas del Occidente, Centro y Sur de México: Revista Mexicana de Ciencias Geológicas, en prensa.

Sonder, L. J., Jones, C. H., 1999, Western United States extension: How the West was widened: Annual Review of Earth and Planetary Sciences, 27, 417-462.

Staude, J. M., Barton, M. D., 2001, Jurassic to Holocene tectonics, magmatism, and metallogeny of northwestern Mexico: Geological Society of America Bulletin, 113, 1357-1374.

Stewart, J. H., 1988, Latest Proterozoic and Paleozoic southern margin of North America and the accretion of Mexico: Geology, 16, 186-189.

Stewart J. H., 1998, Regional characteristics, tilt domains, and extensional history of the later Cenozoic Basin and Range Province, western North America, en Faulds J. E. y Stewart, J. H. (eds.), Accommodation Zones and Transfer Zones: The Regional Segmentation of the Basin and Range Province: Geological Society of America Special Paper, 323, 47-74.

Stewart, J. H., Poole F. G., 2002, Inventory of Neoproterozoic and Paleozoic strata in Sonora, Mexico: U.S. Geological Survey OpenFile Report, 02-97, $50 \mathrm{p}$.

Stewart, J. H., Roldán-Quintana, J., 1991, Upper Triassic Barranca Group; Nonmarine and shallow-marine rift-basin deposits of northwestern Mexico, en Pérez-Segura, E., Jacques-Ayala, C. (eds.), Studies of Sonoran geology: Geological Society of America, Special Paper, 254, 19-36.

Stewart, J. H., Poole, F. G., Harris, A. G., Repetski, J. E., Wardlaw, B. R., Mamet, B. L., Morales-Ramirez, J. M., 1999, Neoproterozoic (?) to Pennsylvanian inner-shelf, miogeoclinal strata in Sierra Agua Verde, Sonora, Mexico: Revista Mexicana de Ciencias Geológicas, $16,35-62$.

Stewart, J. H., (y otros 23 autores), 1998, Map showing Cenozoic tilt domains and associated structural features, western North America, en Faulds, J. E. y Stewart, J. H. (eds.), Accommodation Zones and Transfer Zones: The Regional Segmentation of the Basin and Range Province: Geological Society of America Special Paper, 323.

Stock, J. M., Hodges, K. V., 1989, Pre-Pleistocene extension around the Gulf of California and the transfer of Baja California to the Pacific Plate: Tectonics, 8, 99-115.

Stock, J. M., Lee, J., 1994, Do microplates in subduction zones leave a geologic record? Tectonics, 13, 1472-1487.

Suter, M., 2001, the historical seismicity of northeastern Sonora and northwestern Chihuahua, Mexico $\left(28-32^{\circ} \mathrm{N}, 106-111^{\circ} \mathrm{W}\right)$ : Journal of South American Earth Sciences, 14, 521-532.

Suter, M., Contreras, J., 2002, Active Tectonics of Northeastern Sonora, Mexico (Southern Basin and Range Province) and the 3 May 1887 Mw 7.4 Earthquake: Bulletin of the Seismological Society of America, 92, 581-589.

Swanson, E. R., McDowell, F. W., 1984, Calderas of the Sierra Madre Occidental volcanic field western Mexico: Journal of Geophysical Research, 89, 8787-8799.

Swanson, E. R., McDowell, F. W., 1985, Geology and geochronology of the Tómochic caldera, Chihuahua, Mexico: Geological Society of America Bulletin, 96, 1477-1482.

Swanson, E. R., Keizer, R. P., Lyons Jr., J. I., Clabaugh, S. E., 1978, Tertiary volcanism and caldera development near Durango City, Sierra Madre Occidental, Mexico: Geological Society of America Bulletin, 89, 1000-1012.

Tuta, Z., Sutter, J. H., Kesler, S. E., Ruiz, J., 1988, Geochronology of mercury, tin, and fluorite mineralization in northern Mexico: Economic Geology, 83, 1931-1942.

Umhoefer, P. J., Dorsey, R., Willsey, S., Mayer, L., Renne, P., 2001, Stratigraphy and geochronology of the Comondú Group near Loreto, Baja California Sur, Mexico: Sedimentary Geology, 144, $125-147$.

Valencia-Moreno, M., Ruiz, J., Roldán-Quintana, J., 1999, Geochemistry of Laramide granitic rocks across the southern margin of the Paleozoic North American continent, Central Sonora, Mexico: International Geology Review, 41, 845-857.

Valencia-Moreno, M., Ruiz, J., Barton, M. D., Patchett, P. J., Zürcher, 
L., Hodkinson, D., Roldán-Quintana, J. 2001, A chemical and isotopic study of the Laramide granitic belt of northwestern Mexico: identification of the southern edge of the North American Precambrian basement: Geological Society of America Bulletin, 113, 1409-1422.

Valencia-Moreno, M., Ruiz, J., Ochoa-Landín, L., Martínez-Serrano, R., Vargas-Navarro, P., 2003, Geology and Geochemistry of the Coastal Sonora Batholith, Northwestern Mexico: Canadian Journal of Earth Sciences, 40, 819-831.

Valencia-Moreno, M., Ochoa-Landín, L., Noguez-Alcántara, B., 2005, Sinopsis de los depósitos de pórfido cuprífero de México, en CoronaEsquivel, R., Gómez-Caballero, J. A. (eds.), Acta de Sesiones, XXVI Convención Internacional de Minería, AIMMGM, Veracruz, Ver., México, 123-126.

Van der Lee, S., Nolet, G., 1997, Upper mantle S velocity structure of North America: Journal of Geophysical Research, 102, 22815-22838.

Vega-Granillo, R., Calmus, T., 2003, Mazatán metamorphic core complex (Sonora, Mexico): Structures along the detachment fault ant its exhumation evolution: Journal of South American Earth Sciences, 16, 193-204.

Verma, S. P., 1984, Sr and Nd isotopic evidence for petrogenesis of midTertiary felsic volcanism in the mineral district of Zacatecas, Zac. (Sierra Madre Occidental), Mexico: Isotope Geoscience, 2, 37-53.

Vidal-Solano, J. R., Paz-Moreno, F. A., Iriondo, A., Demant, A., Cochemé, J. J., 2005, Middle Miocene peralkaline ignimbrites in the Hermosillo region (Sonora, México): Geodynamic implications: Compte Rendue Geosciences, en prensa, 337(16), 1421-1430.

Wallace, P., Carmichael, I. S. E., 1989, Minette lavas and associated leucitites from the western front of the MVB: petrology, chemistry and origin: Contribution to Mineralogy and Petrology, 103, 470492.

Ward, P. L., 1995, Subduction cycles under western North America during the Mesozoic and Cenozoic eras, en Miller, D. M., Busby, C. (eds.), Jurassic Magmatism and Tectonics of the North American Cordillera: Geological Society of America Special Paper, 299, 1-45.
Wark, D. A., 1991, Oligocene ash flow volcanism, northern Sierra Madre Occidental: Role of mafic and intermediate-composition magmas in rhyolite genesis: Journal of Geophysical Research, 96, 1338913411.

Wark, D. A., Kempter, K. A., McDowell, F. W., 1990, Evolution of waning, subduction-related magmatism, northern Sierra Madre Occidental, Mexico: Geological Society of America Bulletin, 102, 1555-1564.

Webber, K. L., Fernández, L. A., Simmons, W. B., 1994, Geochemistry and mineralogy of the Eocene-Oligocene volcanic sequence, southern Sierra Madre Occidental, Juchipila, Zacatecas, Mexico: Geofísica Internacional, 33, 77-89.

Wilson, F. 0I., Rocha, S. V., 1949, Coal deposits of the Santa Clara district near Tónichý, Sonora, Mexico: U.S. Geological Survey Bulletin, 962A, $80 \mathrm{p}$.

Wong, M., Gans, P. B., 2003, Tectonic implications of early Miocene extensional unroofing of the Sierra Mazatán metamorphic core complex, Sonora, Mexico: Geology, 31, 953-956.

Wong, M., Gans, P. B., 2004, Evidence for early crustal thickening, poly-phase Oligo-Miocene extension, and footwall rotation at the Sierra Mazatán metamorphic core complex, Sonora, Mexico: EOS, American Geophysical Union, Fall Meeting 2004, abstract \#T41E-1270

Wortel, R., Spakman, W., 2000, Subduction and slab detachment in the Mediterranean-Carpathian region: Science, 290, 1910-1917.

Manuscrito recibido: Febrero 4, 2005

Manuscrito corregido recibido: Octubre 23, 2005

Manuscrito aceptado: Noviembre 25, 2005 